Working

Paper

Department

of Economics

$\mathrm{Ca}^{\prime}$ Foscari University of Venice

Francesco Bosello

Carlo Carraro

Enrica De Cian

An Analysis of Adaptation as a Response to

Climate Change 


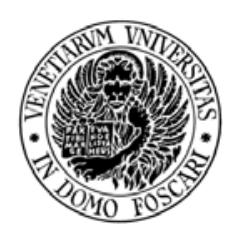

\title{
An Analysis of Adaptation as a Response to Climate Change
}

\author{
Francesco Bosello, University of Milan, Fondazione Enrico Mattei, and CMCC, \\ Carlo Carraro, University of Venice, Fondazione Enrico Mattei, CEPR, CESifo and CMCC, \\ Enrica De Cian, University of Venice, and Fondazione Enrico Mattei
}

First Draft: June 2009; This Draft: September 2009

\begin{abstract}
Climate change is likely to have relevant effects on our future socio-economic systems. It is therefore important to identify how markets and policy jointly react to expected climate change to protect our societies and well-being. This study addresses this issue by carrying out an integrated analysis of both optimal mitigation and adaptation at the global and regional level. Adaptation responses are disentangled into three different modes: reactive adaptation, proactive (or anticipatory) adaptation, and investments in innovation for adaptation purposes. The size, the timing, the relative contribution to total climate-related damage reduction, and the benefit-cost ratios of each of these strategies are assessed for the world as a whole, and for developed and developing countries in both a cooperative and a non-cooperative setting. The study also takes into account the role of price signals and markets in inducing and diffusing adaptation. This leads to two scenarios: A pessimistic one, in which policy-driven adaptation bears the burden, together with mitigation, of reducing climate damage; and an optimistic one, in which markets also autonomously contribute to reducing some damages by modifying sectoral structure, international trade flows, capital distribution and land allocation. For all scenarios, the costs and benefits of adaptation are assessed using WITCH, an integrated assessment, intertemporal optimization, forward-looking model. Extensive sensitivity analysis with respect to the size of climate damages and of the discount rate has also been carried out.
\end{abstract}

\section{Keywords}

Climate change impacts, mitigation, adaptation, integrated assessment model

JEL Codes

Q54, Q56, Q43

This paper has been prepared for the Copenhagen Consensus 2009. AD-WITCH, the model used in this study, has been developed by FEEM in cooperation with the OECD. The authors gratefully acknowledge their financial support. They are also grateful to Shardul Agrawala, Rob Dellink, Kelly de Bruin and Richard Tol for helpful comments. Nonetheless, the views expressed in this paper are the authors' sole responsibility. Finally, the contribution of all colleagues who worked to the development of the original WITCH model in particular Valentina Bosetti, Emanuele Massetti, and Massimo Tavoni - is gratefully acknowledged.

Department of Economics

Ca' Foscari University of Venice

Cannaregio 873, Fondamenta San Giobbe

30121 Venice Italy

Fax: ++39 0412349210 


\section{Introduction}

Adaptation has become a strategic negotiation issue only recently, although UNFCCC (1992) already referred to it in Art. 2 and Art. 4. Among other things, the difficulty of implementing national and international mitigation policies and the increasing awareness of climate inertia eventually put adaptation under the spotlight of science and policy. The EU has recently released the "Green Paper on Adaptation" (see EU, 2007) and many EU countries have prepared and started to implement national adaptation plans. The Bali action plan (2008) has identified the need for enhanced adaptation action by Parties of the Convention, and adaptation is among the five key building blocks for a strengthened response to climate change. COP 13 has established the Adaptation Fund Board with the role of managing the Adaptation Fund, established at COP7. COP14 at Poznan (2009) also made some progress on a number of important issues concerning adaptation.

Indeed, the ultimate question policy makers are interested in is how to reduce the climate-change vulnerability of socio-economic systems in the most cost-effective way. This can be done both through mitigation and adaptation. But this requires on the one hand a thorough knowledge of the size and the regional distribution of damages, and on the other hand a precise assessment of the cost/effectiveness of alternative policies and of their strategic complementarity or trade-off.

An extended literature has investigated the different dimensions of mitigation strategies, whereas much less can be found on adaptation. Even less on the interactions between adaptation and mitigation. The recent increasing emphasis on adaptation thus raises a set of still unanswered questions concerning the design of an optimal mix of mitigation and adaptation measures. And the cost-benefit ratio of different adaptation/mitigation options. New relevant insights need to be provided on the optimal resource allocation between mitigation and adaptation. Or on the optimal timing of mitigation and adaptation measures. Or on the marginal contribution to reducing vulnerability of market and policy driven adaptation strategies.

This study addresses these and other issues using AD-WITCH, an Integrated Assessment Model (IAM) that has been developed for the joint analysis of adaptation and mitigation. Compared to the few existing studies in the field, the proposed modeling framework provides a more detailed characterization of the adaptation process, which is disentangled into three components: anticipatory, reactive and innovative adaptation. In addition, it provides an updated quantitative support for the calibration of adaptation costs and benefits. Therefore, in this study, we will be able to:

- Analyse adaptation to climate change both in isolation and jointly with mitigation strategies

- Provide a comparative cost-benefit analysis of both adaptation and mitigation

- Assess the marginal contribution to the benefit-cost ratio of different adaptation modes.

We will start with a cost-benefit analysis of macro-policy driven responses to climate change, namely, adaptation, mitigation, and then adaptation and mitigation implemented jointly. By narrowing down the focus on policy-driven adaptation, we will then compute the benefit-cost ratios of three macro adaptation strategies (reactive, anticipatory or proactive and knowledge adaptation).We will also assess how market-driven adaptation reduces the vulnerability of economic systems to climate change. Finally, we will re-compute the benefit-cost ratios for different policydriven adaptation strategies net of market-drive autonomous adaptation to climate change.

AD-WITCH, the model used to carry out most of the analysis, is an optimal growth Integrated Assessment model endowed with an adaptation module to compute the costs and benefits of policy- 
driven mitigation and adaptation strategies. Given the game-theoretic and regional structure of ADWITCH (see the Appendix), both first best and second best climate policies can be computed. In this study, we focus on a first best world in which all externalities are internalized by the adopted policy. The social planner implements the optimal levels of adaptation and mitigation, i.e. the level that equalizes marginal costs and benefits across world regions and time periods.

At the same time, this study emphasises that adaptation is also driven by changes in relative prices, which lead to what can be defined as market-driven adaptation. Market-driven adaptation may affect the size and the regional distribution of climate change damages. As a consequence, policydriven adaptation should be planned on the basis of the climate change damages net of market adjustments.

To account for both market-driven and policy-driven adaptation, two different modeling tools have been used. The ICES model, which is a highly disaggregated computable general equilibrium model, has been used to identify the effects of market-driven adaptation. ICES and AD-WITCH have then been integrated to provide a full assessment of both market- and policy-driven adaptation. More precisely, the effects of market-driven adaptation on regional climate damages have been estimated using the ICES model. These estimates have been used to modify WITCH's climate change damage functions to compute climate damages net of market-driven adaptation.

The final part of this study describes specific adaptation proposals. These are consistent with the analysis carried out in the first part of the study, and build upon existing estimates of costs and benefits of specific adaptation strategies.

\section{Background concepts}

In this study, climate change is defined as a set of alterations in the average weather caused by global warming, which is due to emissions of greenhouse gases (GHGs). Climate change affects not only average surface temperature, but it also involves other physical modifications, such as changes in precipitations, intensity and frequency of storms, and the occurrence of droughts and floods.

Average temperature is already 0.7 degree above preindustrial level and further warming might be substantial if no immediate global action is undertaken. Even if all radiative forcing agents were held constant at the 2000 level, a further warming would be observed due to the inertia of oceans (IPCC, 2007). According to the main IPCC scenarios, world-average temperature is likely to increase in the business as usual scenarios as shown in Figure 1, which also shows our projections. Projected global temperature changes above preindustrial levels range between +2.8 and $+4{ }^{\circ} \mathrm{C}$.

Anthropogenic climate change, accelerating the natural trend, will induce a series of impacts on natural and social ecosystems with potentially both negative and positive consequences on human well being. As highlighted in the IPCC AR4 (2007), already a moderate warming produces negative consequences: increasing number of people exposed to water stresses, extinction of species and ecosystems, decrease in cereal productivity at low latitudes, land loss due to sea level rise in coastal areas, increase in mortality and morbidity associated to change in the incidence of vector borne diseases or to increased frequency and intensity of heath waves; infrastructural disruption and mortality increase due to more frequent and intense extreme weather event occurrence. 
Figure 1: Temperature estimates of the IPCC SRES ${ }^{1}$ (IIASA), the WITCH model (Bosetti et. al 2006) and the AD-WITCH baseline scenario used in this study

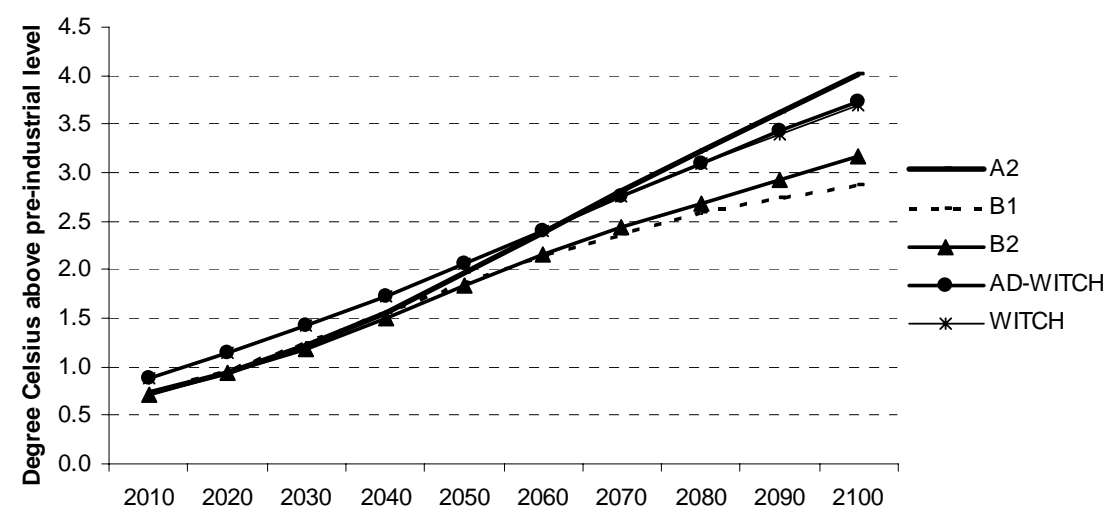

Source: Our elaboration.

A first classification of climate change impacts distinguished between market and non-market impacts. Market effects can be valued using prices and observed changes in demand and supply, whereas non-market effects have no observable prices and therefore require other methods such as valuations based on willingness to pay.

The recent literature points to the large potential damages from climate change, especially on developing countries and on non-market sectors (IPCC, 2007; Stern, 2007). In particular, important non-market impacts are those on health. Current estimates are largely incomplete and most assessments have looked at specific diseases (vector-born diseases, cardiovascular and respiratory diseases). Moreover, indirect economic implications may be relevant. Nonetheless, for the US only, Hanemman (2008) estimates large impacts on health, reporting a loss of 1990 \$US10 billion per year against the \$US 2 billion reported in Nordhaus and Boyer (2000).

Climate change can lead to a significant rise in sea level and catastrophic events with implications on migrations and stock of capital. Insurance companies are an important source of information regarding estimates of capital losses due to climate change impacts. UNFCCC (2007) reports a cost of protecting infrastructure from climate change in North America between 1990 \$US4 and 64 billion already in 2030 , when temperature increase is likely to be far below $2.5^{\circ} \mathrm{C}$.

The Munich Re insurance company developed a database which catalogues great natural catastrophes that had severe impacts on the economic system. Such a database underestimates damages from climate, because only large events are included. Yet estimated losses are in the order of $0.5 \%$ of current world GDP, and damages are increasing at a rate of $6 \%$ a year in real terms. Using this information and adjusting for the under-reporting of other minor impacts, UNFCCC (2007) extrapolated a cost between 1 and 1.5\% of world GDP in 2030, which corresponds to 1990 \$US850-1 350 billion. Nordhaus and Boyer reported similar figures for total impacts, and for a temperature increase of $2.5^{\circ} \mathrm{C}$, which is likely to occur at least several decades after 2030 .

For a temperature increase above $2.5^{\circ} \mathrm{C}$, the majority of Impact Assessment (IA) models currently used to evaluate the full cost of climate change, forecast net losses from climatic changes ranging roughly from a tiny percent to $2 \%$ of world GDP (Figure 2 ).

\footnotetext{
${ }^{1}$ Available at: http://www.iiasa.ac.at/Research/GGI/DB/
} 
Figure 2. Climate change damages as a function of global mean temperature increase (above preindustrial levels)

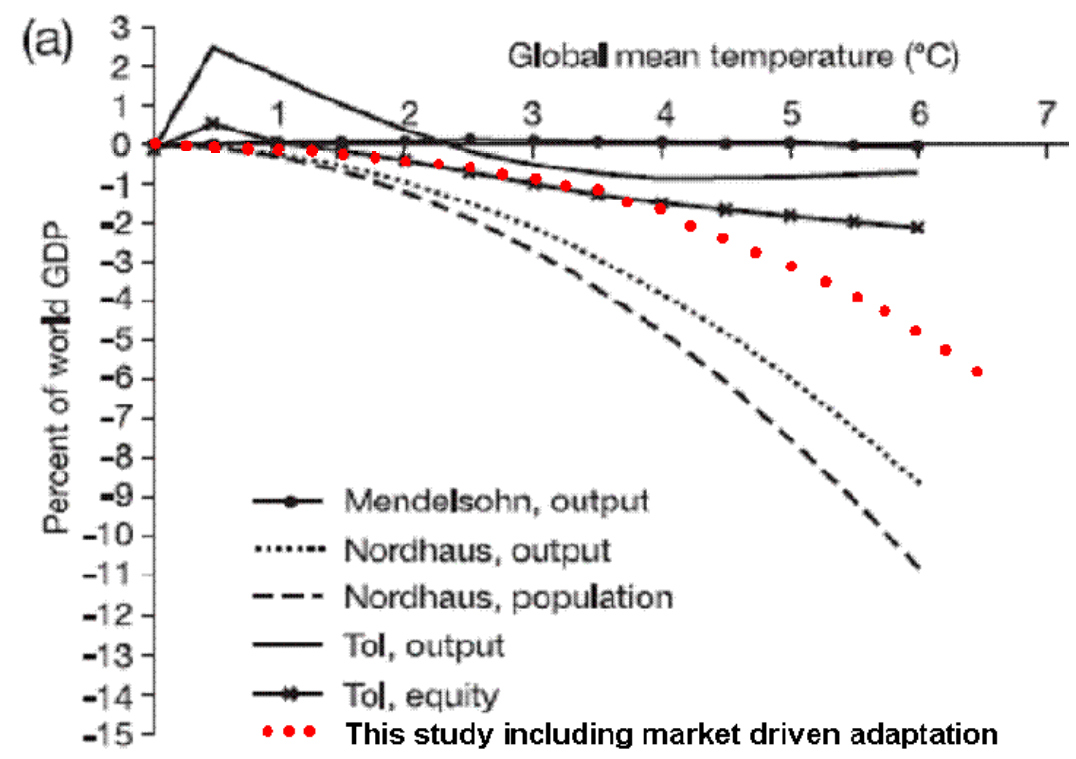

Source: Our adaptation from IPCC AR4 (2007)

Table 1: Regional climate change impacts as \% of GDP corresponding to a temperature increase of $+2.5^{\circ} \mathrm{C}$ (negative figures are gains)

\begin{tabular}{|l|c|r|c|c|c|c|c|}
\hline & $\begin{array}{c}\text { ICES model } \\
\text { (Bosello et al. } \\
\text { 2009)* }\end{array}$ & $\begin{array}{c}\text { AD-WITCH model } \\
\text { (Bosello et al. } \\
\text { 2009a)** }\end{array}$ & $\begin{array}{c}\text { Fankhauser } \\
\text { (Fankhauser } \\
\text { and Tol } \\
\text { 1996) }\end{array}$ & $\begin{array}{c}\text { Tol } \\
\text { (Fankhauser } \\
\text { and Tol, 1996) }\end{array}$ & $\begin{array}{c}\text { Nordhaus } \\
\text { and Boyer } \\
\text { (2000) }\end{array}$ & $\begin{array}{c}\text { Mendelsohn et al. } \\
\text { (2000) }\end{array}$ & $\begin{array}{c}\text { Pierce et al. } \\
\text { (1996) }\end{array}$ \\
\hline USA & 0.2 & 0.4 & 1.3 & 1.5 & 0.4 & -0.3 & 1 \\
\hline WEURO & -1.3 & 1.6 & 1.4 & 1.6 & 2.8 & n.a. & 1.4 \\
\hline EEURO & 0.8 & 0.5 & n.a. & 0 & 0.7 & n.a. & -0.3 \\
\hline KOSAU & 0.9 & 0.8 & n.a. & 0 & -0.4 & n.a. & 1.4 \\
\hline CAJANZ & -0.8 & 0.5 & n.a. & 3.8 & 0.5 & 0.1 & 1.4 \\
\hline TE & 0.9 & 0.8 & 0.4 & -0.4 & -0.7 & -11 & 0.7 \\
\hline MENA & 0.2 & 2.9 & n.a. & 5.5 & 1.9 & n.a. & 4.1 \\
\hline SSA & 2.0 & 5.1 & n.a. & 6.9 & 3.9 & n.a. & 8.7 \\
\hline SASIA & 3.0 & 5.5 & n.a. & 0 & 4.9 & 2 & n.a. \\
\hline CHINA & 1.7 & 0.5 & 2.9 & -0.1 & 0.2 & -1.8 & 5 \\
\hline EASIA & 2.3 & 4.2 & n.a. & 5.3 & 1.8 & n.a. & 8.6 \\
\hline LACA & 1.8 & 2.3 & n.a. & 3.1 & 2.4 & 1.4 & 4.3 \\
\hline
\end{tabular}

Source: our adaptation from the quoted studies

* This study includes market driven adaptation

** This study includes only policy driven adaptation

Climate change is not uniform over the world though, moreover impacts are diverse and highly differentiated by regions. Regions themselves differ for their intrinsic adaptive capacity. These dimensions, i.e. exposure, sensitivity and autonomous adaptive capacity determine a highly differentiated regional vulnerability to climate change. Accordingly, the global picture can provide only a very partial and potentially misleading insight on the true economic cost of climate change. Aggregation can indeed conceal vulnerability and climate change costs "hot spots" as depicted in 
Table 1. As a general rule, developing countries would be more affected than their developed counterparts.

Notwithstanding the differences in results, - driven by different model specifications, modelling approaches and underlying assumptions - the inspection of Table 1 highlights the following robust messages:

- Even an almost null aggregate loss potentially experienced by the world as a whole, and associated to a moderate climatic change, entails high costs for some regions. It is even more so in the case of moderate to high aggregate economic losses.

- There is a clear "equity-adverse" effect from the distribution of climate change impacts: higher costs are experienced by developing regions which are already facing serious challenges to their social economic development; moreover, within a country or region, climate change adverse effects hit more severely weaker social groups which are both more exposed and less able to adapt.

What is true at the world level applies at the regional level as well. Even a net gain for a region compounds both positive and negative effects. Some of these negative effects can be particularly concerning also for a developed region. Think for instance to an increase in mortality due to more frequent and intense heath waves, hitting aged population; loss of coastal areas due to sea-level rise; increase in hydro-geological risk due to an increase in frequency and intensity of extreme weather events. Table 2 summarizes the damage estimates for a $2.5^{\circ} \mathrm{C}$ increase in global temperature above its 1900 level, both for the whole economy (Total) and broken down by sectors, as estimated in Nordhaus and Boyer (2000).

Table 2. Climate change impacts in different world regions under a $2.5^{\circ} \mathrm{C}$ increase in global temperature above its 1900 level

\begin{tabular}{|c|c|c|c|c|c|c|c|c|}
\hline Region & TOTAL & Agriculture & $\begin{array}{r}\text { Other } \\
\text { vulnerable } \\
\text { market }\end{array}$ & Coastal & Health & $\begin{array}{r}\text { Non- } \\
\text { market } \\
\text { time use }\end{array}$ & Catastrophic & Settlements \\
\hline United States & 0.45 & 0.06 & 0 & 0.11 & 0.02 & -0.28 & 0.44 & 0.1 \\
\hline China & 0.22 & -0.37 & 0.13 & 0.07 & 0.09 & -0.26 & 0.52 & 0.05 \\
\hline Japan & 0.5 & -0.46 & 0 & 0.56 & 0.02 & -0.31 & 0.45 & 0.25 \\
\hline EU & 2.83 & 0.49 & 0 & 0.6 & 0.02 & -0.43 & 1.91 & 0.25 \\
\hline Russia & -0.65 & -0.69 & -0.37 & 0.09 & 0.02 & -0.75 & 0.99 & 0.05 \\
\hline India & 4.93 & 1.08 & 0.4 & 0.09 & 0.69 & 0.3 & 2.27 & 0.1 \\
\hline Other high income & -0.39 & -0.95 & -0.31 & 0.16 & 0.02 & -0.35 & 0.94 & 0.1 \\
\hline High-income OPEC & 1.95 & 0 & 0.91 & 0.06 & 0.23 & 0.24 & 0.46 & 0.05 \\
\hline Eastern Europe & 0.71 & 0.46 & 0 & 0.01 & 0.02 & -0.36 & 0.47 & 0.1 \\
\hline Middle-income & 2.44 & 1.13 & 0.41 & 0.04 & 0.32 & -0.04 & 0.47 & 0.1 \\
\hline $\begin{array}{l}\text { Lower middle- } \\
\text { income }\end{array}$ & 1.81 & 0.04 & 0.29 & 0.09 & 0.32 & -0.04 & 1.01 & 0.1 \\
\hline Africa & 3.91 & 0.05 & 0.09 & 0.02 & 3 & 0.25 & 0.39 & 0.1 \\
\hline Low-income & 2.64 & 0.04 & 0.46 & 0.09 & 0.66 & 0.2 & 1.09 & 0.1 \\
\hline \multicolumn{9}{|l|}{ Global } \\
\hline Output-weighted & 1.5 & 0.13 & 0.05 & 0.32 & 0.1 & -0.29 & 0.17 & 1.02 \\
\hline Population-weighted & 2.19 & 0.17 & 0.23 & 0.12 & 0.56 & -0.03 & 0.1 & 1.05 \\
\hline
\end{tabular}

Source: Nordhaus and Boyer (2000)

Among rich countries, Europe is estimated to suffer most from climate change, because of the assumption of high vulnerability to catastrophic events. Among developing regions, Africa and 
India face larger climate impacts due to impacts on health and catastrophic events, respectively. Impacts on agriculture vary a lot with the climatic conditions of the regions and become positive for cold or mild regions (e.g. Russia, China). Similar pattern can be identified for impacts on energy use, with cold regions being more positively affected (Russia).

Current climate change policies - under discussion within the EU (Cf. COM (2005); COM (2007)) aim at setting a "prudential" $2^{\circ} \mathrm{C}$ threshold to temperature increase above preindustrial level within the century. The aim is to (Cf. COM (2007) page 2) "limit the impacts of climate change and the likelihood of massive and irreversible disruptions of the global ecosystem". Thus, even assuming a successful accomplishment, the world will be anyway exposed to a certain degree of climate change and to its negative consequences for the century to come. Moreover, the stated target is considered particularly ambitious: it requires aggressive mitigation actions from developed regions, coupled with an extended international participation involving a still-to-reach explicit commitment to binding emission reduction from major polluters among developing countries. Accordingly, it is very likely that the world will face a higher temperature increase and more damaging consequences than those expected from a $2^{\circ} \mathrm{C}$ warming.

In the light of this, as stressed by the "EU White Paper on Adaptation" (2009), mitigation needs to be necessarily coupled with adaptation actions. These, be they anticipatory or reactive, represent the only viable option to cope with unavoidable climate change impacts that mitigation cannot eliminate.

\section{Defining adaptation: a multidimensional concept}

Adaptation to climate change received a wide set of definitions, by the scientific and the policy environments (among the first group, see e.g.: Burton (1992), Smit (1993), Smithers and Smit (1997), Smit et al. (2000) among the second group, see e.g.: UNDP (2005), EEA (2005), UNFCCC (2006)). The large number of not always coincident definitions already highlights a specific problem concerning adaptation: it is a process that can take the most diverse forms depending on where and when it occurs and on who is adapting to what.

Indeed, probably the most comprehensive, known and widely accepted definition of adaptation is the one provided by the 2001, IPCC AR3 which states "[adaptation is any] adjustment in ecological, social, or economic systems in response to actual or expected climatic stimuli, and their effects or impacts. This term refers to changes in processes, practices or structures to moderate or offset potential damages or to take advantages of opportunities associated with changes in climate" (IPCC TAR, 2001) which is general enough to encompass the widest spectrum of options.

Adaptation can be identified along three dimensions:

- the subject of adaptation (who or what adapts)

- the object of adaptation (what they adapt to)

- the way in which adaptation takes place (how they adapt).

This last dimension includes what resources are used, when and how they are used and with which results (Wheaton and Maciver, 1999).

The subject of adaptation: Who or what adapts. Adaptation materialises in changes in ecological, social and/or economic systems. These changes can be the result of natural responses and in this case they usually involve organisms or species, or of socio-economic or institutional reactions in which case they are undertaken by individual or collective actors, private or public agents.

\footnotetext{
${ }^{2}$ Italics is ours.
} 
The object of adaptation: What they adapt to. In the case of climate change, adaptive responses can be induced either by changes in average conditions or by changes in variability of extreme events. While in the first case the change is slow and usually falls within the "coping range" of systems, in the second case changes are abrupt and outside this coping range (Smit and Pilifosova, 2001).

How adaptation occurs: Modes, resources and results. The existing literature (see e.g. Smit et al. 1999; Klein and Tol, 1997; Fankhauser et al., 1999; IPCC, 2001) proposes several criteria that can be used to identify the different adaptation processes. Table 3 offers a tentative summary of this classification based upon spatial and temporal aspects, forms and evaluation of performances.

Table 3. Adaptation: Possible criteria for classification

\begin{tabular}{|l|c|}
\hline Concept or Attribute & Autonomous $\rightarrow$ Planned \\
\hline Purposefulness & Anticipatory $\rightarrow$ Reactive, Responsive \\
\hline Timing & Short term $\rightarrow$ Long term \\
\hline Temporal Scope & Localised $\rightarrow$ Widespread \\
\hline Spatial Scope & Retreat - accommodate - protect - prevent \\
\hline Function/Effects & Structural - legal - institutional \\
\hline Form & Effectiveness-efficiency-equity-feasibility \\
\hline $\begin{array}{l}\text { Valuation of } \\
\text { Performance }\end{array}$ & \\
\hline
\end{tabular}

Source: Our adaptation from Smit et al. 1999

This study focuses on a different way of classifying adaptation to climate change, by distinguishing between autonomous or "market-driven" and planned or "policy-driven" adaptation. Inside policy driven adaptation, we will distinguish between anticipatory or proactive and responsive or reactive adaptation.

The IPCC (IPCC TAR, 2001) defines autonomous adaptation as: "adaptation that does not constitute a conscious response to climatic stimuli but is triggered by ecological changes in natural systems and by market or welfare changes in human systems" and planned adaptation as: "adaptation that is the result of a deliberate policy decision based on an awareness that conditions have changed or are about to change and that action is required to return to, maintain, or achieve a desired state”

This apparently clear distinction, may originate some confusion when adaptation involves socioeconomic agents. Indeed, climate change may induce market or welfare effect triggering reactions in private agents without the necessity of a planned strategy designed by a public agency, but "just" as a response to scarcity signals provided by changes in relative prices. A typical example of this is the effect of climate change on crops' productivity. This has both physical effects (changing yields) and economic effects (changing agricultural goods' prices) that can induce farmers to some adaptation (for example changes in the cultivation type or timing). This form of private socioeconomic adaptation even though responding to a plan and originated by (rational) economic decisions is considered autonomous or "market driven" (see e.g. Leary 1999, Smith et a. 1996). On the contrary, the term planned adaptation is reserved to public interventions by governments or agencies $^{3}$.

\footnotetext{
3 The IPCC (IPCC TAR, 2001) provides also the definition of private adaptation: "adaptation that is initiated and implemented by individuals, households or private companies. Private adaptation is usually in the actors' rational self interest" and of public adaptation that is: "adaptation that is initiated and implemented by governments at all levels. Public adaptation is usually directed at collective needs".
} 
Another important distinction is the one based on the timing of adaptation actions which distinguishes between anticipatory or proactive adaptation and reactive or responsive adaptation. They are defined by the IPCC (IPCC, TAR, 2001) as: "adaptation that takes place before and after impacts of climate change are observed", respectively. There can be circumstances when an anticipatory intervention is less costly and more effective than a reactive action (typical example is that of flood or coastal protection), and this is particularly relevant for planned adaptation. Reactive adaptation is a major characteristic of unmanaged natural system and of autonomous adaptation reactions of social economic systems.

The temporal scope defines long-term and short- term adaptation. This distinction can also be referred to tactical opposed to strategic, or to instantaneous versus cumulative (Smit et al., 1999). In the natural hazards field it is adjustment versus adaptation (Smit et al. 2000)

For the sake of completeness, let us mention other classifications of adaptation. Based on spatial scope, adaptation can be localized or widespread, even though it is noted that adaptation has an intrinsic local nature (Fussel and Klein, 2006). Several attributes can also characterize the effects of adaptation. According to Smit et al. 1999 they can be: accommodate, retreat, protect, prevent, tolerate etc. Based on the form adaptations can take they can be distinguished according to whether they are primarily technological, behavioural, financial, institutional, or informational.

Finally the performance of adaptation processes can be evaluated according to the generic principles of policy appraisal: cost-efficiency ${ }^{4}$, cost-effectiveness, administrative feasibility and equity. As noted by Adger (2005), in such appraisal effectiveness has to be considered latu-sensu. Indeed, it is important to account for spatial and temporal "spillovers" of adaptation measures. Basically, a locally effective adaptation policy may negatively affect neighbouring regions, and a temporary successful adaptation policy can weaken vulnerability in the longer term, both constitute examples of maladaptation. By the same token efficiency, effectiveness, equity are not "absolute", but context specific, varying between countries, sectors within countries, actors engaged in adaptation processes.

\section{Mitigation and adaptation as a single integrated policy process}

Adaptation and mitigation are both viable strategies to combat damages due to climate change. However they tackle the problem from completely different angles.

Mitigation and adaptation work at different spatial and time scales. Mitigation is "global" and "long term" while adaptation is "local" and "shorter term" (Klein et al., 2003; Fussel and Klein, 2006; Tol, 2005; Wilbanks, 2005, Ingham et al. 2005a). This has several important implications.

Firstly, mitigation can be considered as a "permanent" solution to anthropogenic climate change. Indeed, once abated, one ton of say CO2, cannot produce damage anymore (unless its removal is temporary like in the case of carbon capture and sequestration provided by forests or agricultural land). In contrast, adaptation is more temporary as it typically addresses current or expected damages. It thus may require adjustments should the damage change or be substantially different from what was originally expected.

Secondly, the effects of mitigation and adaptation occur at different times (Wilbanks, 2005; Klein et al., 2003; Fussel and Klein, 2006). Mitigation is constrained by "long-term climatic inertia", while adaptation by a "shorter-term, social-economic inertia". In other words, emission reductions today will translate in a lower temperature increase and ultimately lower damage only in the (far) future,

\footnotetext{
4 The concept of cost efficiency implies that resources are used in the best possible way, cost effectiveness that resources to reach a given target - that can be sub-optimal - are used in the best possible way. The practical implementation of both concepts requires that actions respond to some kind of cost benefit criterion.
} 
whereas adaptation measures, once implemented, are immediately effective in reducing the damage $^{5}$. This differentiation is particularly relevant under the policy making perspective: probably, the stronger reason for the scarce appeal of mitigation policies is their "certain" and "present" cost facing a future and thus uncertain benefit ${ }^{6}$. This can be less of an issue for adaptation. Moreover the different intertemporal characteristics tend to expose mitigation more than adaptation to subjective assumptions in policy decision making, like the choice of the discount rates. It can be expected that a lower discount rate, putting more weight on future damages, can increases the appeal of mitigation with respect to adaptation.

Thirdly, mitigation provides a "global", whereas adaptation provides a "local" response to anthropogenic climate change. The benefits induced by a ton of carbon abated are experienced irrespectively of where this ton has been abated. Differently, adaptation entails measures implemented locally whose benefits advantage primarily the local communities targeted. The global public good nature of emissions reduction creates the well known incentive to free ride. This is one of the biggest problems in reaching a large and sustainable international mitigation agreement (on the vast related literature on this see e.g.: Carraro and Siniscalco, 1998, Bosetti et al. 2009a); again this should be less of a problem in the case of adaptation policies.

It is worth mentioning that mitigation involves decision making at the highest level, i.e. national governments, is implemented at the country level (Tol, 2005), and concerns "large", highly concentrated sectors (like e.g. energy and energy intensive industries (Klein et al., 2003)). Adaptation needs to be implemented at an atomistic level involving a much larger number of stakeholders. Thus, at least in principle, the design of an international policy effort could be easier and the related coordination and transaction costs lower - for mitigation, than for adaptation.

In addition, in the absence of international coordination, substantial unilateral mitigation actions are unlikely to occur. Here the concern is double: on the one hand, the environmental effectiveness of unilateral action is likely to be small; on the other hand, national goods and services of the abating country can loose competitiveness in international markets if their prices "incorporate" the cost of the tighter emission standards. This is not necessarily so with adaptation: its smaller scale and the excludability of its benefits can spur also a unilateral effort.

The different spatial effectiveness of adaptation and mitigation is also relevant in the light of "spatial uncertainty" of climate change damages (Lecoq and Shalizi, 2007). Not knowing exactly where and with which intensity negative climatic impacts are going to hit, policy decision should bias toward mitigation which is "globally effective"; on the contrary adaptation should be used to deal with reasonably well understood local phenomena.

Finally there is an equity dimension. Abatement intrinsically endorses the "polluter-pays" principle. Each one abates her own emissions (directly or indirectly if "where" flexibility is allowed) 7 . This is not necessarily the case with adaptation: it can well alleviate damages which are not directly provoked by the affected community. This is particularly important for international, especially North/South, climate negotiations. Indeed adaptation is particularly needed in developing countries which are either more exposed or vulnerable (higher sensitivity, lower capacity to adapt) to climate change (IPCC, 1996; IPCC, 2001, IPCC 2007), while historically they contributed relatively less to the problem. Adaptation in developing countries thus calls objectively for strong international support.

\footnotetext{
${ }^{5}$ It has to be stressed that economic inertias can be long as well e.g. implementing coastal protection interventions can take many years (or even decades) and that adaptation may not be immediately effective as it is the case for anticipatory adaptation.

${ }^{6}$ Fussel and Klein, (2006) note that monitoring mitigation effectiveness is easier than monitoring adaptation. They refer to the fact that it is easier to measure emission reduction than quantify the avoided climate change damage due to adaptation. They do not refer to the quantification of the avoided future damage due to emission reduction.

${ }^{7}$ Again this is not necessarily so in the case of sequestration activities.
} 
For what said - and following a widely accepted efficiency and common wisdom principle according to which a wider portfolio of options should be preferred to a narrower one - it seems reasonable to integrate mitigation and adaptation in the design of a more cost-effective policy to combat climate change (Ingham et al., 2005a; Kane and Yohe, 2000; Parry, 2001). This is particularly true in the light of the overall uncertainty that still surrounds our understanding of climatic, environmental, social-economic processes, which ultimately determines the uncertainty in the assessment of the costs and benefits of climate change policy. In an uncertain framework, a precautionary policy would avoid both the extremes of total inaction and of drastic immediate mitigation. The optimal strategy would be a combination of mitigation and adaptation measures (Kane and Shogren 2000; McKibbin and Wilcoxen, 2004). In other words, decision maker needs to place herself somewhere inside the decision space represented by the triangle of Figure 3: vertex are possible, but unlikely.

How mitigation and adaptation should be combined? This intuitively depends on their degree of substitutability or complementarity. Kane and Shogren (2000) analyse this issue in the context of the economic theory of endogenous risk. They demonstrate that when adaptation and mitigation both reduce the risk of adverse effects of climate change, they are both used by agents until expected marginal benefits and costs are equated across strategies. Corner solutions (adaptation or mitigation only outcomes) are also discussed as theoretical possibilities, if for instance an international mitigation agreement failed to be signed, making agents aware of the practical ineffectiveness of (unilateral) mitigation action or if, conversely, the climate regime is so strict to eliminate the necessity to adapt to any climate change damage. The analysis of agents' response to increased climate change risk is more complex. It depends on two effects: a direct effect of risk on the marginal productivity of a strategy and an indirect effect of risk which is determined by risk impacts on the other strategy and by the relationship between the two strategies. The indirect effect amplifies (dampens) the direct effect if the marginal productivity of one strategy increases (decreases) and the two strategies are complement (substitutes) or if marginal productivity decreases (increases) and the strategies are substitutes (complements). Kane and Shogren (2000) suggest that the actual relationship between adaptation and mitigation strategies is an empirical matter.

Figure 3. Mitigation adaptation and impacts: a schematic “decision space”

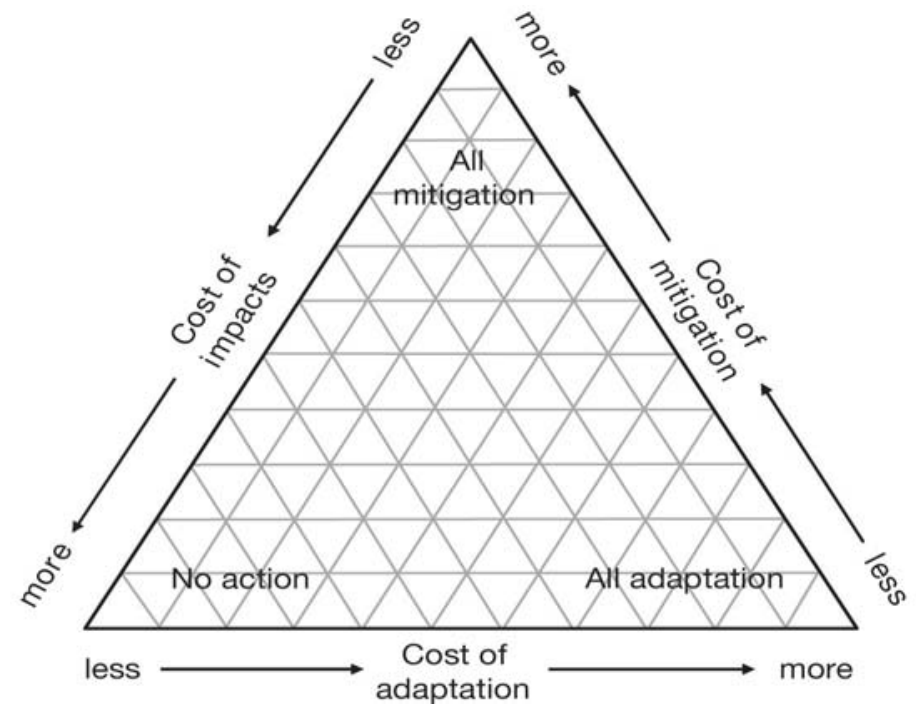

Source: IPCC AR4 (2007) 
Figure 4: Technical change and optimal abatement in the presence of adaptation and mitigation

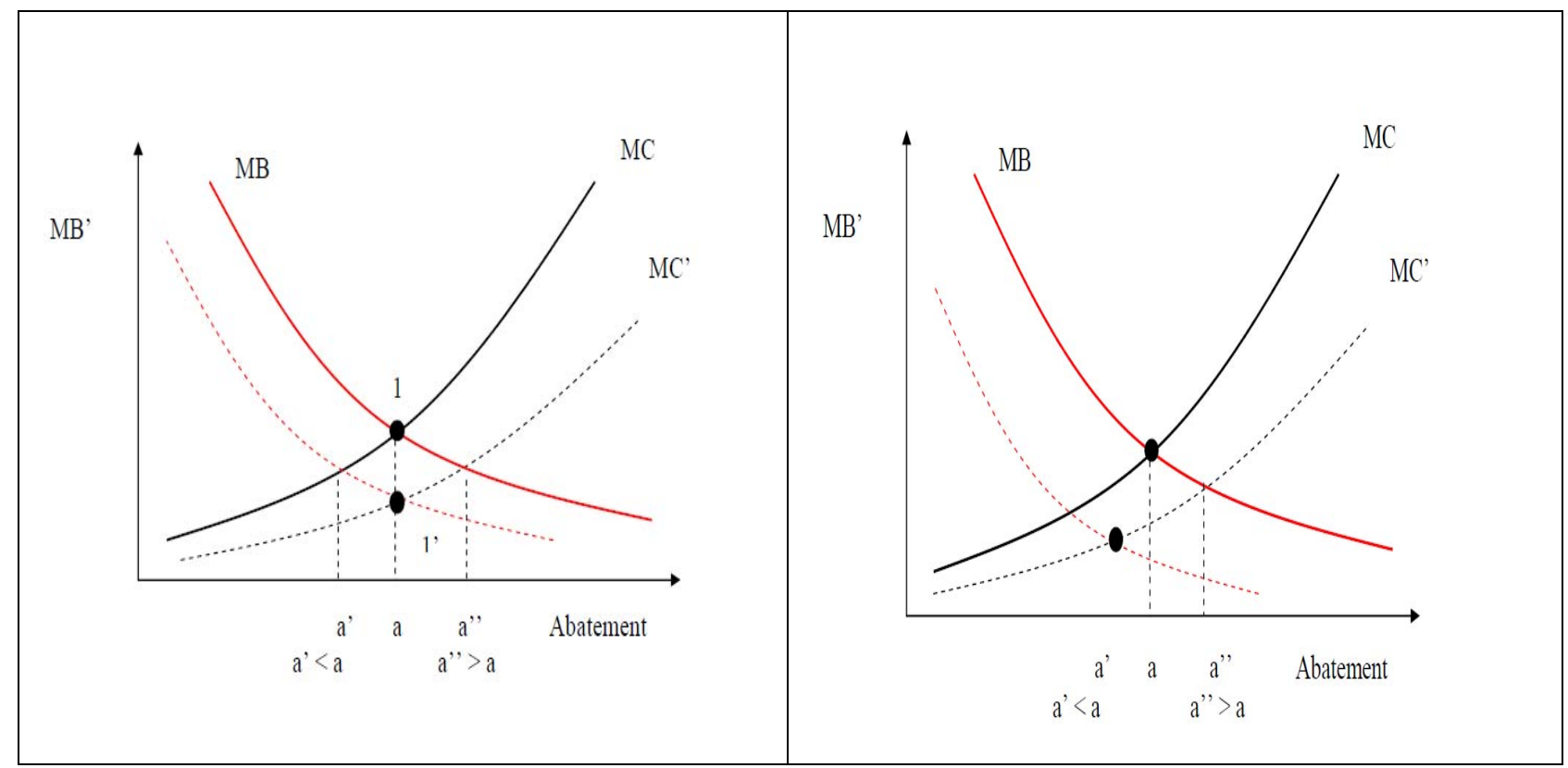

Source: Our elaboration.

Figure 4 provides a neat representation of the trade-off between mitigation and adaptation, taking into account the potential effects of technical change. The role of technical change as a key element to reduce abatement costs and therefore to encourage cheaper abatement effort has long been studied in the climate-economy literature (e.g. Bosetti et al. 2009). However, such analyses have neglected potential interactions that may arise in the presence of adaptation responses. Technical change as conceived by most Integrated Assessment models featuring endogenous technical change would reduce marginal abatement cost from $M C$ to $M C$ ' (see Figure 4). In the absence of any adaptation effort, abatement would increase to $a$ '. However, adaptation affects the optimal level of mitigation and thus of abatement, because it increases the damage that can be tolerated, thus reducing the marginal benefit from abatement. Should adaptation shift the marginal benefit curve downward (from $M B$ to $M B$ '), then final abatement could be even lower than the initial level $a$ (see the right-hand side panel of Figure 4 where the final equilibrium $a^{\prime}$ is smaller than $a$ ).

Therefore, it is crucial to assess the exact nature of the relationship between mitigation and adaptation. However, the literature on this topic, either the one focussing on the general characteristics of mitigation and adaptation or the one proposing specific case studies, does not seem to converge on a consistent characterisation of the trade-off between the two.

According to Klein et al., (2003) complementarity can be invoked as important synergies can be created between the two strategies when measures that control greenhouse gas concentration also reduce adverse effects of climate change or vice versa. In addition, there is the possibility that many adaptation measures implemented specifically in developing countries may also promote the sustainability of their development (see e.g.; Huq et al., 2003, Dang et al., 2003).

Parry et al. (2001) highlight that mitigation delaying climate change impacts can "buy more time" to reduce vulnerability through adaptation (the converse is more controversial, see Klein et al., (2007)). Symmetrically, adaptation can rise thresholds which need to be avoided by mitigation (Yohe and Strzepek, 2007). 
Consequently there is an intuitive appeal to exploit and foster synergies by integrating mitigation and adaptation.

An excessive emphasis on synergies can present some risks as well (Klein et al., 2003, 2007; Dang et al., 2003; Tol, 2005). Adaptation measures could pose institutional or coordination difficulties, especially at the international level, and these may be transmitted to the implementation of mitigation measures if the two are conceived as tightly linked. Synergetic interventions can be less cost effective than separate mitigation, adaptation and especially (sustainable) development interventions.

There are finally objective trade-offs between mitigation and adaptation (Tol, 2005, Bosello 2008, de Bruin et al. 2007). Resources are scarce: hence, if some are used for mitigation, less are available for adaptation, and vice versa. This particular point is clarified by Ingham et al. (2005a,b) who demonstrate that mitigation and adaptation are substitutes in economic terms, thus implying that if say the cost of mitigation falls, agents' optimal response would be to increase mitigation and decrease adaptation.

It is worth noting that substitutability is not in contradiction with the fact that mitigation and adaptation should be both used in climate change policies. Substitutability justifies an integrated approach to mitigation and adaptation as mitigation, or adaptation alone, cannot optimally deal with climate change. In the language of lay people they would be defined as complementary, but this is so also for instance in IPCC (1996), Pielke (1998). What they refer to is rather the idea that an increase in climate related damage cost would increase both mitigation and adaptation efforts, which is exactly the typical "income effect" with normal goods. Finally, as noted by Tol (2005), if adaptation is successful, a lower need to mitigate could be perceived.

Turning to more case-specific examples, Klein et al. (2007) discuss many circumstances in which adaptation and mitigation can complement (facilitate) or substitute (conflict with) each other. In general each time adaptation implies an increased energy use from fossil sources, emissions will increase and mitigation becomes more costly. This is the case for instance of adaptation to changing hydrological regimes and water scarcity, through increasing reuse of wastewater and the associated treatment, deep-well pumping, and especially large-scale desalination, which would increase energy use in the water sector, with subsequent increased emissions and mitigation costs (Boutkan and Stikker (2004) quoted by Klein et al., 2007), or the case of indoor cooling which is proposed as a typical adaptation in a warming world (Smith and Tirpak 1989, quoted by Klein et al., 2007).

However, there are also adaptation practices which decrease energy use and thus facilitate mitigation (for instance, new design principles for commercial and residential buildings could simultaneously reduce vulnerability to extreme weather events and energy needs for heating and/or cooling). Carbon sequestration in agricultural soils highlights as well a positive link from mitigation to adaptation. It creates an economic commodity for farmers (sequestered carbon) and makes the land more valuable by improving soil and water conservation, thus enhancing both the economic and environmental components of adaptive capacity (Boehm et al., 2004; Butt and McCarl, 2004; Dumanski, 2004 quoted by Klein et al. 2007).

There are finally ambiguous cases. For instance avoided forest degradation implies in most cases an increased adaptive capacity of ecosystems (through biodiversity preservation) and climate (nonemissions) benefits. However, if incentives to sequester carbon by afforestation and reforestation spur an over-plantation of fast-growing alien species, biodiversity can be harmed (Caparros and Jacquemont 2003, quoted by Klein et al. 2007) and the natural system can become less adaptable.

These examples demonstrate the intricate inter-relationships between adaptation and mitigation, and also the links with other environmental concerns, such as water resources and biodiversity, with profound policy implications. 


\section{Adaptation strategies and macro, policy-driven, integrated measures}

Given the multifaceted features of adaptation, and the difficulty to compare the very different adaptation actions or even the same adaptation strategy in different locations, the choice of this study is to aggregate adaptation responses into three main categories: anticipatory adaptation, reactive adaptation and adaptation $R \& D$.

Anticipatory adaptation implies building a stock of defensive capital that must be ready when the damage materializes. It is subject to "economic inertia": investment in defensive capital translates into protection capital after some years. Hence, it needs to be undertaken before the damage occurs. By contrast, reactive adaptation is immediately effective and it can be put in place when the damage effectively materializes.

Reactive adaptation is represented by all those actions that need to be undertaken every period in response to those climate change damages that can not be or were not accommodated by anticipatory adaptation. They usually need to be constantly adjusted to changes in climatic conditions. Examples of these actions are energy expenditures for air conditioning or farmers' yearly changes in seasonal crops' mix.

Investing in R\&D and knowledge can be seen as a peculiar form of anticipatory adaptation. Innovation activity in adaptation or simply "knowledge adaptation" is represented by all those R\&D activities and investments that make adaptation responses more effective. These are especially important in sectors such as agriculture and health, where the discovery of new crops and vaccines is crucial to reduce vulnerability to climate change (Barrett, 2008) ${ }^{8}$.

These three groups of adaptation measures will be contrasted one against the other and with mitigation in a cost benefit analysis in both a non-cooperative and cooperative (first-best) setting. The analysis will be conducted with the AD-WITCH model (see Appendix I for more information). $\mathrm{AD}-\mathrm{WITCH}$ is a climate-economic, dynamic-optimization, Integrated Assessment model that can be solved under two alternative game-theoretic scenarios:

- In a non-cooperative scenario, each of the 12 regions in which the world is disaggregated maximises its own private welfare (defined as the present value of the logarithm of per capita consumption), taking other regions' choices as given. This yields a Nash equilibrium, which is also chosen as the baseline. In this context, externalities are not internalized.

- In a cooperative scenario, a benevolent social planner maximizes global welfare, i.e. takes into account the full social cost of climate change. In this scenario, the first best cooperative outcome in which all externalities are internalized can be achieved.

The climate change damage function used by the AD-WITCH model includes a reduced-form relationship between temperature and gross world product which follows closely Nordhaus and Boyer (2000), both in the functional form and in the parameter values. The resulting patterns of regional damages are thus in line with what depicted in Tables 1 and 2. Higher losses are estimated in developing countries: in South Asia (including India) and Sub-Saharan Africa, especially because of higher damages in agriculture, from vector-borne diseases and because of catastrophic climate impacts.

Damage estimates in agriculture, coastal settlements and catastrophic climate impacts are significant in Western Europe, resulting in higher damages than in other developed regions. In China, Eastern EU countries, non-EU Eastern European countries (including Russia), Japan-Korea, climate change up to $2.5^{\circ} \mathrm{C}$ would bring small benefits, essentially because of a reduction in energy

\footnotetext{
${ }^{8}$ To test the generality of results, Appendix III proposes an alternative specification in which R\&D contributes to build "adaptive capacity" that improves the effectiveness of all adaptation actions be they proactive or reactive.
} 
demand for heating purposes (non-EU Eastern European countries including Russia) or positive effects on agricultural productivity (China).

Nonetheless recent evidence - an important contribution on this is the 2007 Stern Review, but also UNFCCC (2007) and the IPCC's AR4 (IPCC, 2007) - suggests that climate change damages may probably be higher than the values proposed in the RICE model by Nordhaus and Boyer (2000). Probably, the most important reason is that RICE, as well as AD-WITCH and many other IA models), only partially captures non-market impacts, which are confined to the recreational value of leisure. Important climate related impacts on biodiversity and ecosystem losses or on cultural heritage are not part of the damage assessment.

Secondly the model abstracts from very rapid warming and large-scale changes of the climate system ("system" surprises). As a consequence, AD-WITCH yields climate related impacts that, on average, are smaller than those described in studies like the 2007 Stern Review or the UNFCCC (2007) report, which do consider the possibility of abrupt climate changes.

Thirdly, the time horizon considered in this report also plays also a role. The longer it is, the larger the observed damages from climate change, as temperature is projected to keep an increasing trend. Like most IAMs, AD-WITCH considers the dynamics of economic and climatic variables up to 2150, while, for instance, the Stern Review reaches the year 2200.

Finally, the AD_WITCH model is partly based on out-of-date evidence, as many regional estimates contained in Nordhaus and Boyer (2000) are extrapolations from studies that have been carried out for one or two regions, typically the United States.

In order to account for new evidence on climate-related damages and economic impacts, the costbenefit analysis of adaptation has been performed under two different specifications of the damage functions. The standard one, based on the assessments contained in Nordhaus and Boyer (2000). And a new one, characterised by a much higher damage from climate change, about twice the standard one. This new specification of the damage function yields values of damages larger than those contained in UNFCCC (2007) and close to those in Stern (2007).

As suggested by Stern (2007), we have also assessed the benefit cost ratios of adaptation under two possible values of the pure rate of time preference. The standard one, again based on Nordhaus and Boyer (2000), is equal to $3 \%$ declining over time. The new one is much lower and equal to $0.1 \%$, as in Stern (2007)). Still the AD-WITCH model does not perform a risk assessment on threshold effects or on discontinuous low probability high damage impacts, which go beyond the scope of this report ${ }^{9}$.

Summing up, four cases will be considered when analyzing the costs and benefits of mitigation, adaptation and of different types of adaptation:

1. LDAM_HDR : low damage - high discount rate. This is the baseline scenario with a discount rate set initially at 3\% and then declining over time as in WITCH, DICE and RICE (see Nordhaus and Boyer, 2000).

\footnotetext{
${ }^{9}$ However, it is likely that the general conclusions of the present study would not change. What can change is the relative weight of adaptation and mitigation in the optimal policy mix. As adaptation to catastrophic events can only be partial, and given that the probability of their occurrence can be lowered only by reducing temperature increase, mitigation could become more appealing than adaptation when the occurrence of catastrophic events is accounted for.
} 
2. LDAM_LDR: low damage - low discount rate. The damage is the same as in the baseline; the discount rate is $0.1 \%$ and then declining, as in Stern (2007).

3. HDAM_LDR: high damage - low high discount. The damage is about twice the damage in baseline; the discount rare is $0.1 \%$ and then declining, as in the Stern Review.

4. HDAM_HDR: high damage - high discount rate. The damage is about twice the damage in baseline; the discount rate is $3 \%$ and then declining over time as in WITCH, DICE and RICE.

\subsection{Optimal integrated climate-change strategy in a non cooperative setting.}

The main strategic difference between mitigation and adaptation responses to global warming can be summarized as follows. Mitigation provides a public good that can be enjoyed globally, while adaptation provides private or club goods. Mitigation is thus affected by the well known "free riding" curse, while this is much less of an issue for adaptation.

In the absence of climate change international cooperation, climate change policies at the regional level are chosen to equalize marginal private benefits and marginal private costs, without internalizing negative externalities imposed globally. Because of the free-riding incentive, little mitigation effort is thus undertaken.

In practice, in a non-cooperative scenario, when both adaptation and mitigation are chosen optimally, equilibrium abatement (mitigation) is so low that emissions almost coincide with the no policy case (Figure 5, left). Optimal (non-cooperative) adaptation reduces climate change damages and therefore provides an incentive to increase emissions compared to the no policy case (noncooperative no policy scenario). By contrast, the full appropriability of benefits from adaptation induces regional planners to implement adaptation measures even in the non-cooperative equilibrium. Expenditures for adaptation reach 3.2 USD trillion or $0.8 \%$ of world GDP in 2100 (Figure 5, right). Cumulated over the century and discounted at the 3\% discount rate, they total about 9 USD trillion, $77 \%$ of which taking place in developing countries, and the remaining in developed countries.

Figure 5: Equilibrium adaptation and mitigation in the non-cooperative scenario

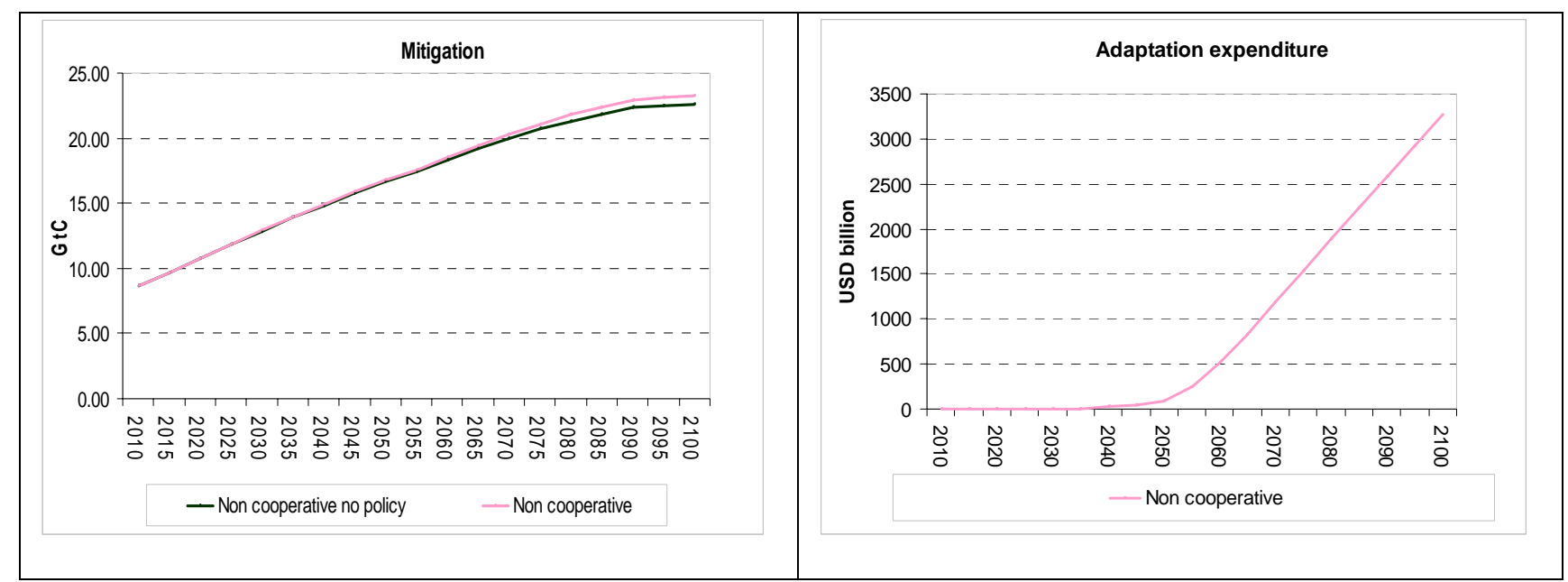


Figure 6 shows total climate change damage (residual damages + adaptation expenditure) in the absence of any policy. It amounts to an annual average of 584 USD billion already in 2035, and increases exponentially over time. Adaptation reduces substantively residual damages (see again Figure 6), up to $55 \%$ in 2100 . Adaptation starts slowly in the first two decades. Consistently with the AD-WITCH damage function, damages from climate change are indeed low in the first two decades. Hence, adaptation, typically addressing current and near-term damages, is only marginally needed. This applies also to anticipatory adaptation. Economic inertia in the model is about five years. As a consequence, adaptation investments do not need to start too in advance. When considering higher damages and higher preferences for the future (the high damage and low discount rate case), adaptation starts earlier - already in 202060 USD billions are allocated to the reduction of damage. Hence, total damage reduction increases - it amounts to more than $70 \%$ in 2100 (see Figure 7).

Figure 6: Residual damage in the non-cooperative scenario

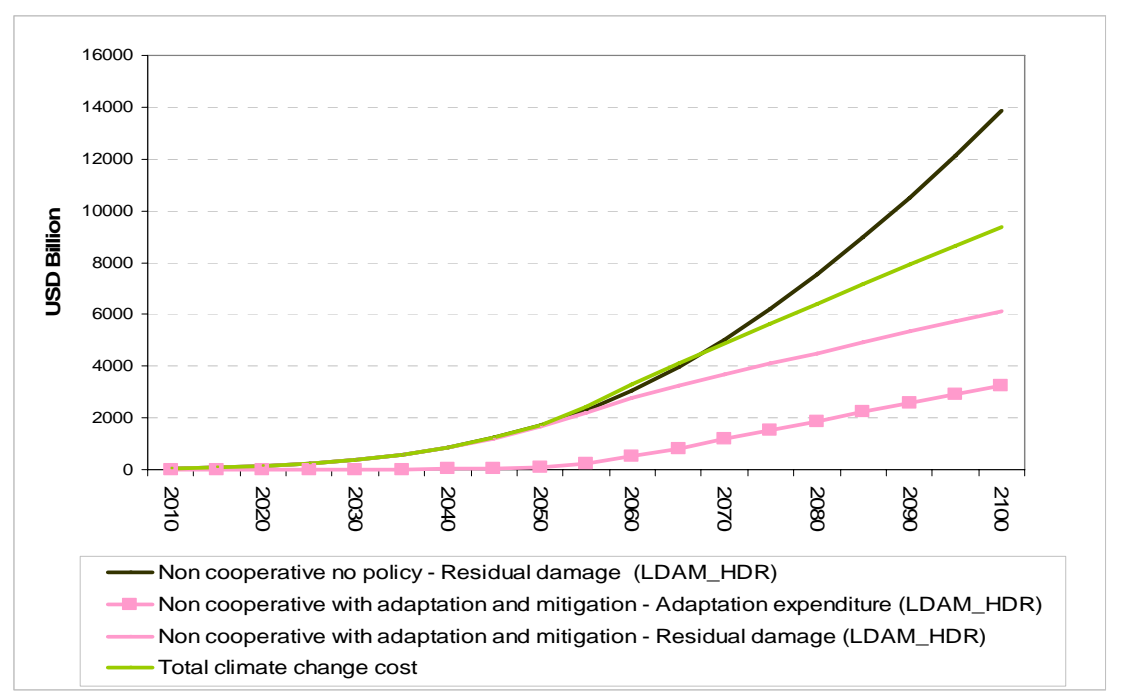

Figure 7: Residual damage in the non-cooperative scenario - High damage Low discount rate

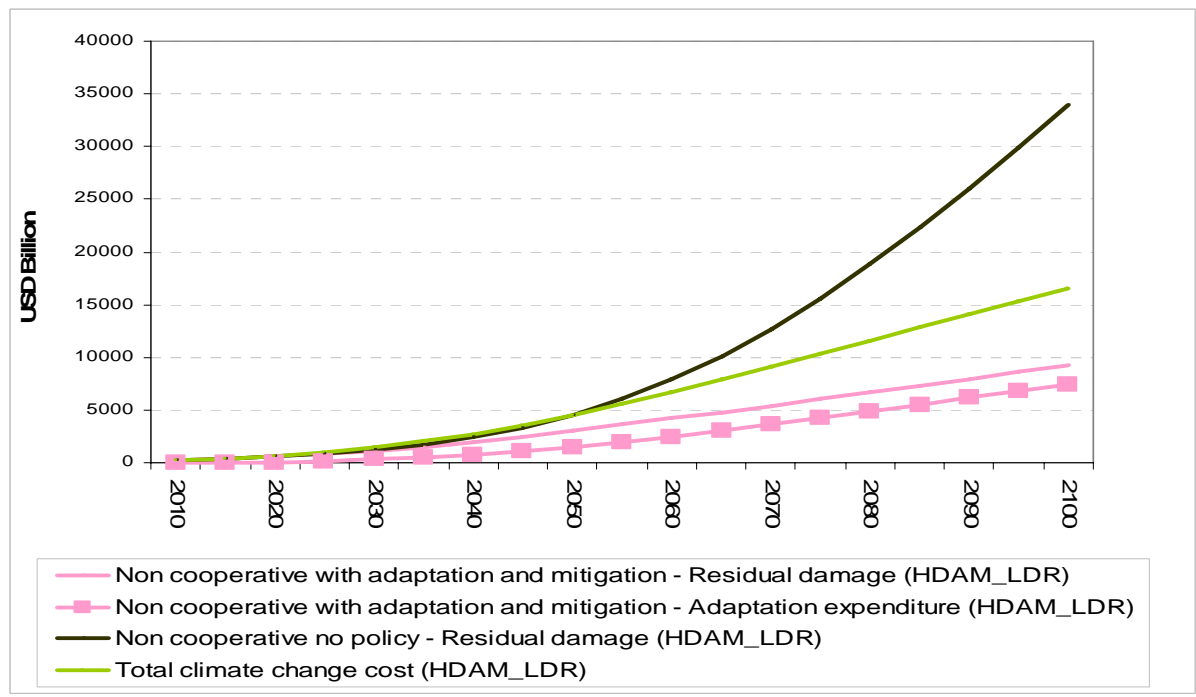


The benefit-cost ratios (BCRs) of adaptation, measured as the discounted sum of avoided damages over the discounted sum of total adaptation expenditures, are reported in Table 4. On a sufficiently long-term perspective, they are larger than one. Had we chosen a longer time period they could have been even higher, as in the model benefits increase more than costs, due to the stronger convexity of the damage function with respect to the adaptation cost function ${ }^{10}$.

Figure 4 also shows adaptation BCRs increase more when climate damage increases than when the discount rate decreases. When damages become more relevant all along the simulation period and not only at its later stages, adaptation becomes relatively more useful.

Table 4. Benefit-cost ratios of adaptation in four scenarios (non-cooperative scenario with adaptation and mitigation)

\begin{tabular}{|ccccc|}
\hline $\begin{array}{c}\text { USD 2005 Trillion } \\
\text { 3\% Discounting 2010-2105 }\end{array}$ & LDAM_HDR & HDAM_HDR & LDAM_LDR & HDAM_LDR \\
Benefits & 16 & 62 & 227 & 695 \\
Costs & 10 & 25 & 134 & 270 \\
BCR & 1.67 & $\mathbf{2 . 4 1}$ & $\mathbf{1 . 6 9}$ & $\mathbf{2 . 5 7}$ \\
\hline
\end{tabular}

Benefits are measured as total discounted avoided damages compared to the non cooperative no policy case Costs are measured as total discounted expenditures on adaptation.

Summing up: the theoretical insight ${ }^{11}$ that, in a non-cooperative setting, adaptation is the main climate policy tool is confirmed by our results. Mitigation is negligible at the non-cooperative equilibrium. As a consequence, adaptation investments are high and increasing over time. Most importantly, the benefit-cost ratio is larger than one. Higher emissions in the presence of adaptation, and the relatively higher sensitivity of adaptation to the level of climate damages, already highlight the potential strategic complementarity between mitigation and adaptation. This issue will be addressed more deeply in the next sections.

\subsection{An optimal integrated climate-change strategy in a cooperative scenario.}

In a cooperative scenario, all externalities originated by emissions are internalized. Accordingly, emission abatement (mitigation) is considerably higher than in the non-cooperative scenario (Figure 8 , left). Adaptation is still undertaken, but slightly less than in the non cooperative case (Figure 8 , right). Higher cooperative mitigation efforts reduce the need to adapt with respect to the non cooperative scenario. This result is robust to different discount factors and damage levels (see Figure 9).

As expected, abatement is further increased when the discount rate decreases or the damage from climate change increases. Adaptation is reduced accordingly. This effect is not "proportional" to emission reduction though. The "discounting" effect, which tends to favor mitigation by increasing the weight of future damages, is partly offset by the "damage" effect, which increases future and present damages and calls for both mitigation and adaptation.

\footnotetext{
${ }^{10}$ This result is driven by our model assumptions, which are anchored on calibration data.

${ }^{11}$ There is an extensive literature on international environmental agreements showing the non cooperative abatement level is negligible at the equilibrium. Therefore, adaptation remains the only option to reduce climate danages.
} 
Figure 8: Optimal adaptation and mitigation in a cooperative scenario

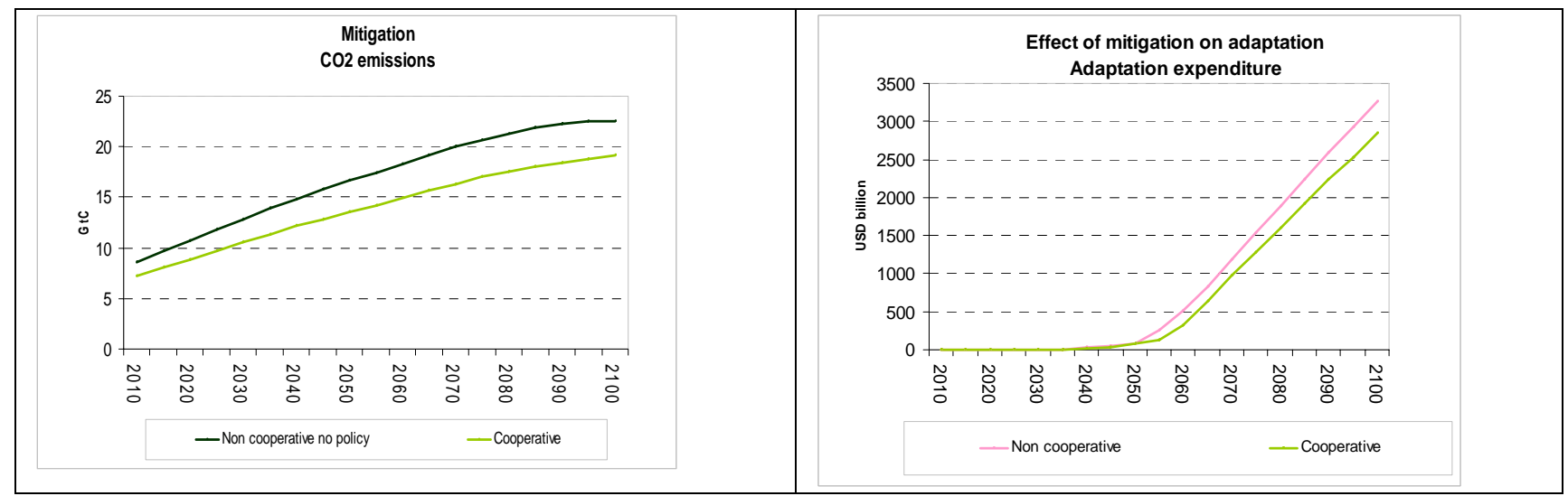

Figure 9: Effects of mitigation on adaptation
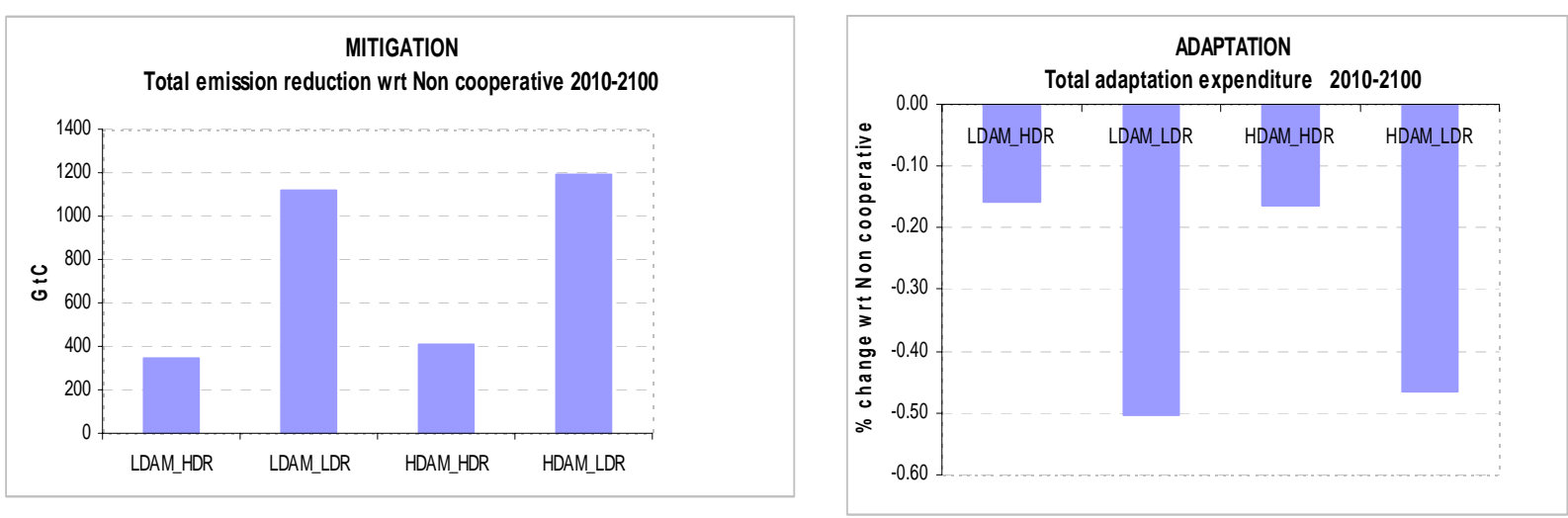

The trade-off between optimal mitigation and adaptation emerges also when analyzing cooperative mitigation with and without adaptation. As shown by Figure 10, adaptation reduces the need to mitigate, i.e. cooperative emissions in the presence of adaptation are higher. Nonetheless, even in the presence of adaptation, which can potentially reduce by $50 \%$ climate change damage, mitigation remains an important and far from negligible component of the optimal response to climate change.

After 2050 , on a 5-year average, optimal emission reduction is approximately $17 \%$ compared to the no policy case. This stresses again the strategic complementarity between mitigation and adaptation. Both reduce climate-related damages. Therefore their integration can increase total welfare (proxied by cumulated discounted consumption) as shown by Figure 11. Notice also that cumulated consumption decreases less by giving up adaptation than mitigation. Indeed, investments in (proactive) adaptation crowd out consumption. This effect is amplified by the discounting process in earlier periods. 
Figure 10: CO2 emissions

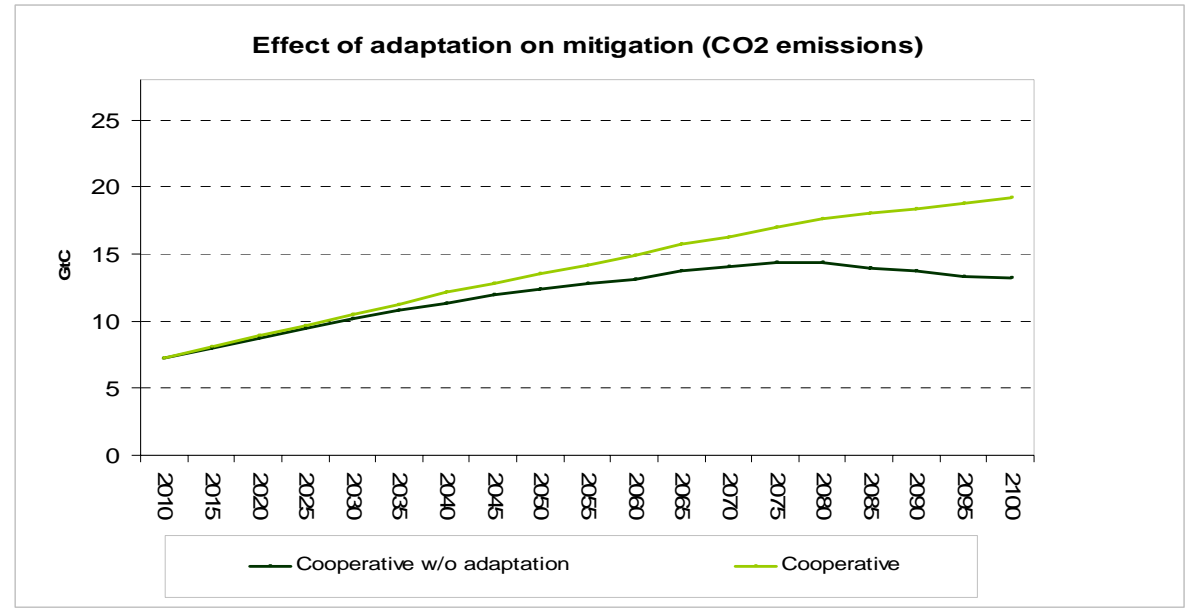

Figure 11: Global welfare

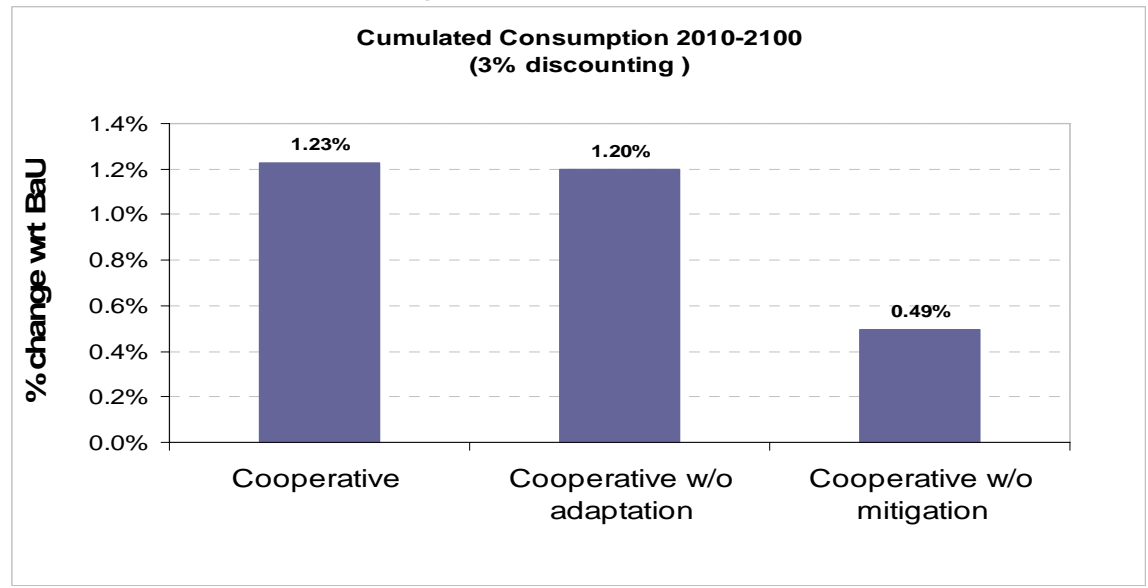

Further information on the relation between mitigation and adaptation is provided by Table 5 . In 2100, mitigation cuts the potential climatic damage by roughly 3 USD trillion, whereas adaptation by nearly 8 USD trillion. Interestingly, the two strategies, when jointly chosen, reduce climate change damages by 8.2 USD trillion, which is less than the sum of what the two strategies could accomplish if adopted separately. Mitigation and adaptation remain indeed competing strategies. On the benefit side, because adaptation reduces the marginal benefit of mitigation. And on the cost side, because both compete for scarce resources. Accordingly, when they are used jointly, there is a lower incentive to use each of the two.

Table 5. Strategic complementarity between adaptation and mitigation

\begin{tabular}{|cccccc|}
\hline \multicolumn{5}{c}{ Damage reduction in the cooperative case wrt baseline (2005 USD trillion) } \\
2035 & Mitigation only & Adaptation only & Sum & Adaptation \& Mitigation & Interaction effect \\
2050 & 0.04 & 0.00 & 0.05 & 0.04 & 0.00 \\
2075 & 0.20 & 0.10 & 0.30 & 0.23 & -0.06 \\
2100 & 0.99 & 2.24 & 3.23 & 2.43 & -0.80 \\
\hline
\end{tabular}


Table 6. Timing of adaptation and mitigation in a cooperative scenario

\begin{tabular}{|cccc|}
\hline $\begin{array}{c}\text { Adaptation } \\
\text { (Total protection costs - Billion USD 2005) }\end{array}$ & 2035 & 2050 & 2100 \\
Mitigation \\
(emission \% change wrt BaU)
\end{tabular}

Table 6 highlights another important difference between adaptation and mitigation: their timing. Mitigation starts well in advance with respect to adaptation. Abatement is substantial when adaptation expenditure is still low. Mitigation needs to be implemented earlier than adaptation. It works "through" carbon cycle inertia. Accordingly action needs to start soon to grasp some benefits in the future. By contrast, adaptation measures work "through" the much shorter economic inertia, and can thus be implemented when relevant damages occur, which is from the third decade of the century.

Table 7 disentangles the effectiveness of mitigation and adaptation when they are chosen optimally. It shows clearly that mitigation is preferred when the discount rate is low, whereas adaptation prevails when damages are high.

Table 7: Damage reduction due to different strategies

\begin{tabular}{|cccc|}
\hline LDAM_LDR & Mitigation\&Adaptation & Mitigation & Adaptation \\
2050 & $34 \%$ & $31 \%$ & $3 \%$ \\
2075 & $56 \%$ & $39 \%$ & $17 \%$ \\
2100 & $72 \%$ & $45 \%$ & $27 \%$ \\
\hline LDAM_HDR & Mitigation\&Adaptation & Mitigation & Adaptation \\
2050 & $14 \%$ & $11 \%$ & $3 \%$ \\
2075 & $39 \%$ & $11 \%$ & $28 \%$ \\
2100 & $59 \%$ & $9 \%$ & $50 \%$ \\
\hline HDAM_LDR & Mitigation\&Adaptation & Mitigation & Adaptation \\
2050 & $49 \%$ & $32 \%$ & $17 \%$ \\
2075 & $72 \%$ & $43 \%$ & $29 \%$ \\
2100 & $82 \%$ & $47 \%$ & $35 \%$ \\
\hline HDAM_HDR & Mitigation\&Adaptation & Mitigation & Adaptation \\
2050 & $33 \%$ & $12 \%$ & $21 \%$ \\
2075 & $61 \%$ & $10 \%$ & $51 \%$ \\
2100 & $74 \%$ & $8 \%$ & $66 \%$ \\
\hline
\end{tabular}

Table 8 shows the benefit-cost ratio of adaptation in the non cooperative and in the cooperative scenarios. The benefit-cost ratio of adaptation improves when it is optimally complemented by mitigation $^{12}$. This is another way of expressing the rule that two instruments are better than one instrument at the first best, i.e. (net) welfare can be enhanced by increasing the degrees of freedom

\footnotetext{
12 This happens also to mitigation, not shown.
} 
of the policymaker. When combined, both adaptation and mitigation can "better" be used than in isolation, i.e. with a higher BCR.

Table 8: Benefit-Cost Ratio (BCR) of adaptation and of joint adaptation mitigation

\begin{tabular}{|cccc|}
\hline USD 2005 Trillion & \multicolumn{2}{c|}{ BCR adaptation } & BCR joint adaptation and mitigation \\
3\% Discounting 2010-2105 & Non & & \\
Benefits & cooperative & Cooperative & Cooperative \\
Costs & 16 & 14 & 19 \\
BCR & 10 & 8 & 9 \\
\hline
\end{tabular}

Benefits are measured as discounted avoided damages compared to non-cooperative no policy case

Adaptation costs are measured as discounted expenditures on adaptation

Mitigation costs are measured as additional investments in carbon-free technologies and energy efficiency compared to

the non-cooperative no policy case

The sensitivity analysis reported in Table 9 highlights that adaptation becomes more profitable when climate related damages increase. Indeed, compared to mitigation which reduces mainly future damages, adaptation is more rapidly effective on contrasting future and present damages. Accordingly, in a "high damage world" (but without climate catastrophes), adaptation becomes the preferred strategy and this is reflected in an increasing benefit-cost ratio. When the discount rate declines, the opposite occurs: future damages become more relevant; mitigation is thus preferred; the benefit-cost ratio of adaptation declines accordingly. As shown in Table 7, with low discounting a larger share of damage reduction is achieved with mitigation. Similar results hold also when adaptation and mitigation are implemented jointly.

Table 9: Sensitivity analysis. Benefit-Cost Ratio (BCR)

of adaptation and of joint adaptation and mitigation in the cooperative scenario

\begin{tabular}{|ccccc|}
\hline \multicolumn{5}{|c|}{ Adaptation } \\
USD 2005 Trillion & \multicolumn{4}{c|}{} \\
3\% Discounting 2010-2105 & LDAM_HDR & HDAM_HDR & LDAM_LDR & HDAM_LDR \\
Benefits & 14 & 55 & 99 & 337 \\
Costs & 8 & 21 & 65 & 144 \\
\hline BCR & $\mathbf{1 . 7 3}$ & $\mathbf{2 . 6 3}$ & $\mathbf{1 . 5 2}$ & $\mathbf{2 . 3 3}$ \\
\hline \multicolumn{6}{c}{ Joint adaptation and mitigation } \\
\hline USD 2005 Trillion & & & & \\
3\% Discounting 2010-2105 & LDAM_HDR & HDAM_HDR & LDAM_LDR & HDAM_LDR \\
Benefits & 19 & 67 & 294 & $81 \overline{1}$ \\
Costs & 10 & 24 & 266 & 347 \\
BCR & 1.93 & 2.82 & 1.10 & 2.34 \\
\hline
\end{tabular}

Summing up, mitigation and adaptation are strategic complements. Therefore, they should be integrated in a welfare maximizing climate policy. It is worth stressing again that the possibility to mitigate (adapt) reduces, but does not eliminate, the need to adapt (mitigate). The optimal climate policy mix is composed by both mitigation and adaptation measures. The benefit cost ratio of a policy mix where adaptation and mitigation are optimally integrated is larger that the one in which mitigation and adaptation are implemented alone. 


\subsection{Unraveling the optimal adaptation strategy mix:}

The analysis performed so far does not disentangle the role of different adaptation strategies. This is the aim of this section. Let us consider first the relationship between proactive (anticipatory) and reactive adaptation. As shown by Figure 12 and Table 10, the non cooperative and the cooperative scenarios highlight the same qualitative behavior: not surprisingly anticipatory adaptation is undertaken in advance with respect to reactive adaptation.

Consequently, until 2085 the bulk of adaptation expenditure is devoted to anticipatory measures; reactive adaptation becomes the major budget item afterwards. This is the optimal response to climate damage dynamics. When it is sufficiently low, it is worth preparing to face future damages. When eventually it becomes high and increasing, larger amount of resources need to be invested in reactive interventions, coping with what cannot be accommodated ex ante.

Figure 12: Scale and timing of adaptation investments

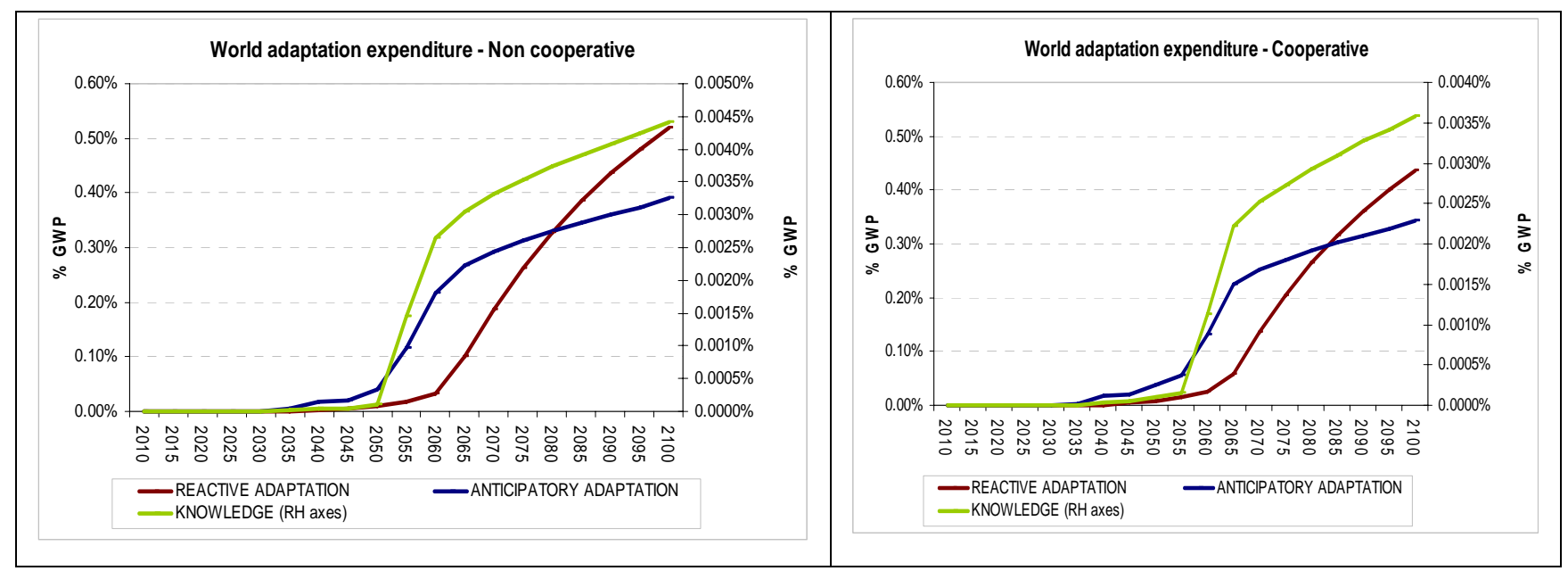

Table 10. Expenditure composition of the adaptation mix

\begin{tabular}{|ccc|}
\hline $\mathbf{2 0 3 5}$ & $\begin{array}{c}\text { Non-cooperative } \\
\text { setting }\end{array}$ & $\begin{array}{c}\text { Cooperative } \\
\text { setting }\end{array}$ \\
Reactive Adaptation & $0.2 \%$ & $0.6 \%$ \\
Anticipatory Adaptation & $99.6 \%$ & $99.1 \%$ \\
Knowledge Adaptation & $0.2 \%$ & $0.2 \%$ \\
\hline 2050 & Non-cooperative & Cooperative \\
Reactive Adaptation & setting & setting \\
Anticipatory Adaptation & $19.5 \%$ & $17.2 \%$ \\
Knowledge Adaptation & $80.3 \%$ & $82.6 \%$ \\
2100 & $0.2 \%$ & $0.2 \%$ \\
\hline Reactive Adaptation & Non-cooperative & Cooperative \\
Anticipatory Adaptation & setting & setting \\
Knowledge Adaptation & $56.8 \%$ & $55.8 \%$ \\
& $42.7 \%$ & $43.8 \%$ \\
\end{tabular}


Notice that investments in adaptation R\&D show a behavior similar to anticipatory adaptation, but the scale of dedicated resources is much smaller. This result depends on the calibration data: we relied on quantitative estimates provided by UNFCCC (2007) on the aggregate amount of money that could be spent on R\&D in agriculture, which is estimated to be around 7 USD Billion in 2060, a very tiny amount compared to world GDP ${ }^{13}$.

The results shown in Figure 12 and Table 10 are based on the full availability of resources and political consensus to implement the optimal policy mix. What happens when first best options are not available? In other words, what kind of adaptation strategy should a decision maker prefer were he/she forced to make a choice between different adaptation measures because of resource scarcity? The answer to this question is summarized by Table 11. It reports the benefit-cost ratio when either one of the three options is foregone.

Table 11: Benefit-Cost Ratio (BCR) of adaptation strategy mix in the cooperative scenario

\begin{tabular}{|cccc|}
\hline $\begin{array}{c}\text { Option excluded from the } \\
\text { optimal mix }\end{array}$ & & & \\
$\begin{array}{c}\text { USD 2005 Billion } \\
\text { 3\% Discounting 2010-2105 }\end{array}$ & $\begin{array}{c}\text { Reactive } \\
\text { adaptation }\end{array}$ & $\begin{array}{c}\text { Anticipatory } \\
\text { Adaptation }\end{array}$ & $\begin{array}{c}\text { Knowledge } \\
\text { Adaptation } \\
\text { Benefits }\end{array}$ \\
Costs & 789 & 7.4 & 13657 \\
BCR & 771 & 5.7 & 7938 \\
& 1.02 & 1.30 & 1.72 \\
\hline
\end{tabular}

If just only one adaptation strategy were to be chosen, reactive adaptation should be privileged. Indeed, the non implementation of reactive adaptation would induce a worsening of the benefit cost ratio of the whole climate change strategy by $41 \%$ (and by $45 \%$ in welfare terms). By contrast, the impossibility to use anticipatory adaptation would decrease the benefit cost ratio by $24 \%$ (33\% in welfare term).

R\&D adaptation appears to be the less crucial adaptation option. But this depends on the way it is modeled. R\&D adaptation improves the productivity of reactive adaptation. Hence, its elimination does not impair excessively reactive adaptation itself. Appendix III illustrates an alternative formulation in which R\&D augments the productivity of both proactive and reactive adaptation and in which adaptation R\&D investments are therefore much larger. Nonetheless, all other conclusions are robust to changes in the model specification as described in Appendix III.

\subsection{Regional analysis}

In order to provide insights on regional specificities, this section disaggregates the above results between developed and developing countries. Even this broad disaggregation is sufficient to highlight substantial differences.

Figure 13 and Table 12 stress the higher vulnerability and the higher need to adapt of developing countries. Not surprisingly, NON-OECD countries spend a higher share of their GDP on adaptation

\footnotetext{
${ }^{13}$ UNFCCC (2007) provides estimates for 2030. We scale this number up proportionally to the temperature gap between 2030 and our reference $2.5^{\circ} \mathrm{C}$, which is our calibration point.
} 
than OECD countries. This is driven by their higher damages - by the end of the century, also in absolute terms, optimal adaptation expenditure is nearly 5 times higher in NON-OECD than in OECD countries - and by their lower GDP.

Figure 13. Adaptation expenditures in NON OECD and OECD countries

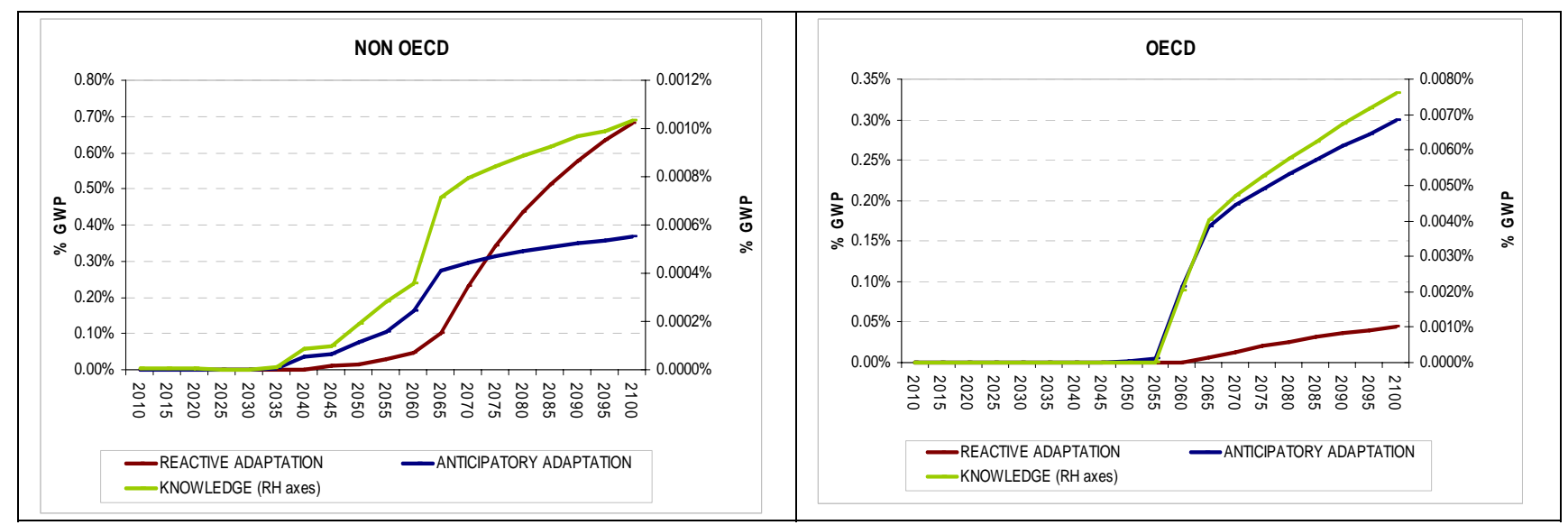

Table 12: Adaptation and mitigation in OECD and NON-OECD regions in the cooperative scenario

\begin{tabular}{|c|c|c|}
\hline & OECD & NON OECD \\
\hline & \multicolumn{2}{|c|}{2035} \\
\hline Reactive Adaptation (USD Billion) & 0 & 0 \\
\hline Anticipatory Adaptation (USD Billion) & 0 & 2 \\
\hline Knowledge Adaptation (USD Billion) & 0 & 0 \\
\hline Total Adaptation expenditure (USD Billion) & 0 & 2 \\
\hline \multirow[t]{2}{*}{ Mitigation (emission reduction \%) } & $-24 \%$ & $-15 \%$ \\
\hline & \multicolumn{2}{|c|}{2050} \\
\hline Reactive Adaptation (USD Billion) & 0 & 13 \\
\hline Anticipatory Adaptation (USD Billion) & 2 & 62 \\
\hline Knowledge Adaptation (USD Billion) & 0 & 0 \\
\hline Total Adaptation expenditure (USD Billion) & 2 & 76 \\
\hline \multirow[t]{2}{*}{ Mitigation (emission reduction \%) } & $-24 \%$ & $-16 \%$ \\
\hline & \multicolumn{2}{|c|}{2100} \\
\hline Reactive Adaptation (USD Billion) & 62 & 1520 \\
\hline Anticipatory Adaptation (USD Billion) & 421 & 821 \\
\hline Knowledge Adaptation (USD Billion) & 11 & 2 \\
\hline Total Adaptation expenditure (USD Billion) & 494 & 2344 \\
\hline Mitigation (emission reduction \%) & $-18 \%$ & $-14 \%$ \\
\hline
\end{tabular}

It is also worth noting the different composition and timing of the optimal adaptation mix between the two regions. NON-OECD countries rely mainly on reactive measures, which in 2100 contribute to $65 \%$ of total adaptation expenditure, whereas OECD countries focus on anticipatory measures, which constitute $85 \%$ of their total expenditure on adaptation. As for the timing, adaptation in NON-OECD is undertaken much earlier than in OECD regions.

The different composition of adaptation responses depends upon two facts ${ }^{14}$ : firstly, the regional characteristics of climate vulnerability. In OECD countries, the higher share of climate change

\footnotetext{
${ }^{14}$ More on the calibration procedure can be found in Appendix I and in another Annex available upon request.
} 
damages originates from loss of infrastructures and coastal areas, whose protection requires a form of adaptation that is largely anticipatory. In NON-OECD countries, a higher share of damages originates from agriculture, health, and the energy sectors (space heating and cooling). These damages can be accommodated more effectively through reactive measures.

Secondly, OECD countries are richer. Thus, they can give up relatively more easily their present consumption to invest in adaptation measures that will become productive in the future. By contrast, NON-OECD countries are compelled by resource scarcity to act "in emergency".

Only the expenditure on adaptation R\&D is higher in OECD countries than in NON-OECD countries. Data on R\&D and innovation aimed at improving the effectiveness of adaptation are very scarce. Starting from OECD (2007), we decided to distribute adaptation R\&D to different regions on the basis of current expenditure on total R\&D, which is concentrated in OECD countries. This explains why adaptation $R \& D$ investments in developing countries in 2100 is roughly $1 / 10$ and $1 / 5$ of that of developed regions - as a share of their GDP and in absolute terms, respectively.

Table 13: Sensitivity analysis. Benefit-Cost Ratio of adaptation and of joint adaptation and mitigation in the cooperative scenario - OECD regions

\begin{tabular}{|c|cccc|}
\hline $\begin{array}{c}\text { Adaptation } \\
\text { USD 2005 Trillion }\end{array}$ & L & & \\
3\% Discounting 2010-2105 & LDAM_HDR & HDAM_HDR & LDAM_LDR & HDAM_LDR \\
Benefits & 2.2 & 16 & 14 & 93 \\
Costs & 1.5 & 5.9 & 12 & 39 \\
\hline BCR & $\mathbf{1 . 4 5}$ & $\mathbf{2 . 6 4}$ & $\mathbf{1 . 1 2}$ & $\mathbf{2 . 3 8}$ \\
\hline \multicolumn{7}{|c}{} \\
\hline Joint adaptation and mitigation \\
3\% Discounting 2010-2105 & LDAM_HDR & HDAM_HDR & LDAM_LDR & HDAM_LDR \\
Benefits & 4.2 & 21 & 68 & 238 \\
Costs & 1.8 & 6.6 & 146 & 164 \\
BCR & $\mathbf{2 . 2 3}$ & $\mathbf{3 . 1 7}$ & $\mathbf{0 . 4 6}$ & $\mathbf{1 . 4 5}$ \\
\hline
\end{tabular}

Table 14: Sensitivity analysis. Benefit-Cost Ratio of adaptation and of joint adaptation and mitigation in the cooperative scenario - NON-OECD regions

\begin{tabular}{|c|c|c|c|c|}
\hline \multicolumn{5}{|c|}{ Adaptation } \\
\hline $\begin{array}{l}\text { USD } 2005 \text { Trillion } \\
\text { 3\% Discounting 2010-2105 }\end{array}$ & & & JDAM & HDM IDP \\
\hline Benefits & $1 \overline{1}$ & $40^{-}$ & $8 \overline{6}$ & $24 \overline{3}$ \\
\hline Costs & 6 & 15 & 53 & 105 \\
\hline BCR & 1.79 & 2.63 & 1.61 & 2.31 \\
\hline \multicolumn{5}{|c|}{ Joint adaptation and mitigation } \\
\hline $\begin{array}{c}\text { USD } 2005 \text { Trillion } \\
\text { 3\% Discounting 2010-2105 }\end{array}$ & LDAM HDR & HDAM HDR & LDAM LDR & HDAM LDR \\
\hline Benefits & $1 \overline{5}$ & $4 \overline{6}$ & $22 \overline{6}$ & $57 \overline{3}$ \\
\hline Costs & 6.9 & 16 & 128 & 183 \\
\hline BCR & 2.11 & 2.85 & 1.77 & 3.13 \\
\hline
\end{tabular}

Table 13 and 14 show the benefit-cost ratio of adaptation, and of adaptation and mitigation jointly. In NON-OECD countries, the combination of the two strategies always show a higher benefit-cost 
ratio than adaptation alone (Table 14). By contrast, in OECD regions (Table 13) this remains true only with a high discount rate. With a lower discounting, mitigation increases its weight in the policy mix. The additional effort undertaken by OECD countries, which is the group of countries investing more on low carbon technologies, benefits mostly NON-OECD regions. In other words, in a cooperative setting OECD countries are called to abate partly on behalf of NON-OECD countries. For example, consider the low damage, low discount case (LDAM_LDR). Global benefits of joint adaptation and mitigation amount at 294 USD trillion (see Table 9). $75 \%$ of these benefits occurs in NON-OECD countries, for a total benefit of 226 USD trillion, whereas OECD countries receive the remaining 25\% (68 USD trillion), though they bear slightly higher costs.

Again, what happens if first best options were not fully available? If just only one adaptation strategy were to be chosen, anticipatory adaptation should be privileged by OECD countries, whereas NON-OECD should prioritize expenditure on reactive adaptation (see Table 15).

Indeed, the elimination of anticipatory adaptation from the adaptation option basket of OECD countries induces a worsening of the benefit-cost ratio of the whole climate change strategy equal to $72 \%$. The impossibility to use reactive adaptation in NON-OECD countries reduces the overall benefit-cost ratio by $48 \%$ (Table 15 ).

The difference between developing and developed regions is notable. Foregoing reactive adaptation is much more damaging for developing than for developed countries, consistently with what observed about the regional structure of damages and the adaptation expenditure, whereas the opposite holds for anticipatory adaptation. Again, R\&D adaptation appears to be the adaptation option one can give up less regretfully.

Table 15: Marginal contribution of specific policy-driven strategies

\begin{tabular}{|cccc|}
\hline & WORLD & OECD & NONOECD \\
Reactive adaptation & $-41 \%$ & $-29 \%$ & $-48 \%$ \\
Anticipatory adaptation & $-24 \%$ & $-72 \%$ & $-24 \%$ \\
Knowledge adaptation & $-0.36 \%$ & $-2 \%$ & $-0.1 \%$ \\
\hline
\end{tabular}

These results, although driven by our model specification and calibration, contain some preliminary policy implications:

- OECD countries invest heavily in anticipatory adaptation measures. This depends on their damage structure. Planned anticipatory adaptation is particularly suited to cope with sealevel rise, but also with hydro geological risks induced by more frequent and intense extreme events, which are a major source of negative impacts in the developed economies. Thus, it is more convenient to act ex ante rather than ex post in OECD countries.

- In NON-OECD countries, climate change adaptation needs are presently relatively low, but will rise dramatically after the mid-century, as long as climate change damages will increase. In 2050, they could amount to 78 USD Billion, in 2065 they will be above 500 USD billion to peak to more than 2 USD trillion by the end of the century. It is sufficient to recall that in 2007 total ODA were slightly above 100 USD billion to understand by how much climate change can stress adaptive capacity in the developing world. NON-OECD countries are unlikely to have the resources to meet their adaptation needs, which calls for international aid and cooperation on adaptation to climate change. 
- At the equilibrium, NON-OECD countries place little effort on adaptation R\&D and rely primarily on reactive adaptation. This outcome however depends on the particular structure of NON-OECD economic systems. Being poor, other forms of adaptation expenditures, more rapidly effective, mainly of the reactive type, are to be preferred. This suggests that richer countries can help developing countries also by supporting their adaptation R\&D (e.g. by technology transfers) and their adaptation planning.

\section{A comparison with the existing modelling literature}

The modelling literature that analyses the optimal investments in adaptation, their time profile and the trade-off between adaptation and mitigation is thin and still mainly in the "grey" area. To our knowledge, it is confined to Hope (1993, 2007), Bosello (2008), de Bruin et al. (2007), de Bruin, Dellink and Agrawala (2009).

In the PAGE model (Hope, 1993, 2007) adaptive policies operate in three ways: they increase the slope of the tolerable temperature profile, its plateau, and finally they can decrease the adverse impact of climate change when the temperature eventually exceeds the tolerable threshold. However, adaptation is exogenously imposed and costs and benefits are given: the "default" adaptation strategy has a cost in the EU of 3,12 and 25 US billion\$/year (min., mode and max. respectively) to achieve an increase of $1{ }^{\circ} \mathrm{C}$ of temperature tolerability and of additional $0.4,1.6,3.2$ US billion $\$ /$ year to achieve a $1 \%$ reduction in climate change impacts. At the world level, this implies, at a discount rate of 3\% declining, a cost of nearly 3 trillion of US $\$$ to achieve a damage reduction of roughly US $\$ 35$ trillions within the period 2000-2200. Impact reduction ranges from $90 \%$ in the OECD to $50 \%$ elsewhere.

With the given assumptions, the PAGE model could easily justify aggressive adaptation policies (see e.g. Hope et al., 1993), implicitly decreasing the appeal of mitigation. Due to the huge uncertainty about cost and effectiveness of adaptation, more than questioning the credibility of these assumptions, it is worth emphasising that, in the PAGE model adaptation is exogenous. It is not determined by the model, but decided at the outset. Accordingly, mitigation and adaptation cannot be really compared in an optimizing framework.

De Bruin et al. (2007) enrich the Nordhaus (1994) DICE model with explicit cost and benefit functions of a world adaptation strategy. They model adaptation as a flow variable: it needs to be adjusted period by period, but also, once adopted in one period, it does not affect damages in the next period. De Bruin et al. (2007) show that adaptation and mitigation are strategic complements: optimal policy consists of a mix of adaptation measures and investments in mitigation. This result holds also in the short-term, even though mitigation will only decrease damages in later periods. Adaptation is the main climate change cost reducer until 2100, whereas mitigation prevails afterwards. In addition, it is shown that benefits of adaptation are higher than those of mitigation until 2130.

The authors highlight the trade-off between the two strategies: the introduction of mitigation decreases the need to adapt and vice versa. However, the second effect is notably stronger than the first one. Indeed, mitigation lowers only slightly climate related damages, especially in the shortmedium term. Therefore, it does little to decrease the need to adapt, particularly during the first decades.

Sensitivity over the discount rate points out that mitigation becomes relatively more preferable as the discount rate becomes lower. Intuitively, mitigation reduces long-term climatic damages: thus, it becomes the preferred policy instrument as these damages become more relevant. 
All these results are consolidated in de Bruin et al. (2009), which repeat the analysis with an updated calibration of adaptation costs and benefits and propose also regional results. They show that in terms of utility for low level of damages adapting only is preferable than mitigating only. However, the relationship is reversed when climate damages increase.

Bosello (2008) compares adaptation and mitigation using the FEEM-RICE model (Buonanno et al. 2000), a modified version of Nordahus' RICE 1996 model in which technical progress is endogenous. Differently from De Bruin et al. (2007) and de Bruin and Dellink (2009), adaptation is modelled as a stock of "defensive capital" that is accrued over time by a periodical protection investment. Firstly, it is shown that mitigation should be optimally implemented in early periods whereas adaptation should be postponed to later stages. Accordingly, and this is the first key qualitative difference with de Bruin et al. (2007), the main damage reducer is mitigation and not adaptation at least in the first decades. Mitigation has to be anticipated because of its delayed effects driven by environmental inertia; adaptation can be postponed partly because it is more rapidly effective, but mainly because it is not worth reducing consumption by investing in adaptation when damage is low. Adaptation becomes cost efficient only when climate related damage is sufficiently high.

The second important difference with respect to de Bruin et al. (2007) is that when climate damage becomes large, albeit both adaptation and mitigation increase, the share of total damage reduction due adaptation increases. In Bosello (2008) adaptation does not "vanishes" after one period as in de Bruin et al. (2007). Therefore, it is more cost effective to cope with incremental damages than in De Bruin et al. (2007).

In all the aforementioned papers, adaptation emerges as a powerful strategy to cope with climate change damage. However, irrespectively of its effectiveness, mitigation is always undertaken. Mitigation and adaptation are again strategic complements. They are also economic substitutes: more investments in mitigation reduce the equilibrium expenditure in adaptation, and vice versa. However, mitigation is more responsive to adaptation than vice versa. Finally, an increased (decreased) inter-temporal preference for the future (a lower (higher) discount rate) shifts the policy emphasis into mitigation (adaptation).

\section{Assessing the role of market driven adaptation}

The analysis conducted so far abstracted from any role potentially played by market-driven adaptation. In other words, either the economic impact assessment or the design of the optimal mix between mitigation and adaptation strategies are based on damage functions not accounting for behavioural changes induced by "market or welfare changes in human systems".

Modelling and then quantifying market-driven adaptation is extremely challenging. In economic terms, this means representing supply and demand reactions to scarcity signals conveyed by prices and triggered by climate-related impacts. Even assuming a satisfactory knowledge of these impacts, this requires to assessing substitution elasticities in consumers preferences and transformation elasticities in production functions for all goods and services. This needs then to be coupled with a realistic picture of inter-sectoral and international trade flows. Some seminal studies in this field exist, which try to capture the autonomous reactions of demand and supply to climate-induced changes in relative prices and/or in the availability of resources. Most studies use applied or computable general equilibrium models (see, for example, Bosello et al. (2006), Bigano et al. (2008), Deke et al. (2001), Darwin and Tol (2001)).

Initially, computable general equilibrium (CGE) models were developed mainly to analyze international trade policies and, partially, public sector economic issues (e.g. fiscal policies). Soon, because of their great flexibility, they became a common tool for economists to investigate the 
consequences of the most diverse economic "perturbations", including those provoked by climate change. Indeed, notwithstanding its complexity, as long as climate-related physical impacts can be translated into a change in productivity, production or demand for the different inputs and outputs of the model, their GDP implications can be determined by a CGE model ${ }^{15}$.

The structure of an integrated climate impact assessment exercise within a general equilibrium framework is presented in Figure 14. Economics is not independent from other disciplines, in particular it comes into play only after climatic changes have been translated into physical consequences (impacts) and then into changes of activities relevant for human welfare.

Figure 14. The structure of a integrated impact assessment exercise

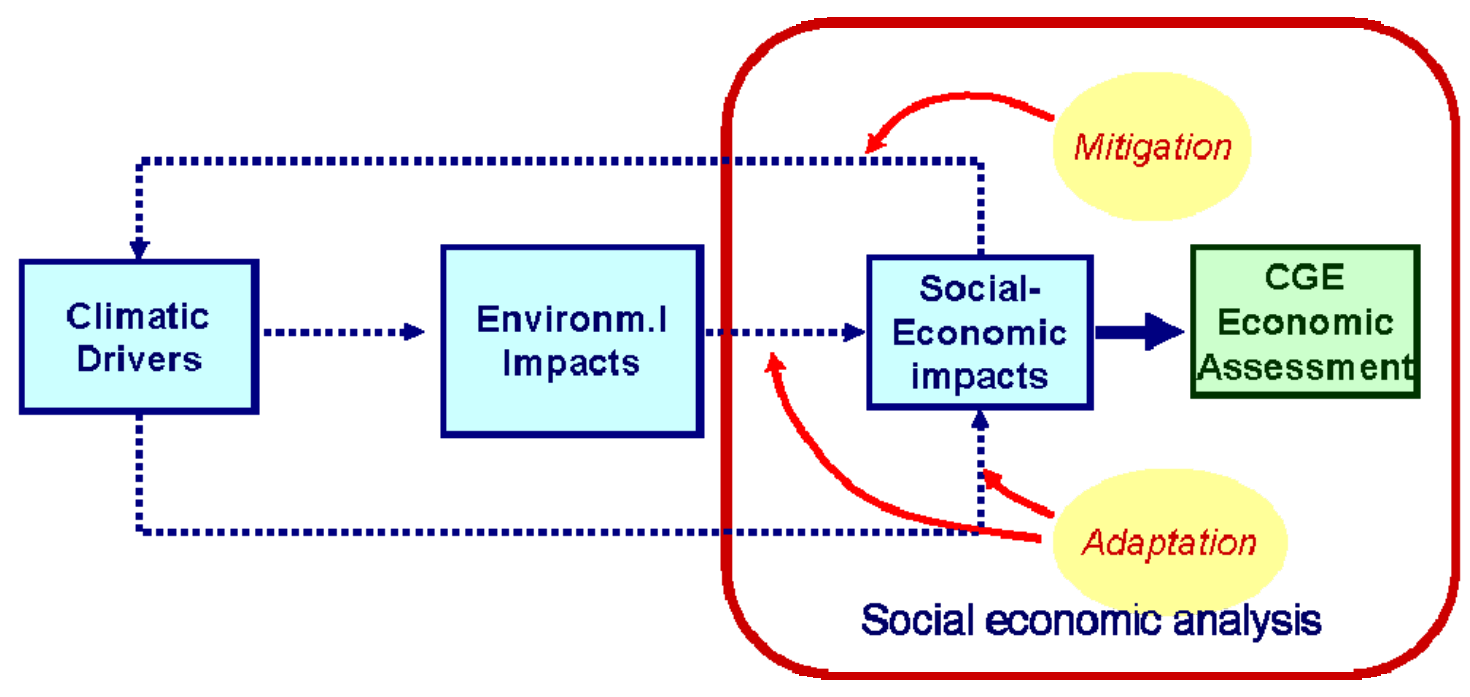

Using a CGE approach for the economic evaluation of climate impacts implies an explicit modelling of sectors and of trade of production factors, goods and services. Changes in relative prices induce sectoral adjustments and changes in trade flows, thus triggering autonomous adaptation all over the world economic system.

Studies in this field however share one or both of the following shortcomings: they analyse climate change impacts in a static framework; and they consider only one or very limited number of impacts. A static approach fails to capture important cumulative effects - think e.g. to a loss of productive capital that need to be compensated by an increased investment rate - thus it is severely limited especially to analyse long-term climate impacts. As to the second issue, albeit some marketdriven adaptation mechanisms can be described even in a single-impact case, interactions among impacts and the full potential of market-driven adaptation are neglected by focusing on one or few impacts.

A recent research effort conducted at FEEM tackled these two limitations. ICES, a recursivedynamic CGE model, has been developed and then used as investigation tool to analyse the higher order costs of an extended set of climate-related impacts (see Table 16) considered one at a time,

\footnotetext{
${ }^{15}$ In principle CGE model offer also the possibility to measure welfare changes captured by changes in indicators other than GDP, like the Hicksian equivalent variation or consumers' surplus from a pre- to a post-perturbation state. However, great care should be placed on their interpretation. Here it is sufficient to mention that CGE models only partially capture changes in stock values (like property), and that they usually miss non market aspects to understand the important limitation of these assessments. Nevertheless a CGE approach has the merit to depict explicitly resource relocation, a crucial aspect of which is international trade, which is not captured by traditional direct costing methodologies.
} 
but also jointly. The study is still in a preliminary phase (many relevant impacts have still to be included, moreover the methodological approach can be improved by a more realistic representation of many features of market functioning) however it can already offer an interesting glimpse of the possible role played by market-driven adaptation.

In this study, the ICES model replicates the same geographical disaggregation of the WITCH and AD-WITCH models. The only difference is that WITCH's WEURO (Western Europe) region is now divided into Mediterranean and Northern Europe, while WITCH's MENA (Middle East and North Africa) region is split into Middle East and North Africa. Seventeen production sectors are considered in our analysis (see Table 17).

Table 16. Impacts analyzed with the ICES model

\begin{tabular}{|c|}
\hline Supply- side impacts \\
\hline Impact on labour quantity (change in mortality - health effect of climate change) \\
\hline Impacts on labour productivity (change in morbidity - health effect of climate change) \\
\hline Impacts on land quantity (land loss due to sea level rise) \\
\hline Impacts on land productivity (Yield changes due to temperature and CO2 concentration \\
changes) \\
Demand-side impacts \\
\hline Impacts on energy demand (change in households energy consumption patterns for heating \\
and cooling)
\end{tabular}

Table 17. Regional and sectoral disaggregation of the ICES model

\begin{tabular}{|c|c|}
\hline \multicolumn{2}{|c|}{ REGIONAL DISAGGREGATION OF THE ICES MODEL (this study) } \\
\hline USA: & United States \\
\hline Med_Europe: & Mediterranean Europe \\
\hline North_Europe: & Northern Europe \\
\hline East_Europe: & Eastern Europe \\
\hline FSU: & Former Soviet Union \\
\hline KOSAU: & Korea, S. Africa, Australia \\
\hline CAJANZ: & Canada, Japan, New Zealand \\
\hline NAF: & North Africa \\
\hline MDE: & Middle East \\
\hline SSA: & Sub Saharan Africa \\
\hline SASIA: & India and South Asia \\
\hline CHINA: & China \\
\hline EASIA: & East Asia \\
\hline $\begin{array}{c}\text { LACA: } \\
\end{array}$ & Latin and Central America \\
\hline \multicolumn{2}{|c|}{ SECTORAL DISAGGREGATION OF THE ICES MODEL (this study) } \\
\hline Rice & Gas \\
\hline Wheat & Oil Products \\
\hline Other Cereal Crops & Electricity \\
\hline Vegetable Fruits & Water \\
\hline Animals & Energy Intensive industries \\
\hline Forestry & Other industries \\
\hline Fishing & Market Services \\
\hline Coal & Non-Market Services \\
\hline Oil & \\
\hline
\end{tabular}


The model, running from 2001-2050, has been calibrated to replicate regional GDP growth paths consistent with the A2 IPCC scenario, and has then been used to assess climate change economic impacts for 1.2 and $3.1{ }^{\circ} \mathrm{C}$ increase in $2050 \mathrm{wrt} 2000$, which is the likely temperature range associated to that scenario. The difference between these values and initial direct costs provides an indication of the possible role of autonomous adaptation. This information then allowed to calibrate world and macro-regional climate change damage functions by explicitly considering market driven adaptation.

Our main results can be summarised as follows (see Appendix II for a more detailed presentation).

Socio-economic systems share a great potential to adapt to climate change. Figure 15 shows the difference between the direct cost of climate change impacts (all jointly considered) and the final impact on regional GDP after sectoral and international adjustments took place. Resource reallocation smoothes, in some cases turns them into gains, initial direct costs. Nevertheless, it is worth highlighting that in some regions (SASIA, EASIA and CHINA) final costs are very close to direct costs and that in China they are higher. This means that some market adjustment mechanisms, primarily international capital flows and terms of trade effect, can exacerbate initial impacts.

Figure 15. Direct vs final climate change costs as \% of regional GDP (in 2050 for a temperature increase of $+3^{\circ} \mathrm{C}$ wrt 2000)

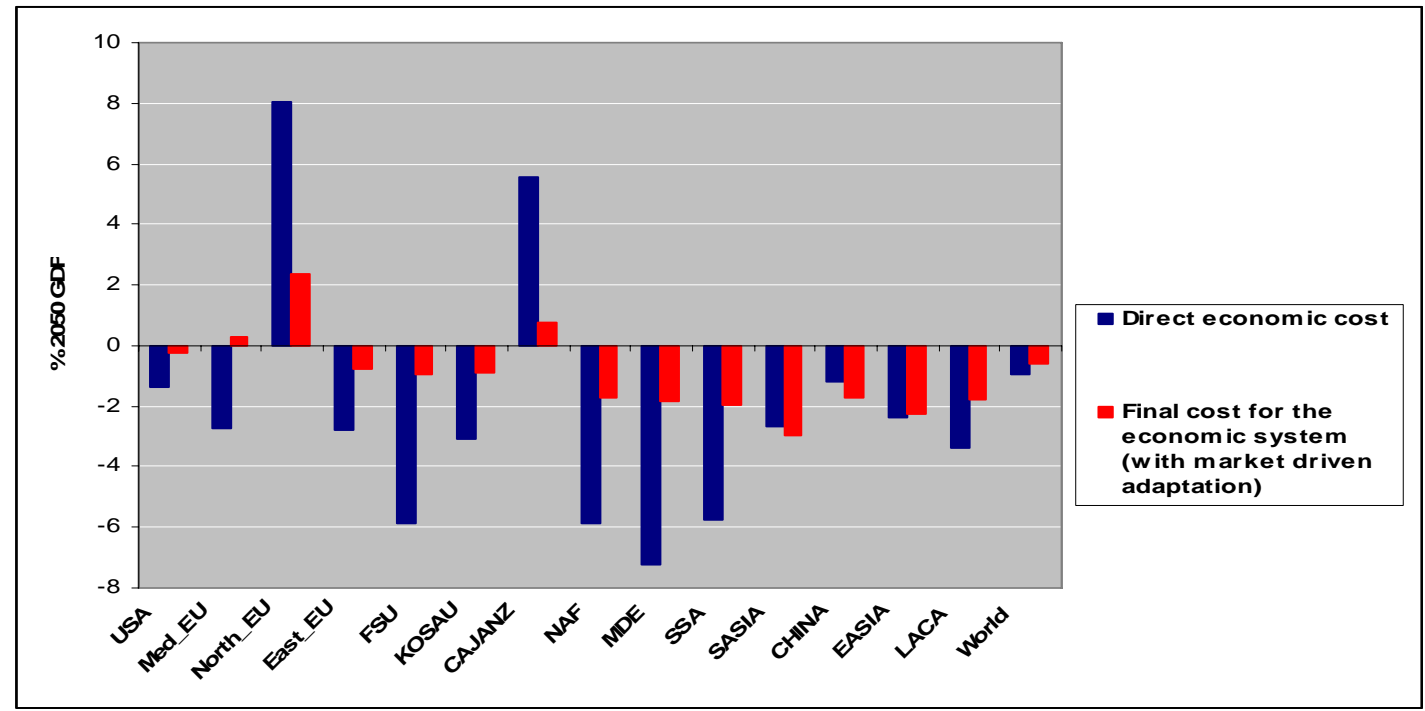

Interactions among impacts are also relevant (see Figure 16). In general, costs of impacts together are higher than the sum of the cost associated to each single impact. This also provides an important justification to performing a joint impact analysis instead of collecting the results provided by a set of single impact studies.

Finally, as clearly shown by Figure 17, climate change impacts at the world level induce costs, even when market-driven adaptation is accounted for. Impacts and adaptive capacity are highly differentiated though, i.e. a relatively small loss at the world level may hide large regional losses. In particular, developing countries remain the most vulnerable to climate change especially because of adverse impacts on the agricultural sector and food production. 
Figure 16. Role of Impact interaction: \% difference between GDP costs of all climatic impacts implemented jointly and the sum of GDP costs associated to each impact implemented individually

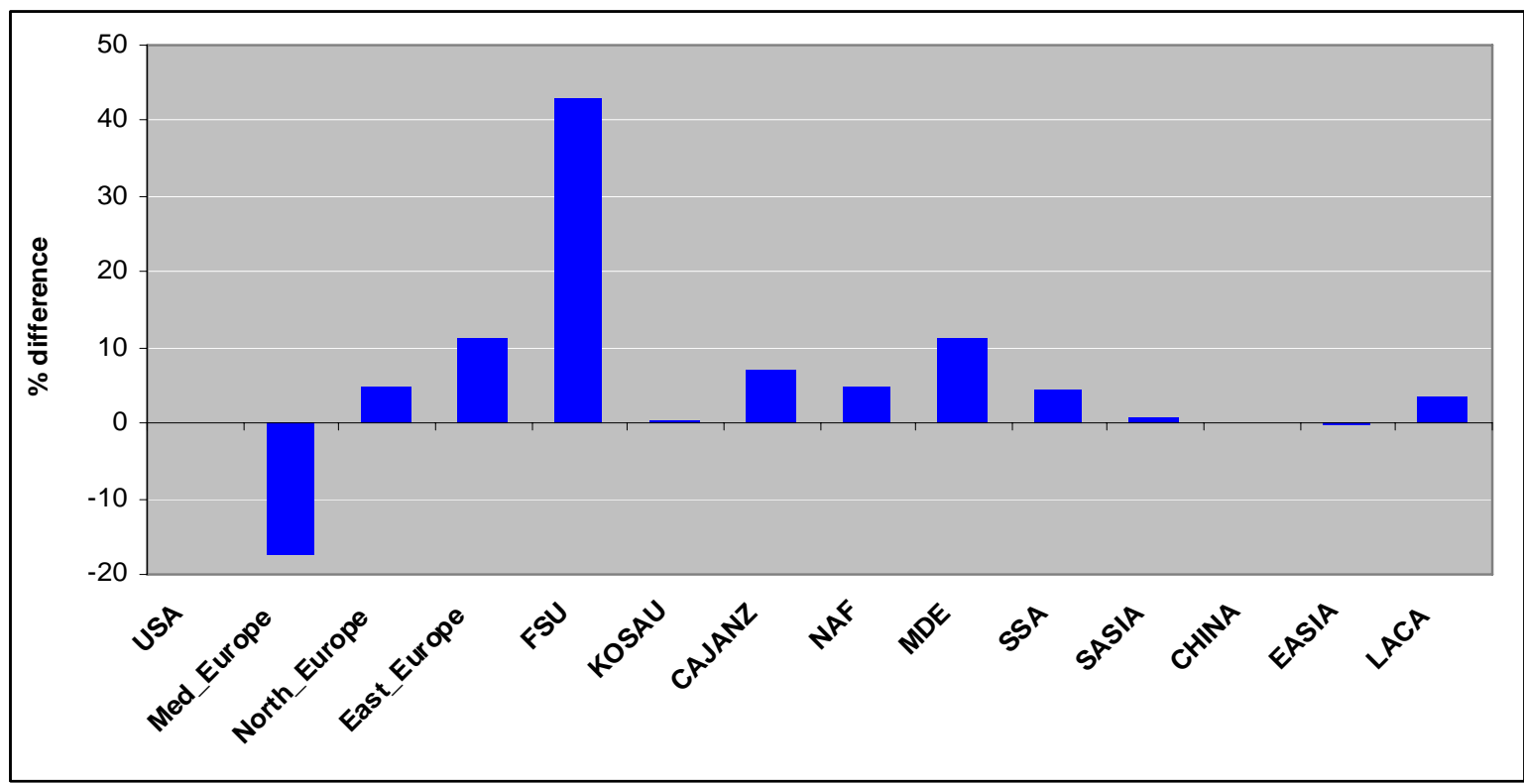

Figure 17. Final climate change impact as \% of regional 2050 GDP

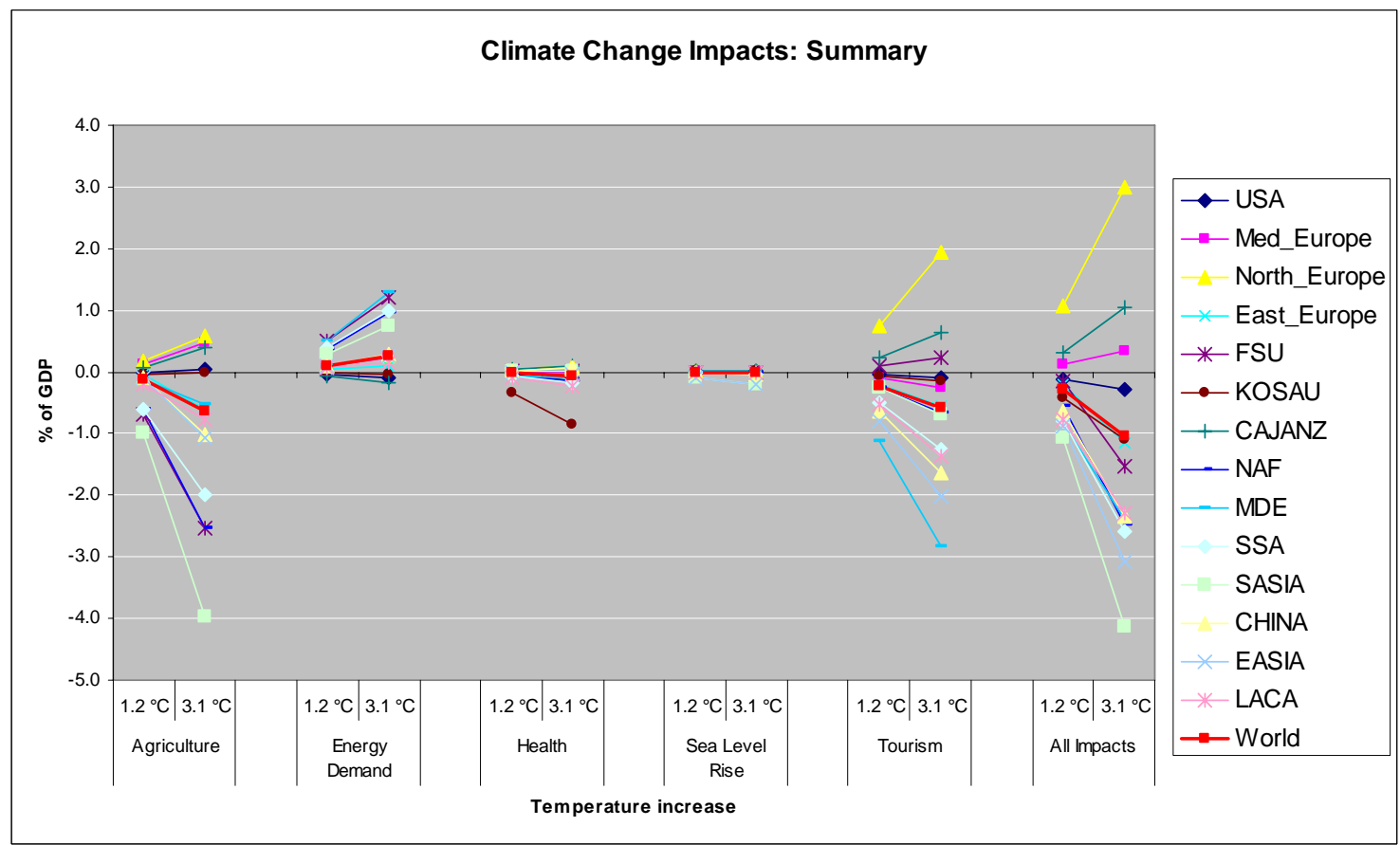

Let us underline that the above results have been computed only for a subset of potential adverse effects of climate change (possible consequences of increased intensity and frequency of extreme weather events and of biodiversity losses for instance are not included). Irreversibilities or abrupt climate and catastrophic changes to which adaptation can be only limited are neglected. Then, the model assumes costless adjustments and no frictions. Finally, the world is currently on an emission path leading to higher temperature increases than the ones consistent with the A2 scenario. Hence, for these four reasons, our analysis is likely to yield a lower bound of climate change costs. It can 
be considered as optimistic and cautious at the same time. Nonetheless, the main conclusion can be phrased as follows.

Despite its impact smoothing potential, market-driven adaptation cannot be the solution to the climate change problem. The distributional and scale implications of climate related economic impacts need to be addressed by adequate policy-driven mitigation and adaptation strategies.

Our study of market-driven adaptation enabled us to re-compute the damage functions for the different regions modelled in WITCH. We have been able to compute the residual damage after market-driven adaptation has displayed its effects and a new equilibrium has been reached in the economic systems. Figure 18 reports our new estimates of world and regional climate damage functions. These new damage functions can be used to re-compute the benefit-cost ratios of different policy-driven adaptation and mitigation strategies.

Fig. 18. Economic cost of climate change including market-driven adaptation

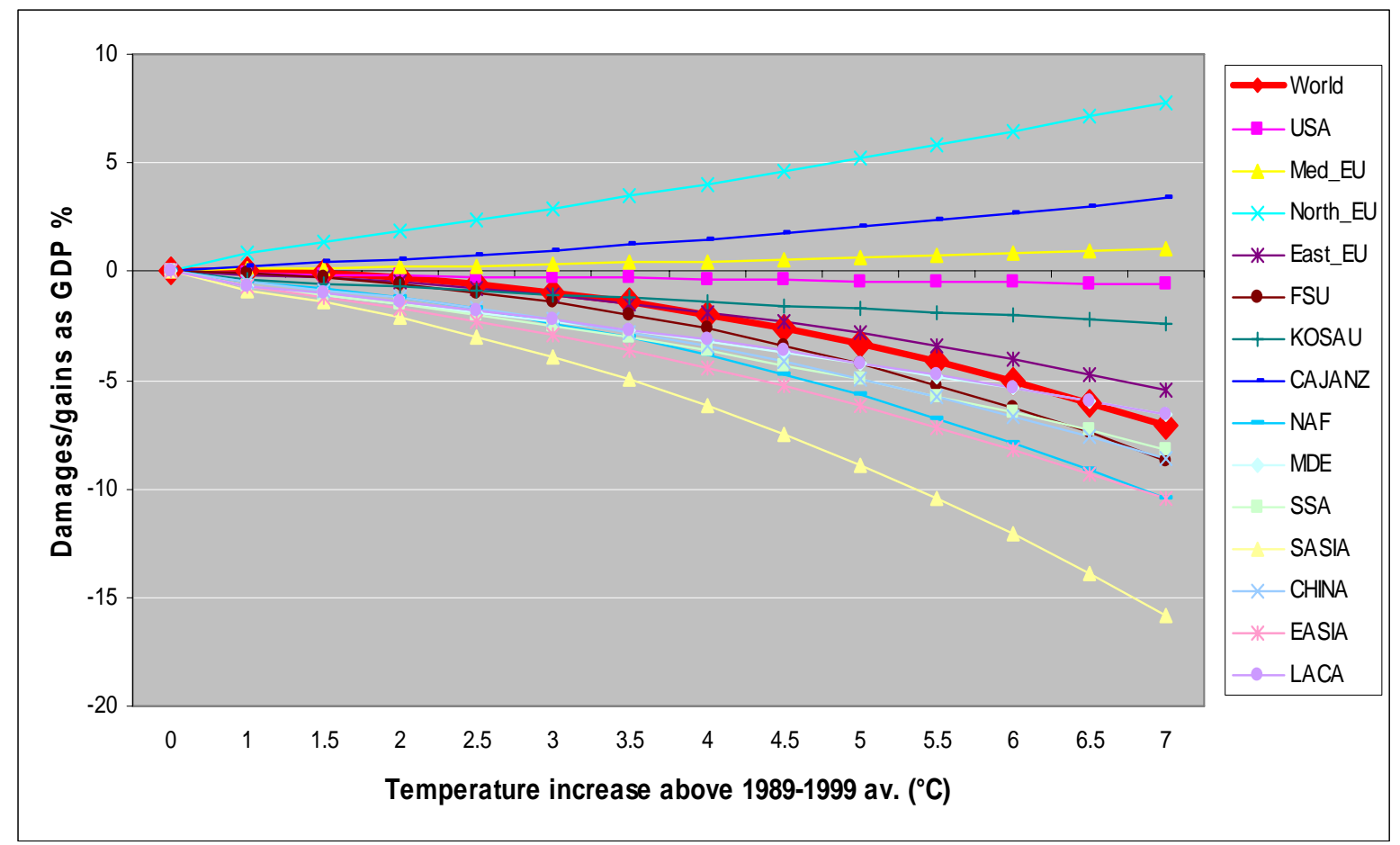

\section{Re-examining policy-driven adaptation: The effects of including market- adjustments}

In this last section, previous results obtained with the AD-WITCH model are re-examined by accounting for the contribution of market-driven adaptation. To do so, firstly AD-WITCH climate damage function has been re-calibrated in order to replicate regionally damage patterns estimated by the ICES model. Then, optimal mitigation and adaptation strategies have been recomputed.

The first clear insight is that market driven adaptation has a strong damage smoothing potential at the global level (see Figure 19). This result hides some important distributional changes. Marketdriven adaptation re-ranks winners and losers. In particular (see Figure 18 and 20), the main OECD countries are likely to gain from climate change, while all NON-OECD countries still loose (even though less than with previous estimates of climate damages). It also hides the fact that a positive 
effect can be the sum of positive and negative impacts. Accordingly the need to adapt can persist even in the presence of a net gain from climate change.

The policy implications are relevant. OECD regions have little reasons to devote large amount of resources on mitigation and adaptation in their own countries. NON-OECD countries still face positive damages, but smaller than in the absence of market-driven adaptation, thus leading to lower adaptation spending also in these countries.

Accordingly, optimal mitigation and policy driven adaptation expenditures are smaller (see Figure 21). In particular, by the end of the century, adaptation expenditure is half of what it would have been in the absence of market-driven adaptation. Even though adaptation expenditure reaches anyway the remarkable amount of 1.5 USD trillions. Almost all this expenditure is concentrated in developing countries.

Figure 19. Climate change damage with and without market driven adaptation

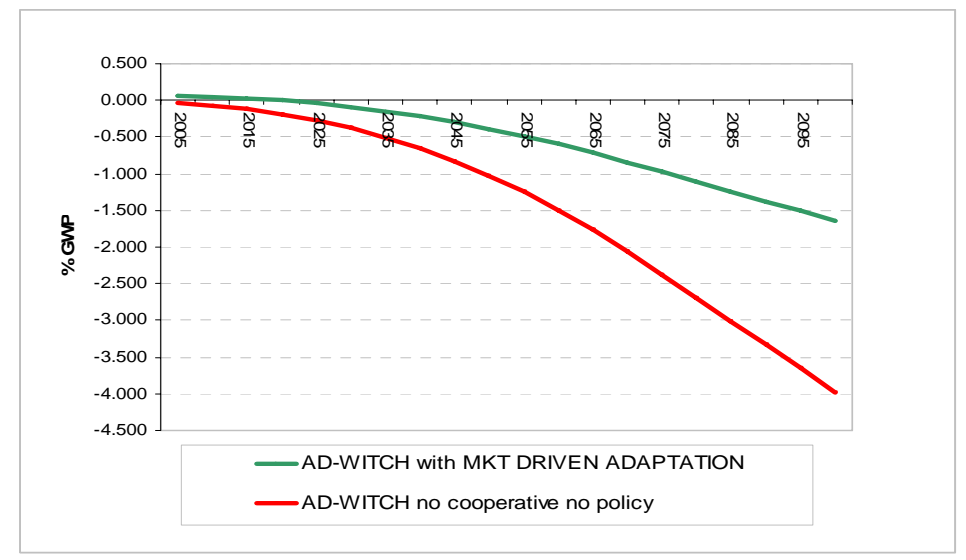

Figure 20. OECD and NON OECD climate change damage with and without market driven adaptation

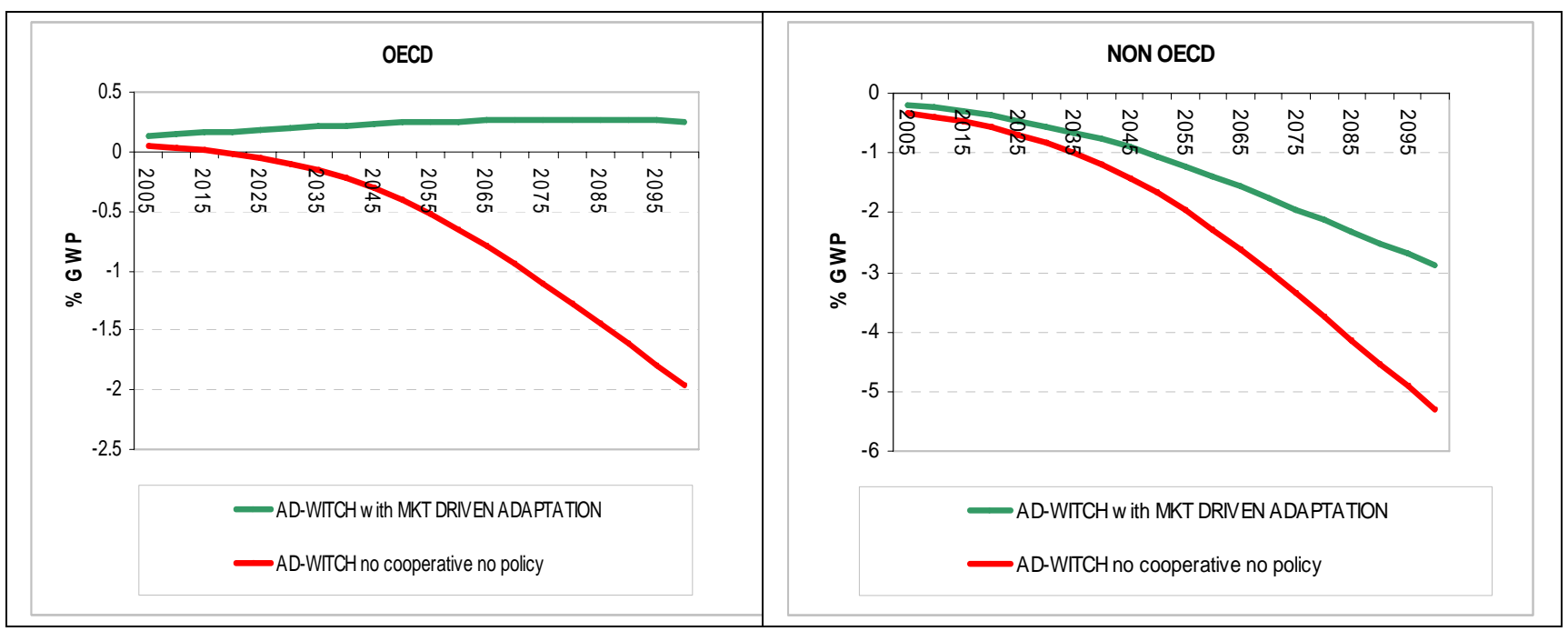


Figure 21: Total protection expenditure

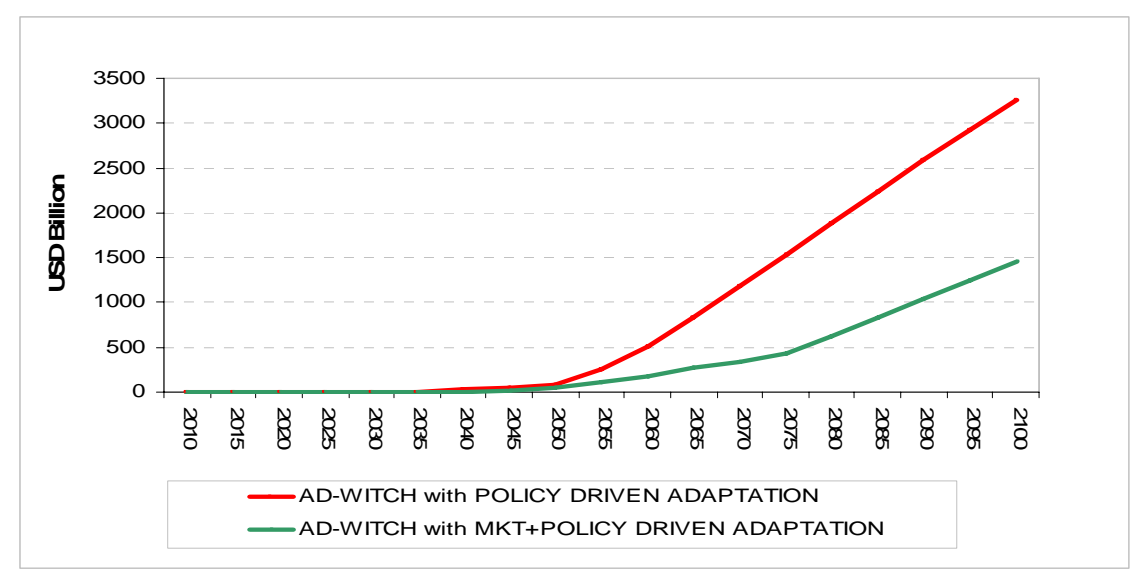

As a consequence, benefit-cost ratios are slightly lower than in the absence of market-driven adaptation, both regionally and globally. The upper part of Table 18 shows global and regional benefit-cost ratios of adaptation, in comparison with those obtained without accounting for marketdriven adaptation (lower part). The largest difference can be seen in OECD regions, where aggregate regional damages have turned positive (overall they have a benefit, see Figure 20). Only few OECD regions still face negative damages, and therefore find it optimal to spend resources on adaptation. Benefit-cost ratios are lower also in developing regions (NON-OECD), reflecting the fact that market-driven adaptation can reduce overall climate change impacts.

Table 18: Benefit-Cost Ratio (BCR) of policy driven adaptation in the presence of market driven adaptation

\begin{tabular}{|cccc|}
\hline USD 2005 Biillion & \multicolumn{3}{c|}{ with Market-driven adaptation } \\
3\% Discounting 2010-2105 & WORLD & OECD & NON OECD \\
Benefits & 5282 & 202 & 5079 \\
Costs & 3123 & 164 & 2959 \\
BCR & 1.69 & 1.24 & 1.72 \\
\hline & \multicolumn{4}{c}{ w/o Market-driven adaptation } \\
USD 2005 Biillion & WORLD & OECD & NON OECD \\
3\% Discounting 2010-2105 & 14 & 2250 & 11535 \\
Benefits & 8 & 1550 & 6434 \\
Costs & $\mathbf{1 . 7 3}$ & $\mathbf{1 . 4 5}$ & $\mathbf{1 . 7 9}$ \\
BCR & &
\end{tabular}

\section{Specific adaptation strategies: insights from the existing literature}

Two are the main policy implications that emerge from the analysis carried out in the previous sections of this report. First of all, the optimal response to climate change entails both mitigation and adaptation measures. Second, the adaptation mix consists of different strategies and such mix is region specific. In OECD countries most resources are devoted to anticipatory adaptation, whereas NON-OECD countries spend more in reactive adaptation. 
As for specific adaptation measures, priority should be given to those measures offering no regret opportunities, i.e. benefits higher than the costs irrespectively of the adaptation (damage reducing) potential. Some of these measures are already well identified, e.g. better insulation of old buildings, improved insulation standards for new building, and more efficient air conditioning systems (McKinsey, 2009).

These measures offer three advantages: they improve adaptation to warmer climates of urban areas, they create important energy savings opportunities which on their own can motivate their adoption, they finally entail carbon emission reductions. Indeed, they are primarily considered mitigation strategies. It would thus be wise to use scarce resources to foster the adoption of these measures first.

The composition of the optimal adaptation mix is related essentially to the regional and sectoral vulnerability, as different types of climate change impacts call for specific interventions. Moreover, whereas some adjustments can take place "autonomously" through markets, other responses require interventions by policy makers.

In developed countries, the higher share of climate change damages seems to be related to extreme and catastrophic events. Damages from sea level rise as well pose a risk on high income countries. Accordingly, resources can be conveniently used to improve the extreme-climate resilience of infrastructures - from settlements to transportation routes - but also to mainstream climate change adaptation into long-term spatial/landscape planning to reduce from scratch the probability of experiencing extreme losses from hydro geological risk respect to which, by definition, adaptation can only be partial. A net of accurate and efficient early warning systems seems to provide a particularly high benefit cost ratio. These forms of adaptation can be classified as anticipatory, as they are to be put in place before the occurrence of the damage.

The World Bank (2006) quantifies the costs of adapting vulnerable infrastructures to the impacts of climate change as a 5\%-20\% increase in investments in 2030, which is reported to amounting at 10 - 100 billions of 2000 US\$. According to the Association of British Insurers, in the UK, accounting for climate change in flood management policies, and including developments in floodplains and increasing investments in flood defences, could limit the rising costs of flood damage to a possible four-fold increase (to $\$ 9.7$ billions) rather than $10-20$ fold by the 2080 s. If all properties in south Florida met the stronger building code requirements of some counties, property damages from another Hurricane Andrew (taking the same track in 2002 as it did in 1992) would drop by nearly $45 \%$ (ABI, 2005).

These adaptation responses include better flood protection, stronger land-use planning, and catchment-wide flood storage schemes. A specific study on costs of flooding for the new developments in East London showed that pro-active steps to prepare for climate change could reduce annual flooding costs by $80-90 \%$, saving almost $\$ 1$ billion.

The major forms of adaptation to sea level rise are protect, accommodate or retreat. Nichols et al. noted that the benefits of adaptation to sea level rise far outweigh the costs, though it is to not clear up to which sea level rise human being can adapt. Total costs including investment costs (beach nourishment and sea dykes) and losses (inundation and flooding) are estimated to be USD $21-22$ billion in 2030 (UNFCCC, 2007). Building sea dike coast is the most expensive option (8 USD billion). However, costs in isolation are not very informative and what is to be considered is the benefit cost ratio.

According to Nicholls and Klein (2003), the costs of coastal protection are justified in most European countries. The avoided damage without protection, at least in the case of the Netherlands, 
Germany and Poland, would amount to the $69 \% 30 \%$ and $24 \%$ of GDP respectively. These benefits largely offset the costs even in the case of highest protection costs. Although average estimates report costs below 1\% GDP (IPCC, 2001; Bosello et al. 2006), Nicholls and Klein (2003) found much higher costs, about $14 \%$ of GDP, which still remain low relative to the potential benefits. Smith and Lazo (2001) report benefit-cost $\operatorname{ratios}^{16}$ for the protection of the entire coastlines of Poland and Uruguay, the Estonian cities of Tallin and Pärnu, and the Zhujian Delta in China. They are in the range of 2.6 to around 20 for a sea level rise of $0.3-1 \mathrm{~m}$.

In developing countries, in addition to catastrophic events, high losses and thus adaptation needs are associated to adverse impacts on agricultural activity and, particularly in Sub-Saharan Africa, on health. Assessing cost benefits of health care policies is always difficult, but these are associated to relatively low cost-benefit ratios as well.

Many studies describe the possible adaptation strategies that can be implemented by health sectors in developed and developing countries (see e.g. WHO, 2005; WHO, 2006). Nevertheless, very few researches try a quantitative cost assessment of these measures. The problem here is twofold: firstly, there is a general lack of information concerning the potential costs of some interventions. Secondly, it is very difficult conceptually and practically to disentangle the costs of adaptation to changes in health status induced by climate change from those related to change in health status per se.

Agrawala and Fankhauser (2008) reports just one study (see Ebi, 2008), providing direct adaptation costs for the treatment of additional number of cases of diarrhoeal diseases, malnutrition and malaria related to climate change. The additional cost for the world as a whole ranges between 4 and 12.6 billion $\$$ by 2030 . In the year 2000 , the additional mortality attributable to climate change was estimated to be 154,000 deaths $(0.3 \%)$, with a burden of 5.5 million $(0.4 \%)$ DALYs ${ }^{17}$. According WHO, in developing countries the most sensitive diseases to climate change are malnutrition, diarrhoeal disease and malaria. Assuming GHG stabilization at $750 \mathrm{ppm} \mathrm{CO} 2$ by 2200, Ebi (2008) estimates an increase in incidence of diarrhoeal disease, malnutrition and malaria due climate change in 2030, respectively of 3\%,10\% and 5\%. Almost all the malnutrition and malaria cases would be in developing countries, with $1-5 \%$ of the diarrhoeal disease affecting developed countries (UNFCC, 2007).

According to the analysis brought about by Ebi (2008), the adaptation response corresponds to an increase of both preventive (anticipatory adaptation) and therapy costs (reactive adaptation). In the 750 ppm scenario, the projected climate change driven expenditure in 2030 would be $2-7$ billion $\$$ for diarrhoeal disease, 81-108 million $\$$ for malnutrition and 2-5.5 billion $\$$ for malaria.

Tables 19-21 rank alternative adaptation strategies in the health sector according to the cost effectiveness criterion. It is worth noting that several strategies are considered even though are not strictly referred to the health sector. This is because, despite their lower cost-effectiveness, they may have advantages also in the health sector. For example, in the case of diarrhoeal disease, within the improvement of water and sanitation facilities there exist interventions like the installation of hand pumps, corresponding to US\$ 94 per DALY averted, and the provision and promotion of basic sanitation facilities, corresponding to US\$270 per DALY averted, that are cost-effective (WB,

\footnotetext{
16 They represent the ratio between the monetized avoided damage and the cost of the intervention.

17 The WHO define DALY (Disability-Adjusted Life Year) as: "a measure of overall disease burden. One DALY can be thought of as one lost year of "healthy" life. DALYs for a disease or health condition are calculated as the sum of the Years of Life Lost (YLL) due to premature mortality in the population and the Years Lost due to Disability (YLD) for incident cases of the health condition. The YLL basically correspond to the number of deaths multiplied by the standard life expectancy at the age at which death occurs. To estimate YLD for a particular cause in a particular time period, the number of incident cases in that period is multiplied by the average duration of the disease and a weight factor that reflects the severity of the disease on a scale from 0 (perfect health) to 1 (dead). (http://www.who.int/healthinfo/global_burden_disease/metrics_daly/en/index.html).
} 
2006). Therefore, these may be considered "no regret" options, increasing development and health benefits at the society level also in the absence of climate change.

Table 19: Most cost/effective strategies against diarrhoeal disease

\begin{tabular}{|l|l|}
\hline Strategies & Cost/effectiveness(US\$ for DALY averted) \\
\hline Breastfeeding promotion & $527-2,001$ \\
\hline Measles immunization & $257-4,565$ \\
\hline Oral Rehydratation Therapy & $132-2,570$ \\
\hline Water and sanitation in rural areas & 1,974 \\
\hline
\end{tabular}

Source: WB(2006a)

Table 20: Most cost/effective strategies against malaria in Sub-Saharan Africa

\begin{tabular}{|l|l|}
\hline Strategies & Cost/effectiveness(\$ for DALY averted) \\
\hline Preventive treatment in pregnancy with newer drugs & $2-11$ \\
\hline Insecticide-treated bed nets & $5-17$ \\
\hline Residual household spraying & $9-24$ \\
\hline Preventive treatment in pregnancy with sulfa drugs & $13-24$ \\
\hline
\end{tabular}

Source: WB(2006a)

Table 21: Most cost/effective strategies against malnutrition

\begin{tabular}{|l|l|}
\hline Strategies & Cost/effectiveness(\$ for DALY averted) \\
\hline Breastfeeding support programs & $3-11$ \\
\hline Growth monitoring and counseling & $8-11$ \\
\hline Capsule distribution & $6-12$ \\
\hline Sugar fortification & $33-35$ \\
\hline
\end{tabular}

Source: WB(2006a)

Agriculture is another sector particularly vulnerable in developing countries. In the literature on adaptation, what is almost missing is the quantification of the costs of adaptation in agriculture (EEA, 2007; Agrawala and Fankhauser, 2008). This is mostly due to the fact that a large part of agricultural adaptation practices are implemented at the farm level and are decided "autonomously" by the farmers without the direct intervention of public agencies suggesting long term planning or investment activities.

Typical examples of these practices are seasonal adjustments in the crop mix or timing, which in the literature are assumed to entail very low if not zero costs. Probably, the most significant cost component of climate change adaptation in agriculture is related to the improvement of irrigation, or water conservation systems. According to the OECD ENV-Linkage model, which simulates projections of the IEA WEO scenario, the additional expenditure on adaptation to adverse impacts of climate change will be about 7 billions $\$$ in 2030 ; the highest share (about 5.8 billion $\$$ ) is estimated to be needed to purchase new capital, for example to improve irrigation system and adopt more efficient agricultural practices (UNFCCC, 2007). As regarding the effectiveness of adaptation, Kirshen et al. (2006) reported broad ranges, depending on the type of measure adopted. Callaway et al. (2006), analyzing management adaptation costs for the Berg River in South Africa, has 
emphasized the role of water management system efficiency, which can increase the benefits of improved water storage capacity by $40 \%$.

A case study on the Mexican agriculture suggests high benefit-cost ratios for proactive adaptation measures in the agricultural sector (Adams et al., 2000). This study assessed the effectiveness of establishing accurate early warning systems, capable of detecting enough in advance climate disturbances. Adams et al. (2000) found that the benefits of an ENSO early warning system for Mexico is approximately US\$ 10 million annually, measured in terms of the saved cost for the agricultural sector that can plan in advance crop timing and mix. The table below summarizes the present value of benefits and costs under different assumptions of information accuracy. Benefits, under different assumption of information accuracy far outweighs the costs, leading to an internal rate of return of at least 30\%. Benefit-cost ratios are even higher for better level of accuracy.

\begin{tabular}{|c|c|c|c|c|c|}
\hline ENSO event probabilities & $\begin{array}{l}\text { Accuracy of } \\
\text { information }\end{array}$ & $\begin{array}{l}\text { Present value of } \\
\text { benefits (\$) }\end{array}$ & $\begin{array}{l}\text { Present value } \\
\text { of costs }(\$)\end{array}$ & $\begin{array}{l}\text { Net present value } \\
\text { of project (\$) }\end{array}$ & $\begin{array}{l}\text { Internal rate } \\
\text { of return (\%) }\end{array}$ \\
\hline \multirow[t]{2}{*}{ 19-year period } & Perfect & 479.9 & 51.5 & 428.4 & 227.5 \\
\hline & $70 \%$ & 87.5 & 51.5 & 36.0 & 22.9 \\
\hline \multirow[t]{2}{*}{ 51-year period } & Perfect & 486.7 & 51.5 & 435.2 & 233.6 \\
\hline & $70 \%$ & 106.4 & 51.5 & 55.0 & 30.4 \\
\hline Climate change induced & Perfect & 637.2 & 51.5 & 587.5 & 441 \\
\hline ENSO frequency & $70 \%$ & 255.8 & 51.5 & 204.3 & 90 \\
\hline
\end{tabular}

The values reported here are couverted from pesos to dollars using the 2001 conversion rate of approximately 9 Pesos to the US dollar. Source: Adams et al. (2000)

The NAPA (National Adaptation Programmes of Action) Project Database contains a list of ranked priority adaptation activities and projects in 39 Least Developed Countries (LDCs). Projects on agriculture and food security have the highest priority for one third of LDCs. The main adaptation activities in this sector are the introduction of drought-prone tolerant or rainfall resilient crops.

Another important area of intervention is Research and Development both in agriculture and health. Innovation is needed to develop "climate-ready" crops (heat-tolerant, drought-escaping, water proof crops) and to advance tropical medicine. This type of adaptation strategy requires some kind of North-South cooperation, because those who need these interventions lack the financial and technical resources to implement them. UNFCCC (2007) reported an additional expenditure on agriculture related R\&D of about 3 USD billion out of the 14 billion required to cope with climate change in agriculture in 2030. The case of innovation exemplifies how market-driven adaptation can accommodate damages only partly, and how policy-driven adaptation is needed to complement other forms of adjustments.

\section{Conclusions and Policy Implications}

Currently debated mitigation targets, such as keeping global warming below $2{ }^{\circ} \mathrm{C}$ as recently endorsed during the L'Aquila G8 summit, are particularly ambitious and require aggressive and immediate mitigation actions in both developed and developing regions. Given the reluctance of some large emitters to subscribe binding commitments, the world will likely be facing a temperature increase above the proposed $2^{\circ} \mathrm{C}$ ceiling. Even in the case in which the $2{ }^{\circ} \mathrm{C}$ target is met, a series of negative consequences for social and economic systems are likely to be observed both in the near and in the far future. 
Therefore, it is important to analyse how to deal with the damages induced by climate change. Is market-driven adaptation sufficient to control climate-related damages? Is it worth investing in short-term ambitious mitigation policies? Or should we postpone action by focussing more on policy-driven adaptation? Is there an optimal level of adaptation and mitigation? Will the focus on adaptation crowd out investments in mitigation?

This study addresses these issues using an integrated analytical framework. Let us summarise in this final section the main conclusions. First, markets cannot deal with all climate damages. Even under the optimist assumptions of this report, market driven adaptation can attenuate the total damage form climate change, but not eliminate it. Globally, direct impacts of climate change in 2050 amount to a loss of about $1.55 \%$ of the Gross World Product. Market-driven adaptation reduces this loss to $1.1 \%$ of GWP. In addition, important distributional impacts remains. Therefore, policy intervention, in the form of either mitigation or adaptation or both, is necessary.

Second, under a social optimum perspective (global cooperation to internalize the social cost of climate change), the optimal strategy to deal with climate change entails the adoption of both adaptation and mitigation measures. Mitigation is always needed to avoid irreversible and potentially unmanageable consequences, whereas adaptation is necessary to address unavoidable climate change damages. The optimal mix of strategies has been shown to be welfare improving. At the global level, their joint implementation increases the benefit cost ratio of each of them.

Third, there is nonetheless a trade-off between mitigation and adaptation. The use of mitigation (adaptation) decreases the need, i.e. the marginal benefit, to adapt (mitigate). In addition resources are scarce. Hence, if some are used for mitigation (adaptation), less are available for adaptation (mitigation). Nonetheless, in the optimal policy mix, the possibility to abate never eliminates the need to adapt and vice versa.

Fourth, in terms of timing, mitigation needs to be carried out earlier, because of its delayed effects driven by environmental inertia, while adaptation can be postponed until damages are effectively higher. Were damages considerable in earlier period, also adaptation would be carried out earlier.

Fifth, both higher damages and lower discount rates foster mitigation and adaptation efforts. However, in the first case, adaptation expenditures increase more than mitigation ones, while in the second case mitigation becomes relatively more important. The intuition goes as follows. If present and future damages increase uniformly, adaptation, which deals effectively with both, is to be preferred. If future damages increase relatively more (because of a lower discounting), mitigation, which is more effective on the distant future, is to be preferred.

Sixth, OECD countries should invest heavily in anticipatory adaptation measures. This depends on their damage structure. Planned anticipatory adaptation is particularly suited to cope with sea-level rise, but also with hydro geological risks induced by more frequent and intense extreme events, which are a major source of negative impacts in the developed economies. Thus, in OECD countries it would be more convenient to act ex ante rather than ex post.

In NON OECD countries, climate change adaptation needs are presently relatively low, but will rise dramatically after the mid-century, as long as climate change damages will increase. In 2050, they will amount to 78 USD Billion, in 2065 they will be above 500 USD billion, to peak to more than 2 USD trillion by the end of the century. NON-OECD countries are unlikely to have the resources to meet their adaptation needs, which calls for international aid and cooperation on adaptation.

NON-OECD countries place little effort on adaptation $R \& D$ and rely primarily on reactive adaptation. This outcome however depends on the particular structure of NON-OECD economic systems. Being poor, other forms of adaptation expenditures, more rapidly effective, mainly of the reactive type, are to be preferred. This suggests that richer countries can help developing countries 

planning.

As shown by our sensitivity analysis, these results are robust to different model specifications and parameterizations.

There is a final important issue to be emphasised. We have shown that both mitigation and adaptation belong to the optimal policy mix to deal with climate change, even though with different timing (mitigation comes first) and different distribution across world regions (more mitigation in developed countries, more adaptation in developing countries). In this optimal policy mix, the balance between adaptation and mitigation depends on the discount rate and the level of damages. This is clearly shown by Table 22 . With low discounting, a larger share of damage reduction is achieved with mitigation. With high damage, a larger share of damage reduction is achieved with adaptation.

Table 22. Share of damage reduction in the optimal policy mix

TOTAL DAMAGE

REDUCTION

(Undiscounted cumulative sum

LDAM_HDR
HDAM_LDR
LDAM_LDR
HDAM_HDR $2010-2100)$

$44 \%$

$73 \%$

ADAPTATION

$77 \%$

$41 \%$

$33 \%$

$85 \%$

MITIGATION

$23 \%$

$59 \%$

$67 \%$

$62 \%$

$15 \%$

Source: Our elaboration

What are the environmental implications of the optimal policy mix? Given that adaptation partly replaces mitigation, thus enabling countries to grow more, but also to emit more, the temperature target is higher that $2^{\circ} \mathrm{C}$ and lies between 2.5 and $3{ }^{\circ} \mathrm{C}$ (let us recall that we do not include in the model catastrophic damages and tipping points). The economic cost of achieving this target is very limited, because mitigation exploits low cost options in developed countries and low marginal abatement costs in developing countries, whereas adaptation takes place far in the future and therefore at low discounted costs.

Figure 22. Temperature change in the four scenarios

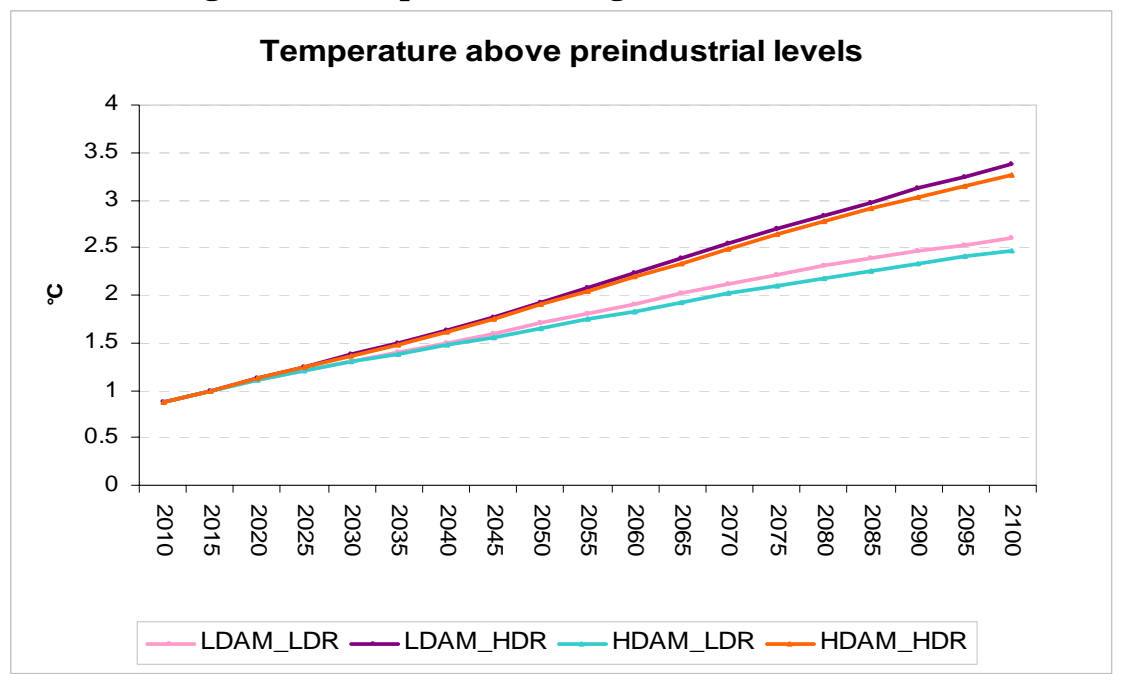


Residual damages are nonetheless low (between 1 and 2\% of GWP, see Figure 23), because of the role of adaptation in offsetting them.

Figure 23. Residual damages from climate change in the four scenarios

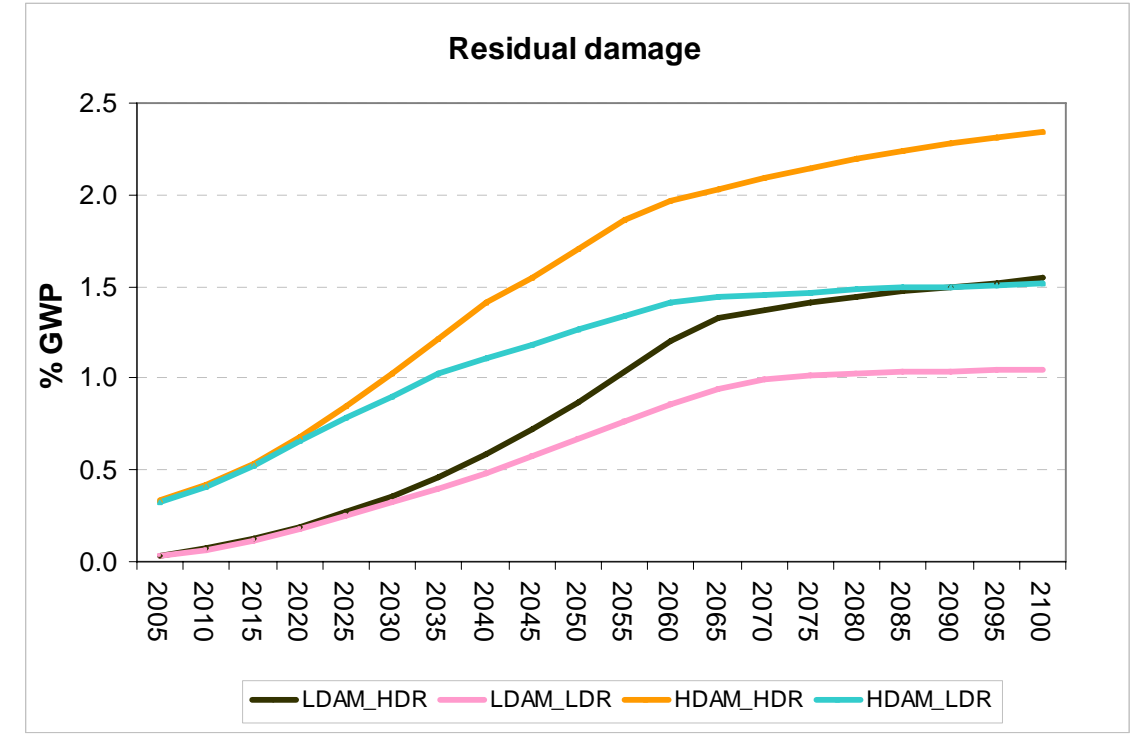

Therefore, the optimal strategy seems to be the one in which mitigation is undertaken (and starts immediately) to offset most dangerous damages from climate change, i.e. to the level that future damages can be dealt with through adaptation. Then, adaptation, if well-prepared in advance, will protect our socio-economic systems, from climate change. The mitigation target could be slightly larger than $2^{\circ} \mathrm{C}$ and compensated by a commitment to invest in adaptation. 


\section{References}

Association of British Insurers, 2005: Financial Risk of Climate Change, Summary Report, June 2005.

Adams, R. M., L.L. Houston and B. A. McCarl, 2000: The benefits to Mexican agriculture of an El Niño-southern oscillation (ENSO) early warning system, Agricultural and Forest Meteorology, 115, 183-194.

Adger, N.W., Arnell, N.W. and E.L. Thompkins, 2005: Successful adaptation to climate change across scales, Global Environmental Change, 15 (2), 77-86.

Agrawala, S. and S. Fankhauser, 2008: Economics aspects of adaptation to climate change. Costs, benefits and policy instrument, OECD, Paris.

Barrett, S., 2008: A Portfolio System of Climate Treaties, The Harvard Project on International Climate Change Agreements, Discussion Paper 08-13.

Bosello, F., Roson, R. and R.S.J. Tol, 2006: Economy Wide Estimates of the Implication of Climate Change: Human Health, Ecological Economics, 58 (3), 579-591.

Bosello, F., 2008: Adaptation, Mitigation and "Green R\&D to Combat Global Climate Change. Insights From an Empirical Integrated Assessment Exercise, CMCC Research Paper No.20.

Bosello, F., Roson, R. and R.S.J. Tol, 2006: Economy Wide Estimates of the Implication of Climate Change: Human Health, Ecological Economics, 58 (3), 579-591.

Bosetti, V., C. Carraro, M. Galeotti, E. Massetti and M. Tavoni, 2006: WITCH: A World Induced Technical Change Hybrid Model, The Energy Journal. Special Issue on Hybrid Modeling of Energy-Environment Policies: Reconciling Bottom-up and Top-down: 13-38.

Bosetti, V. E. Massetti, M. Tavoni, 2007: The WITCH Model. Structure, Baseline, Solutions, FEEM Working Paper, 10-2007.

Bosetti, V., C. Carraro, R. Duval, A. Sgobbi and M. Tavoni, 2009: The Role of R\&D and Technology Diffusion in Climate Change Mitigation: New Perspectives using the WITCH Model, OECD Working Paper No. 664, February.

Bosetti, V., Carraro, C., De Cian, E., Duval, R. Massetti, E. and Tavoni, M., 2009a: The incentives to participate in and the stability of international climate coalitions: a game-theoretic approach using the WITCH Model, OECD Working Paper, Forthcoming.

Boutkan, E. and A. Stikker, 2004: Enhanced water resource base for sustainable integrated water resource management, Natural Resources Forum, 28, (2), 150-154.

Burton, I., 1992: Adapt and Thrive. Canadian Climate Centre unpublished manuscript, Downs view, Ontario.

Buonanno, P., Carraro, C., Castelnuovo, E. and M. Galeotti, 2000: Efficiency and Equity of Emission Trading with Endogenous Environmental Technical Change. In C. Carraro (ed.), Efficiency and Equity of Climate Change Policy, Dordrecht: Kluwer Academic Publishers.

Butt T.A., McCarl B.A., 2004: Farm and forest carbon sequestration: Can producers employ it to make some money? Choices, 19, 3-11.

Caparrós, A. y Jacquemont, F., 2003 : Conflicts between biodiversity and carbon offset programs: economic and legal implications. Ecological Economics, 46 (1), 143-157.

Carraro, Carlo and Domenico Siniscalco, 1998: International Environmental Agreements: Incentives and Political Economy, European Economic Review, 42 (3-5), 561-572. 
Callaway, J.M., et al., 2006: The Berg River Dynamic Spatial Equilibrium Model: A New Tool for Assessing the Benefits and Costs of Alternatives for Coping With Water Demand Growth, Climate Variability, and Climate Change in the Western Cape, AIACC Working Paper 31, The AIACC Project Office, International START Secretariat, Washington, DC, p. 41, available on line at www.aiaccproject.org.

Dang, H.H., Michaelowa, A. and Tuan, D.D., 2003: Synergy of Adaptation and Mitigation Strategies in the Context of Sustainable Development: The case of Vietnam, Climate Policy, 3, Supplement 1, S81-S96.

Darwin, R. and R.S.J. Tol, 2001: Estimates of The Economic Effects of Sea Level Rise, Environmental and Resource Economics, 19 (2), 113-129.

de Bruin K.C., Dellink, R.B. and R.S.J. Tol, 2007: AD-DICE: An Implementation of Adaptation in the DICE Model, FEEM Working Paper, 51.2007.

de Bruin K.C., Dellink, R.B. and S. Agrawala, 2009: Economic aspects of adaptation to climate change: integrated assessment modelling of adaptation costs and benefits, OECD Environment Working Paper, No. 6.

Deke, O., Hooss, K. G., Kasten, C., Klepper, G., \& Springer, K., 2001: Economic Impact of Climate Change: Simulations with a Regionalized Climate-Economy Model, Kiel Institute of World Economics, Kiel, 1065.

Ebi, K.L., 2008: Adaptation costs for climate change cases of diarrhoeal disease, malnutrition and malaria in 2030, Globalization and health 2008, 4 (9).

EEA (European Environment Agency), 2005: Vulnerability and adaptation to climate change in Europe, Report No. 7/2005.

EEA (European Environment Agency), 2007: Climate Change: The Cost of Inaction and the Cost of Adaptation, EEA Technical Report, No. 13/2007.

European Commission, 2005: Winning the Battle Against Global Climate Change, $\mathrm{COM} / 2005 / 0035$.

European Commission, 2007: Limiting global climate change to 2 degrees Celsius - The way ahead for 2020 and beyond, COM2007/0002.

European Commission, 2009: White paper - Adapting to climate change : towards a European framework for action, COM/2009/0147.

Fankhauser, S., Smith, J.B., and Tol, R.S.J., 1999: Weathering Climate Change: Some Simple Rules to Guide Adaptation Decisions Ecological Economics, 30 (1), 67-78.

Füssel H.M. and Klein R.J.T., 2006: Climate Change Vulnerability Assessments: An Evolution of Conceptual Thinking, Climatic Change, 75, 301-329.

Hanemann, W.M., 2008: What is the Cost of Climate Change?, CUDARE Working Paper No. 1027, University of California, Berkeley.

Hope, C., 2003: The marginal impacts of CO2, CH4 and SF6 emissions, Judge Institute of Management Research Paper No.2003/10, Cambridge, UK, University of Cambridge, Judge Institute of Management.

Hope, C., Anderson, J. and P. Wenman, 1993: Policy Analysis of the Greenhouse effect: an Application of the PAGE model, Energy Policy, 21 (3), 327-338.

Hope, C. and Newbery, D., 2007: Calculating the social cost of carbon, Electricity Policy Research Group Working Papers, No. EPRG 07/20. Cambridge: University of Cambridge. 
Huq, S., Rahman, A., Konate, M., Sokona, Y. and H. Reid, 2003: Mainstreaming adaptation in least developed countries, IIED Working Paper, April 2003.

Ingham, A., Ma, J. and Ulph A.M., 2005: Can Adaptation and Mitigation be Complements?, Working Paper 79, Tyndall Centre for Climate Change Research.

Ingham, A., Ma, J. and Ulph A.M., 2005a: How do the Costs of Adaptation affect Optimal Mitigation when there is Uncertainty, Irreversibility and Learning?, Working Paper 74, Tyndall Centre for Climate Change Research.

IPCC, 1996: Climate Change 1995-Impacts, Adaptations, and Mitigation of Climate Change: Scientific-Technical Analyses - Contribution of Working Group II to the IPCC Second Assessment Report.

IPCC, 2001: Climate Change 2001: Impacts, Adaptation and Vulnerability, Contribution of Working Group II to the Third Assessment Report of the Intergovernmental Panel on Climate Change, J.J. McCarthy, O.F. Canziani, N.A. Leary, D.J. Dokken and K.S. White, Eds., Cambridge University Press, Cambridge.

IPCC, 2007: Climate Change 2007: Impacts, Adaptation and Vulnerability, in M. Parry, O. Canziani, J. Palutikof, P. van der Linden, C. Hanson (eds), Contribution of Working Group II to the Fourth Assessment Report on Climate Change, Cambridge University Press, Cambridge.

Jamet, S. and J-C Morlot, 2009: Assessing the Impacts of Climate Change. A Literature Review, OECD Economics Department Working Paper, No. 691.

Kane, S. and G. Yohe, 2000: Societal adaptation to climate variability and change: an introduction, Climatic Change, 45 (1), 1-4.

Kane, S. and J. Shogren, 2000: Linking Adaptation and Mitigation in Climate Change Policy, Climatic Change, 45 (1), 75-102.

Kirshen P, Ruth M and Anderson W., 2006: Climate's long-term impacts on urban infrastructures and services: the case of metro Boston. In: Climate Change and Variability: Local Impacts and Responses. Cheltenham, UK: Edward Elgar Publishers.

Kirshen, 2007: Adaptation Options and Coast of Water Supply, Tuft University, MA.

Klein, R.J.T. and Tol, R.S.J., 1997: Adaptation to Climate Change: Options and Technologies, Institute of Environmental Sciences. Vrije Universiteit, Amsterdam.

Klein, R.J.T., Schipper E.L. and Dessai, S., 2003: Integrating Mitigation and Adaptation into Climate and Development Policy: Three Research Questions, Working Paper 40, Tyndall Centre for Climate Change Research.

Klein, R.J.T., S. Huq, F. Denton, T.E. Downing, R.G. Richels, J.B. Robinson, F.L. Toth, 2007: Inter-relationships between adaptation and mitigation, Climate Change 2007: Impacts, Adaptation and Vulnerability. Contribution of Working Group II to the Fourth Assessment Report of the Intergovernmental Panel on Climate Change, M.L. Parry, O.F. Canziani, J.P. Palutikof, P.J. van der Linden and C.E. Hanson; Cambridge University Press, Cambridge, United Kingdom, p. $745-777$.

Leary, N.A., 1999: A Framework for Benefit-Cost Analysis of Adaptation to Climate Change and Climate Variability, Mitigation and Adaptation Strategies for Global Change, 4 (3-4), 307-318.

Lecoq, F. and Z. Shalizi, 2007: Balancing Expenditures on Mitigation and Adaptation to Climate Change: An Explorations of Issues Relevant for Developing Countries, World Bank Policy Research Working Paper 4299. 
McKibbin, W.J. and Wilcoxen P.J., 2004: Climate Policy and Uncertainty: The Roles of Adaptation Versus Mitigation, Brookings Discussion papers in International Economics, No 161.

McKinsey\&Company, 2009: Pathways to a Low-Carbon Economy. Version 2 of the Global Greenhouse Gas Abatement Curve.

Nicholls, R. J. and R.J.T. Klein, 2003: Climate change and coastal management on Europe's Coast, EVA Working Paper No.3.

Nordhaus, W.D. , 1994: Managing the Global Commons: The economics of the greenhouse effect MIT Press, Cambridge, MA.

Nordhaus, W.D. and J.G. Boyer, 2000: Warming the World: the Economics of the Greenhouse Effect, MIT Press, Cambridge, Massachusetts.

Parry, M., Arnell, N., McMichael, T., Nicholls, R., Martens, P., Kovats, S., Livermore, M., Rosenzweig, C., Iglesias, A. and G. Fischer, 2001: Millions at risk: defining critical climate change threats and targets, Global Environmental Change, 11 (3), 181-183.

Pielke, R.A. Jr., 1998: Rethinking the role of adaptation in climate policies, Global Environmental Change, 8 (2), 159-170.

Smit, B. (ed.), 1993: Adaptation to Climatic Variability and Change, Environment Canada, Guelph.

Smit, B., Burton, I., Klein, J.T. and J. Wandel, 2000: An anatomy of adaptation to climate change and variability, Climatic Change, 45 (1), 223-251.

Smith, J. B. and Lazo, J. K., 2001: A summary of climate change impact assessments from the US Country Studies Programme, Climatic Change, 50 (1-2), 1-29.

Smith, J. B. \& Tirpak, D. A. (eds), 1989: The Potential Effects of Global Climate Change on the United States. Executive Summary (US Environmental Protection Agency. Washington, DC, 1989).

Smit, B. and O. Pilifosova, 2001: Adaptation to Climate Change in the Context of Sustainable Development and Equity. In Climate Change 2001, Contribution of Working Group II to the Third Assessment Report of the IPCC, Cambridge University Press, Cambridge.

Smithers J., and Smit B., 1997: Human adaptation to climatic variability and change. Global Environmental Change, 7 (2): 129-146.

Stern, N., 2007: Stern Review on The Economics of Climate Change. HM Treasury, London: http://www.hm-treasury.gov.uk/sternreview_index.htm

Tol, R.S.J., 2005: Emission abatement versus development as strategies to reduce vulnerability to climate change: an application of FUND, Environment and Development Economics, 10 (05): 615-629.

UNDP, 2005: Adaptation policy framework for climate change: Developing policies strategies and measures, B. Lim and E. Spanger-Siegfred (eds.), Cambridge University Press.

UNFCCC, 2007: Investments and Financial Flows to Address Climate Change, Background paper on analysis of existing and planned investments and financial flows relevant to the development of effective and appropriate international response to climate change, p. 273.

WHO, 2005: Extreme weather events and public health responses, Springer Verlagh, Berlin Heidelberg, Germany.

WHO; 2006: Climate change and adaptation strategies for human health, Steinkopff Verlag, Darmstadt, Germany. 
World Bank, 2006: Clean energy and development: towards an investment framework, World Bank, Washington, DC, 2006.

World Bank, 2006a: Disease Control Priorities in Developing Countries, The International Bank for Reconstruction and Development, The World Bank.

Wheaton, E.E. and D.C. Maciver, 1999: A Framework and Key Questions for Adapting to Climate Variability and Change, Mitigation and Adaptation Strategies for Global Change, 4 (3-4), 215-225.

Wilbanks, T. J., 2005: Issues in developing a capacity for integrated analysis of mitigation and adaptation, Environmental Science \& Policy, 8 (6), 541-547.

Yohe, G. and Strzepek, K., 2007: Adaptation and mitigation as complementary tools for reducing the risk of climate impacts, Mitigation and Adaptation Strategies for Global Change, 12 (5), 727-739. 


\section{Appendix I : The AD-WITCH model}

The WITCH model developed by the climate change group at FEEM (Bosetti et al., 2006; Bosetti et al., 2007) is an energy-economy-climate model designed to explicitly deal with the main features of climate change. It is a regional model in which the non-cooperative nature of international relationships is explicitly accounted for. It is a truly intertemporal optimization model, with a long term horizon covering all century until 2100. The regional and intertemporal dimensions of the model make it possible to differentiate climate policies across regions and over time. Finally, the model includes a wide range of energy technology options, with different assumptions on their future development, which is also related to the level of innovation effort undertaken by countries.

The core structure of the model is described at length in the technical report (Bosetti et al., 2007). The focus of this Annex is on the new elements of the latest version used in this report, and in particular on the Adaptation module of WITCH.

\section{Overall model structure}

WITCH is a dynamic optimal growth general equilibrium model with a detailed ("bottom-up") representation of the energy sector, thus belonging to a new class of hybrid (both "top-down" and "bottom-up") models. It is a global model, divided into 12 macro-regions.

The world economy is indeed disaggregated into twelve macro regions: USA (United States), WEURO (Western Europe), EEURO (Eastern Europe), KOSAU (Korea, South Africa, Australia), CAJANZ (Canada, Japan, New Zealand), TE (Transition Economies), MENA (Middle East and North Africa), SSA (Sub-Saharan Africa), SASIA (South Asia), CHINA (China and Taiwan), EASIA (South East Asia), LACA ( Latin America, Mexico and Caribbean). This grouping has been determined by economic, geographic, resource endowment and energy market similarities.

The model proposes a bottom-up characterisation of the energy sector. Seven different energygenerating technologies are modelled: coal, oil, gas, wind \& solar, nuclear, electricity, and biofuels. Their penetration rate is driven also by endogenous country and sector specific innovation. The model distinguishes between dedicated R\&D investments for enhancing energy efficiency from investment aimed at facilitating the competitiveness of innovative low carbon technologies in both the electric and non-electric sectors (backstops). R\&D processes are subject to stand on shoulders as well on neighbours effects. Specifically, international spillovers of knowledge are accounted for to mimic the flow of ideas and knowledge across countries. Finally, experience processes via Learning by Doing are accounted for in the development of niche technologies such as renewable energy (Wind\&Solar) and the backstops. Through the optimisation process regions choose the optimal dynamic path of different investments, namely in physical capital, in R\&D, energy technologies and consumption of fossil fuels.

We updated the model base year to 2005, and use the most recent estimates of population growth. The annual estimates and projections produced by the UN Population Division are used for the first 50 years $^{18}$. For the period 2050 to 2100 , the updated data is not available, and less recent long term projections, also produced by the UN Population Division ${ }^{19}$, are adopted instead. The differences in

\footnotetext{
18 Data are available from http://unstats.un.org/unsd/cdb/cdb simple data extract.asp? strSearch=\&srID= $13660 \&$ from $=$ simple.

${ }^{19}$ UN (2004), World Population to 2300, Report No. ST/ESA/SER.A/236, Department of Economic and Social Affairs, Population Division, New York.
} 
the two datasets are smoothed by extrapolating population levels at 5 year periods for 2050-2100, using average 2050-2100 growth rates. Similar techniques are used to project population trends beyond 2100 .

The GDP data for the new base year are from the World Bank Development Indicators 2007, and are reported in 2005 US\$. We maintain the use of market exchange rates (MER). World GDP in 2005 equals to 44.2 Trillions US\$. Although GDP dynamics is partly endogenously determined in the WITCH model, it is possible to calibrate growth of different countries by adjusting the growth rate of total factor productivity, the main engine of macroeconomic growth.

The prices of fossil fuels and exhaustible resources have been revised, following the dynamics of market prices between 2002 and 2005. Base year prices have been calibrated following Enerdata, IEA WEO2007 and EIA AEO2008.

\section{Climate Module and GHG Emissions}

We continue to use the MAGICC 3-box layer climate mode ${ }^{20}$ as described in Nordhaus and Boyer (2000). $\mathrm{CO}_{2}$ concentrations in the atmosphere have been updated to 2005 at roughly $385 \mathrm{ppm}$ and temperature increase above pre-industrial at $0.76^{\circ} \mathrm{C}$, in accordance with IPCC 4ar (2007). Other parameters governing the climate equations have been adjusted following Nordhaus $(2007)^{21}$. We have replaced the exogenous non- $\mathrm{CO}_{2}$ radiative forcing in equation with specific representation of other GHGs and sulphates. The damage function of climate change on the economic activity is left unchanged.

In this version of WITCH we maintain the same initial stoichiometric coefficients as in previous versions. However, in order to differentiate the higher emission content of non-conventional oil as opposed to conventional ones, we link the carbon emission coefficient for oil to its availability. Specifically, the stoichiometric coefficient for oil increases with the cumulative oil consumed so that it increases by $25 \%$ when 2000 Billions Barrels are reached. An upper bound of $50 \%$ is assumed. The 2000 figure is calibrated on IEA $2005^{22}$ estimates on conventional oil resource availability. The $25 \%$ increase is chosen given that estimates ${ }^{23}$ range between $14 \%$ and $39 \%$.

Non- $\mathrm{CO}_{2}$ GHGs are important contributors to global warming, and might offer economically attractive ways of mitigating $i^{24}$. Previous versions of WITCH only considers explicitly industrial $\mathrm{CO}_{2}$ emissions, while other GHGs, together with aerosols, enter the model in an exogenous and aggregated manner, as a single radiative forcing component.

In this version of WITCH, we take a step forward and specify non- $\mathrm{CO}_{2}$ gases, modelling explicitly emissions of $\mathrm{CH}_{4}, \mathrm{~N}_{2} \mathrm{O}$, SLF (short lived fluorinated gases, i.e. HFCs with lifetimes under 100 years) and LLF (long lived fluorinated, i.e. HFC with long lifetime, PFCs, and SF6). We also distinguish $\mathrm{SO}_{2}$ aerosols, which have a cooling effect on temperature.

Since most of these gases are determined by agricultural practices, we rely on estimates for reference emissions and a top-down approach for mitigation supply curves. For the baseline

\footnotetext{
${ }^{20}$ Wigley, T.M.L. 1994. MAGICC (Model for the Assessment of Greenhouse-gas Induced Climate Change): User's Guide and Scientific Reference Manual. National Center for Atmospheric Research, Boulder, Colorado.

${ }^{21} \mathrm{http}: / /$ nordhaus.econ.yale.edu/DICE2007.htm

${ }^{22}$ IEA 2005, Resources to Reserves - Oil \& Gas Technologies for the Energy Markets of the Future

${ }^{23}$ Farrell and Brandt, 2005

${ }^{24}$ See the Energy Journal Special Issue (2006) (EMF-21), and the IPCC 4ar WG III (IPCC, 2007)
} 
projections of non- $\mathrm{CO}_{2}$ GHGs, we use EPA regional estimates ${ }^{25}$. The regional estimates and projections are available until 2020 only: beyond that date, we use growth rates for each gas as specified in the IIASA-MESSAGE-B2 scenario $^{26}$, that has underlying assumptions similar to the WITCH ones. $\mathrm{SO}_{2}$ emissions are taken from MERGE v. $5^{27}$ and MESSAGE B2: given the very large uncertainty associated with aerosols, they are translated directly into the temperature effect (cooling), so that we only report the radiative forcing deriving from GHGs. In any case, sulphates are expected to be gradually phased out over the next decades, so that eventually the two radiative forcing measure will converge to similar values.

The equations translating non- $\mathrm{CO}_{2}$ emissions into radiative forcing are taken from MERGE v.5. The global warming potential (GWP) methodology is employed, and figures for GWP as well as base year stock of the various GHGs are taken from IPCC Fourth Assessment Report, Working Group I. The simplified equation translating $\mathrm{CO}_{2}$ concentrations into radiative forcing has been modified from WITCH06 and is now in line with $\mathrm{IPCC}^{28}$.

We introduce end-of-pipe type of abatement possibilities via marginal abatement curves (MACs) for non- $\mathrm{CO}_{2} \mathrm{GHG}$ mitigation. We use MAC provided by EPA for the EMF 21 project $^{29}$, aggregated for the WITCH regions. MAC are available for 11 cost categories ranging from 10 to $200 \mathrm{US} \$ / \mathrm{tC}$. We have ruled out zero or negative cost abatement options. MAC are static projections for 2010 and 2020, and for many regions they show very low upper values, such that even at maximum abatement, emissions would keep growing over time. We thus introduce exogenous technological improvements: for the highest cost category only (the $200 \mathrm{US} \$ / \mathrm{tC}$ ) we assume a technical progress factor that reaches 2 in 2050 and the upper bound of 3 in 2075.

We however set an upper bound to the amount of emissions which can be abated, assuming that no more than $90 \%$ of each gas emissions can be mitigated. Such a framework enables us to keep non$\mathrm{CO}_{2} \mathrm{GHG}$ emissions somewhat stable in a stringent mitigation scenario (530e) in the first half of the century, and subsequently decline gradually. This path is similar to what is found in the CCSP report $^{30}$, as well as in MESSAGE stabilisation scenarios. Nonetheless, the very little evidence on technology improvements potential in non- $\mathrm{CO}_{2} \mathrm{GHG}$ sectors indicates that sensitivity analysis should be performed to verify the impact on policy costs.

\section{Technological Innovation}

WITCH is enhanced by the inclusion of two backstop technologies that necessitate dedicated innovation investments to become economically competitive, even in a scenario with a climate policy. We follow the most recent characterization in the technology and climate change literature, modeling the costs of the backstop technologies with a two-factor learning curve in which their price declines both with investments in dedicated R\&D and with technology diffusion. This improved formulation is meant to overcome the main criticism of the single factor experience curves ${ }^{31}$ by providing a more structural $-R \& D$ investment led- approach to the penetration of new technologies, and thus to ultimately better inform policy makers on the innovation needs in the energy sector.

\footnotetext{
${ }^{25}$ EPA Report 430-R-06-003, June 2006. the report is available from: http://www.epa.gov/climatechange/economics/mitigation.html.

${ }^{26}$ Available at http://www.iiasa.ac.at/web-apps/ggi/GgiDb/dsd?Action=htmlpage\&page=regions

${ }^{27} \mathrm{http}: / /$ www.stanford.edu/group/MERGE/m5ccsp.html

28 http://www.grida.no/climate/ipcc tar/wg1/222.htm, Table 6.2, first Row

$29 \mathrm{http} / / /$ www.stanford.edu/group/EMF/projects/projectemf21.htm

${ }_{30} \mathrm{http}: / / w w w . c l i m a t e s c i e n c e . g o v / L i b r a r y / s a p / s a p 2-1 /$ finalreport/default.htm

31 Nemet, 2006
} 
More specifically, we model the investment cost in a backstop technology as being influenced by a Learning by Researching process (main driving force before adoption) and by Learning by Doing (main driving force after adoption), the so called 2 factor learning curve formulation ${ }^{32}$.

We set the initial prices of the backstop technologies at roughly 10 times the 2005 price of commercial equivalents $(16,000 \mathrm{US} \$ \mathrm{~kW}$ for electric, and $550 \mathrm{US} \$ / \mathrm{bbl}$ for non-electric). The cumulative deployment of the technology is initiated at 1000twh and 1000EJ respectively for the electric and non-electric, an arbitrarily low value ${ }^{33}$. The backstop technologies are assumed to be renewable in the sense that the fuel cost component is negligible; for power generation, it is assumed to operate at load factors comparable with those of baseload power generation.

Backstops substitute linearly nuclear power in the electric sector, and oil in the non-electric one. We assume that once the backstop technologies become competitive thanks to dedicated R\&D investment and pilot deployments, their uptake will not be immediate and complete, but rather there will be a transition/adjustment period. The upper limit on penetration is set equivalent to $5 \%$ of the total consumption in the previous period by technologies other than the backstop, plus the plus the electricity produced by the backstop itself.

\section{Adaptation}

Our goal with the "AD-WITCH" model is firstly to disentangle the different components of climate change costs separating adaptation costs from residual damage; secondly, to attribute adaptation costs and benefits to different adaptation strategies. In the AD-WITCH model these have been clustered in three large categories.

Proactive or anticipatory adaptation, represented by all those actions taken in anticipation to the materialization of the expected damage, aiming at reducing its severity once manifested. Typical examples of these activities are coastal protection, or infrastructure and settlements climate-proving measures. They need some anticipatory planning and (if well designed) are effective along the medium, long-term.

Reactive adaptation, represented by all those actions that need to be undertaken every period in response to those climate change damages that cannot be or were not accommodated by anticipatory adaptation. They usually need to be constantly adjusted to changes in climatic conditions. Examples of these actions are energy expenditures for air conditioning or farmers' yearly changes in seasonal crops' mix.

Innovation activity in adaptation or simply "knowledge adaptation", is represented by all those R\&D activities making adaptation responses more effective. These are especially important in some sectors such as agriculture and health where the discovery of new crops and vaccines are keys to reduce vulnerability to climate change.

The "adaptation basket", which exhibits decreasing marginal productivity, reduces the negative impact from climate change on gross output reducing the climate change damage coefficient in the WITCH damage function. It is composed by the different adaptation activities which are modeled as a sequence of Constant Elasticity of Substitution (CES) nested functions (see Figure AI.1).

\footnotetext{
${ }^{32}$ Kouvaritakis et al., 2000

${ }^{33}$ Kypreos, 2007.
} 


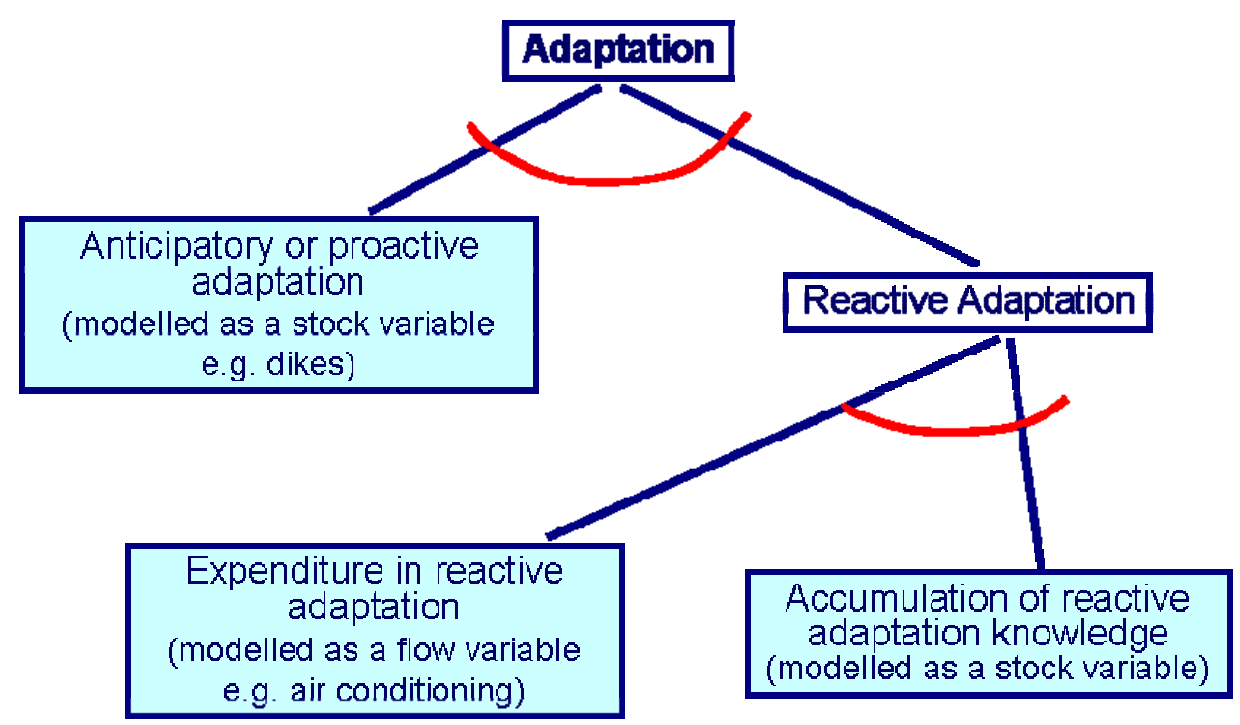

In the first CES nest, total adaptation is a combination of proactive and reactive adaptation. Proactive adaptation is modelled as a "stock" variable: some "defensive capital", accumulates over time because of an adaptation-specific investments activity. As defensive capital does not disappear, investment is needed to cope with "incremental" climate change damage. Proactive adaptation is also subjected to an economic inertia: an initial investment in adaptation takes 5 years to accrue to the defensive stock and thus to become effectively damage reducing.

Services from reactive adaptation are described by a second CES nest compounding reactive adaptation expenditures strictu-sensu, and improvements in adaptation knowledge. Expenditure on reactive adaptation is modelled as a "flow" variable: each simulation period, some expenditure is needed to cope with climate change damages irrespectively on the expenditure in the previous period. Accumulation of adaptation knowledge is modelled as a stock accrued by a periodical adaptation-specific investment in $R \& D$ representing an endogenous progress in reactive adaptation technologies ${ }^{34}$.

Then the cost of each of the adaptation activities considered (i.e.: investment in proactive adaptation, investment in adaptation knowledge and expenditure in reactive adaptation) are included into the national accounting identity. Investment in proactive adaptation, in adaptation knowledge and reactive adaptation expenditure are three additional control variables the AD-WITCH regional decision makers are endowed with, which compete with alternative uses of regional income in the maximization of welfare. These alternative uses are: consumption, investments in physical capital, investments in different energy technologies, investments in energy efficiency R\&D.

\footnotetext{
${ }^{34}$ In fact adaptation R\&D could improve also the effectiveness of proactive adaptation. However, we consider mostly R\&D activities in the health care sector, which in the model is related to the treatment of climate-related diseases and in agriculture, which are both reactive.
} 


\section{Calibration of AD-WITCH}

As in DICE/RICE the WITCH climate change damage function includes both the cost of adaptation and residual damages from climate change. As a consequence, calibrating adaptation in the ADWITCH model requires the separation of those two components, which requires implementing an adaptation function explicating costs and benefits of the different forms of adaptation. The adaptation function is then to be parameterised so as to replicate the damage of the original WITCH model. Detailed description of the calibration process is reported in an appendix available upon request. Here it is worth mentioning three major points.

Firstly, we gathered new information on climate-change damages consistent with the existence of adaptation costs and tried to calibrate $\mathrm{AD}-\mathrm{WITCH}$ on these new values and not on the original values of the WITCH model.

Secondly, due to the optimising behaviour of the AD-WITCH model, when a region gains from climate change, it is impossible to replicate in that region any adaptive behaviour and positive adaptation costs. Accordingly, when our data estimate gains from climate change we rather referred to Nordhaus and Boyer (2000) results if they reported costs. If both sources reported gains (as in the case of TE and KOSAU) we calibrated a damage with the AD-WITCH model originating adaptation costs consistent with the observations.

Thirdly, the calibrated total climate change costs are reasonably similar with the reference values, however correspondence is far from perfect. The main explanation is that consistency need to be guaranteed between three interconnected items: adaptation costs total damage and protection levels. Adaptation costs and damages move together, thus for instance it is not possible to lower WEURO adaptation costs to bring them closer to their reference value (see Table AI.2) without decreasing total damage which is already lower than the reference.

Table AI.1: Different adaptation strategies

\begin{tabular}{|l|}
\hline \multicolumn{1}{|c|}{ Proactive Adaptation Activities $\rightarrow$ Modeled as "stock" variable } \\
\hline Coastal Protection Activities \\
Settlements, Other Infrastructures (Excluding Water) and Ecosystem Protection Activities \\
Water Supply (Agriculture and Other) Protection Activities \\
Setting-up of Early Warning Systems \\
\hline \multicolumn{1}{c|}{ Reactive adaptation activities $\rightarrow$ Modeled as "flow" variable } \\
\hline Agricultural Adaptation Practices \\
Treatment of Climate-Related Diseases \\
Space Heating and Cooling Expenditure \\
\hline Innovation in adaptation constituting $\rightarrow$ Modelled as "stock" variable \\
\hline Research Activities for the Development of Climate-Resilient Crops \\
Research Activities in the Health Sector
\end{tabular}

Table AI.1 summarizes the different adaptation activities for which data were available; Table AI.2 reports the costs of each of these strategies as they emerged from the available literature and the 
values calibrated for the AD-WITCH model; Table AI.3 summarizes estimated and calibrated protection levels; Table AI.4 introduces total damages proposed by Nordhaus and Boyer (2000), by the original WITCH model, those newly estimated by this study and the calibration results by the AD-WITCH model.

Table AI.2: Adaptation costs in response to a 2xCO2 conc. in absolute values and as \% of GDP. Extrapolation from the literature and calibrated values with the AD-WITCH model

\begin{tabular}{|c|c|c|c|c|c|c|c|c|c|c|c|}
\hline & $\begin{array}{c}\text { Water in } \\
\text { Agriculture } \\
\text { (irrigation) } \\
\text { (Billion \$) }\end{array}$ & $\begin{array}{c}\text { Water in } \\
\text { Other } \\
\text { Vulnerable } \\
\text { Markets } \\
\text { (Billion \$) }\end{array}$ & $\begin{array}{c}\text { Early } \\
\text { Warning } \\
\text { Systems } \\
\text { (Million \$) }\end{array}$ & $\begin{array}{c}\text { Coastal } \\
\text { Protection } \\
(\text { Billion } \$)\end{array}$ & $\begin{array}{l}\text { Settl.mnts } \\
\text { (Billion \$) }\end{array}$ & $\begin{array}{c}\text { Cooling } \\
\text { Expenditure } \\
\text { (Billion \$) }\end{array}$ & $\begin{array}{c}\text { Disease } \\
\text { Treatment } \\
\text { Costs } \\
\text { (Billion \$) }\end{array}$ & $\begin{array}{c}\text { Adapt. } \\
\text { R\&D } \\
\text { (Billion \$) }\end{array}$ & $\begin{array}{c}\text { TOTAL } \\
\text { (Billion \$) }\end{array}$ & $\begin{array}{l}\text { TOTAL } \\
\text { (\% of } \\
\text { GDP) }\end{array}$ & $\begin{array}{c}\text { AD- } \\
\text { WITCH } \\
\text { (\% of } \\
\text { GDP) }\end{array}$ \\
\hline USA & 5.0 & 2.1 & 5.0 & 3.6 & 31.3 & 1.1 & 2.9 & 2.92 & 49.0 & 0.12 & 0.15 \\
\hline WEURO & 7.8 & 3.3 & 5.0 & 5.0 & 63.3 & -0.7 & 2.4 & 2.44 & 83.6 & 0.21 & 0.38 \\
\hline EEURO & 12.3 & 5.3 & 5.0 & 0.3 & 2.4 & -0.1 & 0.0 & 0.03 & 20.3 & 0.54 & 0.17 \\
\hline KOSAU & 0.1 & 0.1 & 5.0 & 1.8 & 3.7 & 1.9 & 0.3 & 0.29 & 8.1 & 0.29 & 0.27 \\
\hline CAJANZ & 2.7 & 1.1 & 5.0 & 2.9 & 23.1 & 3.0 & 1.7 & 1.66 & 36.1 & 0.21 & 0.22 \\
\hline TE & 16.9 & 7.2 & 5.0 & 1.7 & 2.0 & 0.1 & 0.1 & 0.06 & 28.1 & 0.40 & 0.26 \\
\hline MENA & 79.1 & 33.9 & 5.0 & 1.2 & 3.2 & 2.1 & 0.1 & 0.14 & 119.8 & 1.48 & 1.01 \\
\hline SSA & 16.1 & 6.9 & 5.0 & 2.7 & 4.0 & 0.5 & 0.0 & 0.01 & 30.2 & 0.78 & 0.96 \\
\hline SASIA & 28.4 & 12.2 & 5.0 & 1.3 & 12.8 & 1.1 & 0.0 & 0.04 & 55.9 & 0.54 & 0.66 \\
\hline CHINA & 12.5 & 5.4 & 5.0 & 1.3 & 9.7 & 0.3 & 0.2 & 0.16 & 29.4 & 0.22 & 0.08 \\
\hline EASIA & 31.2 & 13.4 & 5.0 & 4.3 & 6.0 & 4.7 & 0.0 & 0.04 & 59.6 & 0.84 & 0.65 \\
\hline LACA & 7.2 & 3.1 & 5.0 & 7.7 & 15.0 & 5.7 & 0.1 & 0.07 & 38.9 & 0.19 & 0.52 \\
\hline
\end{tabular}

Table AI.3: Effectiveness of adaptation (1=100\% damage reduction) against 2xCO2 conc. Extrapolation from the literature and calibrated values with the AD-WITCH model

\begin{tabular}{|c|c|c|c|c|c|c|c|c|c|}
\hline & Agriculture & $\begin{array}{c}\text { Other } \\
\text { vulnerable } \\
\text { markets }\end{array}$ & $\begin{array}{c}\text { Cat. } \\
\text { Events }\end{array}$ & $\begin{array}{l}\text { Coastal } \\
\text { systems }\end{array}$ & Settlements & $\begin{array}{c}\text { Non } \\
\text { market } \\
\text { time use }\end{array}$ & Health & $\begin{array}{c}\text { Weighted } \\
\text { total }\left(^{*}\right)\end{array}$ & $\begin{array}{c}\text { AD- } \\
\text { WITCH }\end{array}$ \\
\hline USA & 0.48 & 0.80 & 0.100 & 0.75 & 0.40 & 0.90 & 0.90 & 0.25 & 0.23 \\
\hline WEURO & 0.43 & 0.80 & 0.100 & 0.54 & 0.40 & 0.80 & 0.90 & 0.20 & 0.26 \\
\hline EEURO & 0.43 & 0.80 & 0.100 & 0.63 & 0.40 & 0.80 & 0.60 & 0.34 & 0.35 \\
\hline KOSAU & 0.27 & 0.80 & 0.100 & 0.62 & 0.40 & 0.80 & 0.81 & 0.24 & 0.25 \\
\hline CAJANZ & 0.38 & 0.80 & 0.100 & 0.37 & 0.40 & 0.90 & 0.69 & 0.25 & 0.25 \\
\hline TE & 0.38 & 0.80 & 0.100 & 0.37 & 0.40 & 0.80 & 0.70 & 0.20 & 0.16 \\
\hline MENA & 0.33 & 0.40 & 0.100 & 0.55 & 0.40 & 0.63 & 0.60 & 0.38 & 0.52 \\
\hline SSA & 0.23 & 0.40 & 0.001 & 0.30 & 0.40 & 0.30 & 0.20 & 0.21 & 0.14 \\
\hline SASIA & 0.33 & 0.40 & 0.001 & 0.47 & 0.40 & 0.50 & 0.35 & 0.19 & 0.08 \\
\hline CHINA & 0.33 & 0.40 & 0.100 & 0.76 & 0.40 & 0.70 & 0.40 & 0.22 & 0.14 \\
\hline EASIA & 0.33 & 0.40 & 0.010 & 0.25 & 0.40 & 0.43 & 0.40 & 0.19 & 0.11 \\
\hline LACA & 0.38 & 0.40 & 0.001 & 0.46 & 0.40 & 0.70 & 0.90 & 0.38 & 0.31 \\
\hline
\end{tabular}

(*) Reduction in each category of damage is weighted by the \% contribution of that damage type to total damage. Then weighted damages are summed. 
Table AI.4: Total climate change costs (residual damages and adaptation cost) for a $2 x \mathrm{CO} 2$ conc.

\begin{tabular}{|l|r|r|r|r|}
\hline & $\begin{array}{r}\text { Nordhaus } \\
\text { and Boyer } \\
(2000)\end{array}$ & $\begin{array}{c}\text { WITCH } \\
\text { model }\end{array}$ & This study & $\begin{array}{r}\text { AD- } \\
\text { WITCH } \\
\text { model }\end{array}$ \\
\hline USA & 0.45 & 0.41 & 0.37 & 0.44 \\
\hline WEURO & 2.84 & 2.79 & 2.25 & 1.58 \\
\hline EEURO & 0.70 & -0.34 & 0.82 & 0.55 \\
\hline KOSAU & -0.39 & 0.12 & -0.05 & 0.82 \\
\hline CAJANZ & 0.51 & 0.12 & 0.01 & 0.52 \\
\hline TE & -0.66 & -0.34 & -0.01 & 0.80 \\
\hline MENA & 1.95 & 1.78 & 2.41 & 2.93 \\
\hline SSA & 3.90 & 4.17 & 4.19 & 5.09 \\
\hline SASIA & 4.93 & 4.17 & 4.76 & 5.51 \\
\hline CHINA & 0.23 & 0.22 & 0.22 & 0.50 \\
\hline EASIA & 1.81 & 2.16 & 1.93 & 4.17 \\
\hline LACA & 2.43 & 2.16 & 2.13 & 2.31 \\
\hline
\end{tabular}




\section{Appendix II: Estimating market-driven adaptation with the ICES model}

Through a meta analysis and extrapolations from the exiting impact literature, the set of direct impacts reported in table AII.1 has been computed for the regions of the ICES model.

Table AII.1: climate change impacts (\% change 2000 - 2050)

\begin{tabular}{|c|c|c|c|c|c|c|c|c|c|c|c|c|}
\hline & \multicolumn{6}{|c|}{ HEALTH } & \multicolumn{6}{|c|}{ LAND PRODUCTIVITY } \\
\hline & \multicolumn{2}{|c|}{ Labour Product. } & \multicolumn{2}{|c|}{ Public Exp. } & \multicolumn{2}{|c|}{ Private Exp. } & \multicolumn{2}{|c|}{ Wheat } & \multicolumn{2}{|c|}{ Rice } & \multicolumn{2}{|c|}{ Cereal Crops } \\
\hline & $1.2^{\circ} \mathrm{C}$ & $3.2^{\circ} \mathrm{C}$ & $1.2^{\circ} \mathrm{C}$ & $3.2^{\circ} \mathrm{C}$ & $1.2^{\circ} \mathrm{C}$ & $3.2^{\circ} \mathrm{C}$ & $1.2^{\circ} \mathrm{C}$ & $3.2^{\circ} \mathrm{C}$ & $1.2^{\circ} \mathrm{C}$ & $3.2^{\circ} \mathrm{C}$ & $1.2^{\circ} \mathrm{C}$ & $3.2^{\circ} \mathrm{C}$ \\
\hline$S A$ & -0.06 & -0.18 & -0.15 & -0.28 & -0.02 & -0.03 & -5.66 & -18.89 & -6.19 & -20.37 & -8.18 & -25.15 \\
\hline ed_Europe & 0.01 & 0.01 & -0.10 & -0.18 & 0.00 & -0.01 & -1.14 & -8.33 & -4.62 & -18.94 & -2.00 & -11.8 \\
\hline orth_Europe & 0.06 & 0.16 & -0.35 & -0.88 & -0.01 & -0.03 & 1.50 & -7.74 & -5.90 & -26.01 & 50.00 & 107.82 \\
\hline dol_t & 0.09 & 0.23 & -0.47 & -1.17 & -0.01 & -0.02 & -1.13 & -10.50 & -2.64 & -13.57 & -4.60 & -18.35 \\
\hline & 0.11 & 0.28 & -0.41 & -1.03 & -0.01 & -0.03 & -6.12 & -21.92 & -7.47 & -24.64 & -9.73 & -30.10 \\
\hline SA & -0.43 & -1.14 & 0.57 & 1.62 & 0.04 & 0.11 & -7.78 & -17.00 & -2.90 & -7.41 & -3.11 & -7.38 \\
\hline$A J A$ & 0.09 & 0.22 & 0.03 & 0.24 & 0.00 & 0.00 & -0.74 & -12.33 & -1.87 & -14.31 & -2.24 & -15.17 \\
\hline $\mathrm{F}$ & -0.28 & -0.69 & 2.02 & 4.41 & 0.10 & 0.23 & -12.81 & -42.14 & -10.78 & -41.00 & -12.62 & -45.97 \\
\hline & -0.22 & -0.34 & 1.34 & 1.81 & 0.10 & 0.14 & -8.40 & -32.40 & -11.73 & -38.52 & -13.60 & -43.12 \\
\hline & -0.31 & -0.84 & 0.47 & 1.34 & 0.07 & 0.19 & -9.89 & -15.02 & -7.17 & -7.42 & -8.81 & -10.5 \\
\hline & -0.11 & -0.30 & 0.28 & 0.76 & 0.06 & 0.17 & -2.96 & -13.37 & -4.89 & -17.39 & -6.61 & -21.43 \\
\hline & 0.14 & 0.37 & 0.65 & 1.80 & 0.06 & 0.17 & 0.93 & 2.69 & 0.50 & 1.79 & -1.42 & -2.37 \\
\hline & -0.11 & -0.32 & 1.05 & 2.96 & 0.06 & 0.17 & 2.45 & 9.82 & 0.34 & 5.04 & -1.15 & 1.9 \\
\hline \multirow[t]{4}{*}{ LACA } & -0.14 & -0.39 & 0.68 & 1.98 & 0.07 & 0.19 & -6.69 & -68.10 & -6.61 & -55.65 & -8.25 & -76.37 \\
\hline & \multicolumn{2}{|c|}{ SEA LEV. RISE } & \multicolumn{4}{|c|}{ TOURISM } & \multicolumn{6}{|c|}{ HOUSEHOLDS' ENERGY DEMAND } \\
\hline & \multicolumn{2}{|c|}{ Land Losses } & \multicolumn{2}{|c|}{$\begin{array}{l}\text { Market Serv. } \\
\text { Demand }\end{array}$} & \multicolumn{2}{|c|}{ Income Flows } & \multicolumn{2}{|c|}{ Natural Gas } & \multicolumn{2}{|c|}{ Oil Products } & \multicolumn{2}{|c|}{ Electricity } \\
\hline & $1.2^{\circ} \mathrm{C}$ & $3.2^{\circ} \mathrm{C}$ & $1.2^{\circ} \mathrm{C}$ & $3.2^{\circ} \mathrm{C}$ & $1.2^{\circ} \mathrm{C}$ & $3.2^{\circ} \mathrm{C}$ & $1.2^{\circ} \mathrm{C}$ & $3.2^{\circ} \mathrm{C}$ & $1.2^{\circ} \mathrm{C}$ & $3.2^{\circ} \mathrm{C}$ & $1.2^{\circ} \mathrm{C}$ & $3.2^{\circ} \mathrm{C}$ \\
\hline SA & -0.026 & -0.055 & -0.68 & -1.76 & -0.17 & -0.43 & -13.67 & -35.31 & -18.52 & -47.84 & 0.76 & 1.9 \\
\hline led_ & 007 & -0.015 & -1.86 & -4.81 & -0.40 & -1.02 & -12.68 & -32.76 & -15.84 & -40.91 & 0.76 & 1.9 \\
\hline North & -0.020 & -0.041 & 7.54 & 19.47 & 1.78 & 4.61 & -13.75 & -35.51 & -15.52 & -40.09 & -2.20 & -5.68 \\
\hline East_ & -0.022 & -0.046 & -2.46 & -6.36 & -0.33 & -0.86 & -12.93 & -33.41 & -17.39 & -44.92 & 0.76 & 1.9 \\
\hline & & & 0.00 & -0.01 & 0.00 & 0.00 & -13.02 & -33.65 & -17.39 & -44.92 & 0.75 & 1.94 \\
\hline s & -0.005 & -0.011 & -1.31 & -3.39 & -0.32 & -0.82 & nss & nss & -13.03 & -33.66 & 12.31 & 31.81 \\
\hline CAJANZ & -0.004 & -0.009 & 5.54 & 14.30 & 1.40 & 3.61 & -5.05 & -13.04 & -12.63 & -32.63 & -4.80 & -12.40 \\
\hline NAF & 017 & -0.036 & -2.52 & -6.52 & -0.24 & -0.63 & -8.60 & -22.22 & -13.25 & -34.22 & 5.95 & 15.37 \\
\hline & .004 & -0.007 & -4.67 & -12.06 & -0.91 & -2.34 & -13.12 & -33.89 & -17.39 & -44.92 & 0.74 & 1.92 \\
\hline & -0.066 & -0.139 & -4.43 & -11.45 & -0.37 & -0.96 & nss & nss & -6.51 & -16.83 & 16.35 & 42.23 \\
\hline ASIA & -0.204 & -0.427 & -1.21 & -3.12 & -0.10 & -0.25 & nss & nss & nss & nss & 20.38 & 52.65 \\
\hline CHINA & -0.045 & -0.094 & -4.99 & -12.89 & -0.33 & -0.85 & nss & nss & nss & nss & 20.38 & 52.65 \\
\hline EASIA & .316 & -0.662 & -4.69 & -12.10 & -0.53 & -1.38 & nss & nss & nss & nss & 20.38 & 52.66 \\
\hline LACA & -0.025 & -0.052 & -2.68 & -6.91 & -0.56 & -1.45 & nss & nss & nss & nss & 21.37 & 55.20 \\
\hline
\end{tabular}

Notes:

- Nss: non statistically significant.

- In red those impacts potentially negative

It is firstly evident that, except for the case of land losses to sea-level rise, they are not all necessarily negative. For instance, labour productivity decreases in some regions (at the lower latitude) where the decrease in cold-related mortality/morbidity cannot compensate the increase in heat related mortality/morbidity, but increases in others (typically at the medium to high latitudes) where the opposite happens. The same applies to crops productivity: in hotter regions it decreases (note that the loss of the aggregate KOSAU is mainly due to agricultural losses in Australia) whereas in the cooler regions it tends to increase as for cereal crops in the Northern Europe. Climatic stimuli are indeed regionally differentiated and affect populations or crops with different sensitivity.

Secondly, impacts concern both the supply and the demand side of the economic system. In the first case they can be unambiguously defined as positive or negative: a decrease in labour productivity 
due to adverse health impact is a sure initial loss for the economic system. In the second case, when agents' preferences change, assigning a positive or negative label to an impact is more difficult. For instance, when, due to warmer climates, oil and gas demand for heating purposes decreases, this cannot be considered straightforwardly a cost or a gain before redistributional effects are analyzed.

This said, the larger supply-side impacts in per cent terms concern agricultural markets, whereas labour productivity and land losses to sea-level rise are much smaller. Among demand shifts, the larger relate to household energy consumption: electricity demand for space cooling could increase up to $50 \%$ in hot regions depending on the climate scenario; it decreases in the cooler regions like Northern Europe and in CAJANZ this last dominated by Canada effect. Natural gas and oil demand for heating purposes declines everywhere. Highly relevant are also demand changes for market services, driven by redistribution of tourism flows, accompanied by income inflows (outflows) in those regions where climatic attractiveness increases (decreases). The larger beneficiaries are cooler regions, Northern Europe and CAJANZ (this last again dominated by Canada effect) whereas China, East Asia and Middle East experience a loss.

When all these impacts are used as an input to the CGE model, figure 17 is obtained.

Final effects are dominated by impacts on crops' productivity and on the tourism industry. It can be surprising that sea-level rise and health impacts appear so negligible.

This depends on two facts:

(a) The initially low estimates of the impacts themselves. In the case of sea-level rise, only land losses are part of the assessment and whereas capital losses or people displacement are not considered. In the case of health, both heath and cold related diseases are considered thus the increase in the first is partly counterbalanced by the decrease in the second.

(b) The nature of the analysis. Here what is shown is the reduced (or increased) ability of economic systems to produce goods and services because of climate change. This is what GDP, typically a flow variable, measures. Thus, say a land loss, is not evaluated in terms of loss of property value which can be very high, but in terms of the lower capacity of the economic system hit by that land loss to produce (agricultural) goods. Given the possibility to substitute at least partially a scarcer input with one more abundant, usually effects on GDP are smaller ${ }^{35}$.

Final effects also present Northern Europe, CAJANZ and Mediterranean Europe as winners from climate change. In Northern Europe all impacts except sea-level rise bring gains. In CAJANZ huge positive impacts on tourism demand can explain its gain. More interesting is to comment the case of Mediterranean Europe which benefits from climate change even though, except for a slight gain in labour productivity, all impacts are negative. Indeed if measured in terms of direct costs, climate change entails a net loss higher than the 3\% of GDP (see fig. 15) for the region. However two mechanisms turn this into a small gain. Firstly, an improvement in terms of trade. This is driven by the decrease in energy prices due to the global contraction of GDP and thus of world energy demand, and to the increased agricultural goods prices induced by their reduced supply. This benefits particularly a net energy importer and food exporter like Mediterranean Europe. Secondly, foreign capital inflows. In the model these are driven by expected rate of return to capital. Mediterranean Europe is one region attracting capital as, its rental prices are decreasing, but less than in other regions. These resources spur investment and growth. These two second order effects are stronger than the direct effect.

It is worth stressing that this kind of analysis cannot be performed with models like RICE (or WITCH) which lacks some economic details (the most important is sectoral and international trade)

\footnotetext{
${ }^{35}$ This is for instance why today catastrophic events, entailing huge property losses, translate in no or just very little effects on GDP.
} 
and where damages are summarised by reduced-form equations. While a these assume a given relation between damage and temperature, and the damage usually includes property losses, our exercise estimates that relation quantifying the change in the capacity of an economic system hit by a joint set of impacts to produce goods and services.

As a final remark: the analysis performed does not include the effect of catastrophic losses, we decided to do so due to the uncertainty of those estimates. They are extremely relevant in other studies though, e.g. in Nordhaus and Boyer (2000) they constitute from the $10 \%$ to the $90 \%$ of total regional damages (see Table 2). This means that slightly different assumptions on catastrophic outcomes may change considerably results. 


\section{Appendix III: An alternative formulation of adaptation}

Two critical aspects of our exercise relate to the choice to model (tiny) adaptation knowledge as efficiency improver of reactive adaptation only, and on the assumption of very low damage until 2040. The first assumption is driven by data evidence as investment in adaptation knowledge basically takes place in agriculture and health sector where reactive adaptation is preponderant, the second is an assumption embedded in Nordhaus' damage function. The main consequences are that investment in adaptation knowledge remains very small, that they are performed mainly by developed countries and that adaptation (either proactive or reactive) starts only after 2040.

To test the robustness of our result we propose here a different specification and calibrate the damage in order to have some climate change impacts already at the beginning of the century. Adaptation strategies are now clustered in four large categories as depicted in figure AIII.1. A first decision is whether spend resources on activities (adaptation strategies) or capacity building. Both groups contain some further distinction into other sub-investments or activities. Total capacity consists of two components: generic capacity which is not necessarily related to adaptation and specific capacity, which instead includes capacity specific for adaptation. Adaptation activities include reactive and proactive adaptation measures, as in the main specification considered in the text.

Figure AIII.1: The adaptation tree in the AD_WITCH model

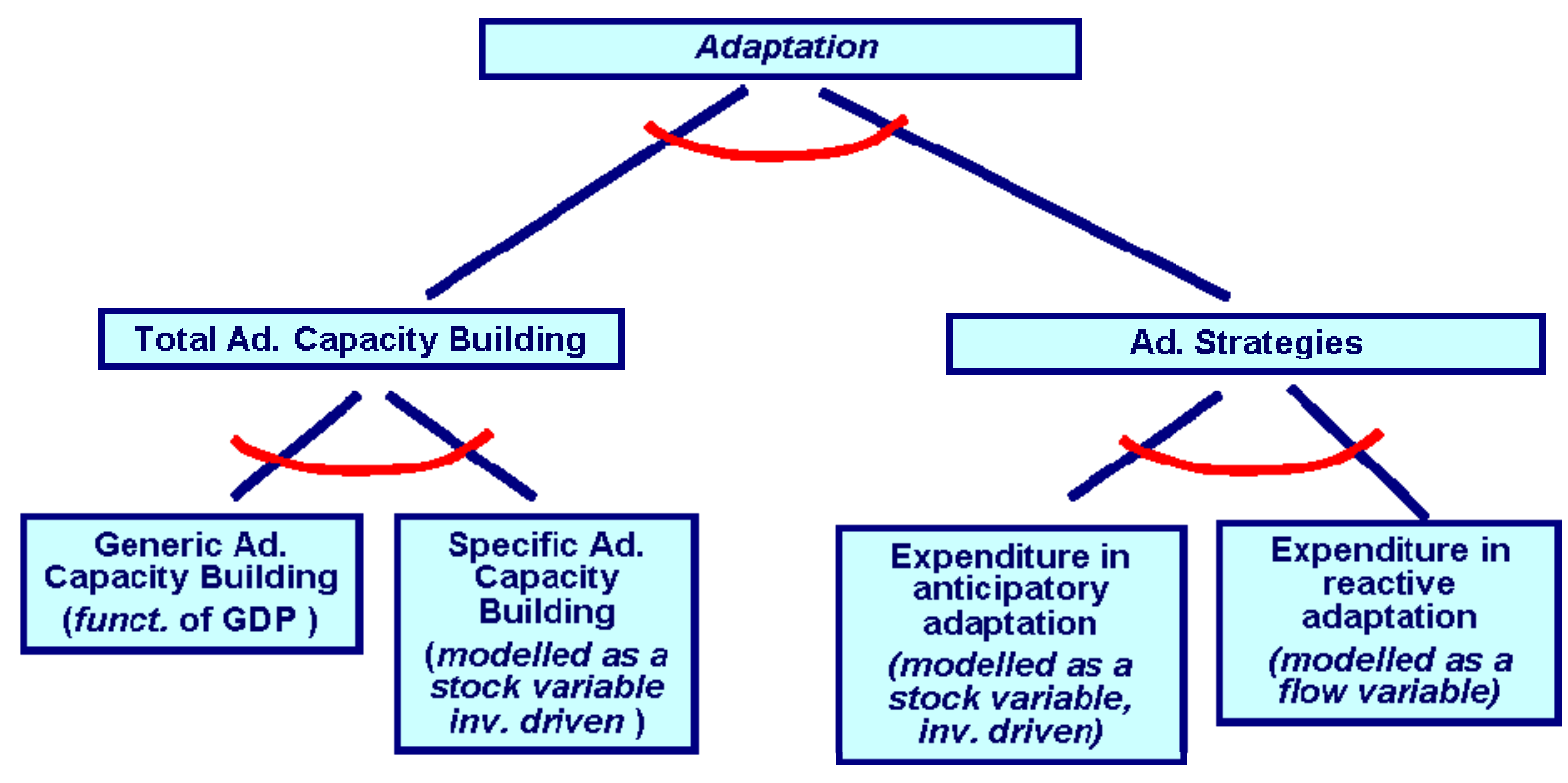

Using this new specification, we have re-computed the optimal adaptation-mitigation mix in the non cooperative scenario. All the qualitative results found with the old specification hold: mitigation is close to zero; the optimal adaptation mix is composed by reactive, proactive and specific capacity (Figure AIII-1). Anticipatory adaptation is undertaken in advance, because of its stock nature, whereas reactive adaptation becomes more important when the damage is sufficiently large. In the long-run anticipatory adaptation stabilizes whereas reactive adaptation keeps increasing.

The regional differentiation of the adaptation basket is also robust to the new specification. NON OECD spend more on adaptation than OECD regions. In the second half of the century, reactive adaptation becomes the main adaptation form in NON OECD, whereas in OECD countries 
anticipatory measures are always the dominant strategy. Once more, the explanation lies in the different climate vulnerability.

Figure AIII-2: Adaptation expenditure

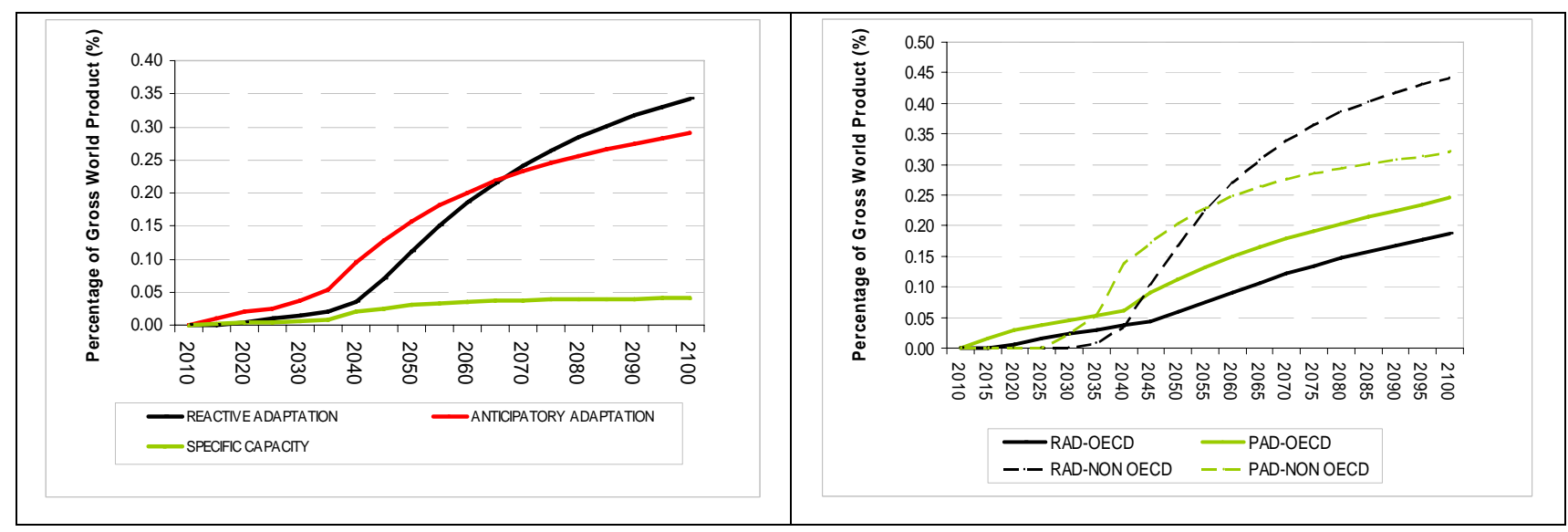

What changes is the path of adaptation. It starts immediately and is smoother. To conclude table AIII-1 reports benefit-cost ratio of all adaptation strategies jointly in the non cooperative scenario. They show the same ranking of the previous analysis.

Table AIII-1: Benefits and costs of adaptation without mitigation (Non cooperative)

\begin{tabular}{|c|c|c|c|}
\hline $\begin{array}{c}\text { USD 2005 Billion } \\
\text { 3\% Discounting 2010-2105 }\end{array}$ & WORLD & OECD & NON OECD \\
\hline Benefits & 29444 & 8641 & 20802 \\
\hline Costs & 11237 & 3548 & 7690 \\
\hline BCR & $\mathbf{2 . 6 2}$ & $\mathbf{2 . 4 4}$ & $\mathbf{2 . 7 1}$ \\
\hline
\end{tabular}

Therefore, even under a different structural specification the model, i.e. even when testing the sensitivity to a different model functional form, our results are largely confirmed and seem to be robust to changes in the specification of the adaptation module. 